Pai Ching Yu

\title{
Registro nacional de operações não cardíacas: aspectos clínicos, cirúrgicos, epidemiológicos e econômicos
}

Tese apresentada à Faculdade de Medicina da Universidade de São Paulo para obtenção do título de Doutor em Ciências

Programa de Cardiologia

Orientador: Prof. Dr. Bruno Caramelli

São Paulo

2010 


\section{Dados Internacionais de Catalogação na Publicação (CIP)}

Preparada pela Biblioteca da

Faculdade de Medicina da Universidade de São Paulo

Creprodução autorizada pelo autor

\section{Yu, Pai Ching}

Registro nacional de operações não cardíacas : aspectos clínicos, cirúrgicos, epidemiológicos e econômicos / Pai Ching Yu. -- São Paulo, 2010.

Tese(doutorado)--Faculdade de Medicina da Universidade de São Paulo. Programa de Cardiologia.

Orientador: Bruno Caramelli.

Descritores: 1.Assistência perioperatória 2.Cirurgia 3.Epidemiologia 4.Mortalidade 5.Morbidade 6.Economia médica

USP/FM/DBD-178/10 


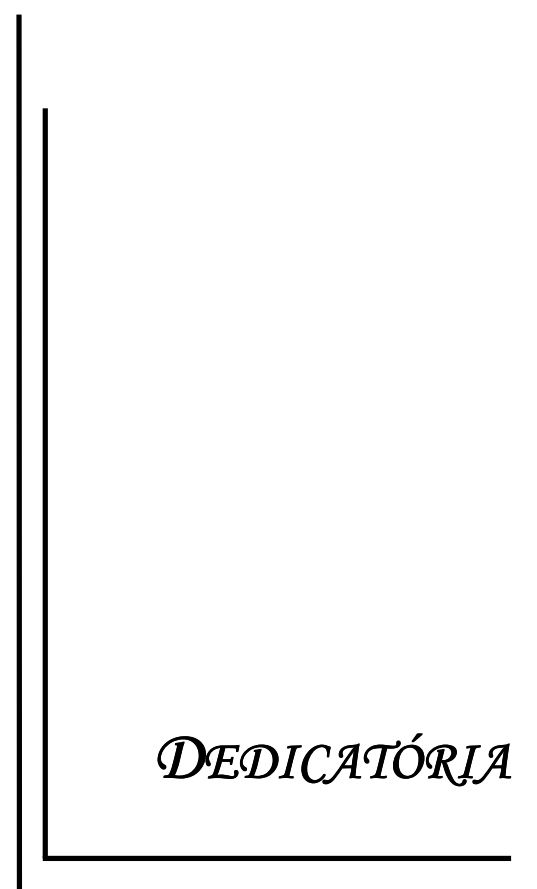


Dedico esta tese à minha família.

Aos meus pais, Yun Kuang e Mei Chun, com gratidão, por ter proporcionado a oportunidade e o privilégio da educação e por ter sempre encorajado os filhos a perseguir os sonhos e ideais.

Aos meus irmãos, Ching Ping, Chi Nan e Fernando pelo convívio, companheirismo e amizade. Por compartilhar os bons momentos da vida. 


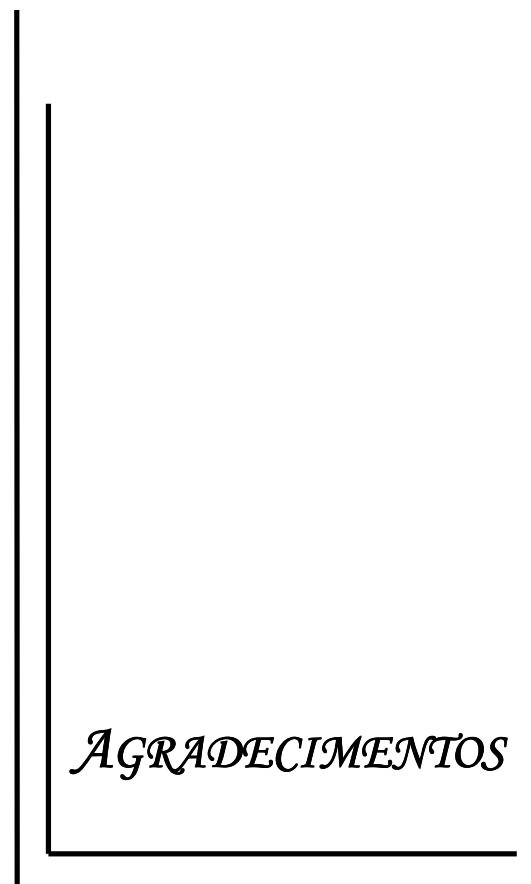


Ao Prof. Dr. Bruno Caramelli, meu orientador, que me introduziu no campo de pesquisa científica, pelos seus ensinamentos inestimáveis que em muito contribuiram para o meu crescimento científico e pessoal. Obrigada pela paciência, incentivo, confiança e o apoio recebido ao longo desta tese.

À minha querida amiga, Dra. Daniela Calderaro, assistente da Unidade de Medicina Interdisciplinar em Cardiologia, pelo exemplo de dedicação, competência e excelência no cuidado dos pacientes e pelos conselhos e apoio nos momentos difíceis ao longo desta jornada.

Aos meus colegas da pós-graduação, Dra. Danielle Menosi Gualandro, Dr. André Coelho Marques, Dra. Carolina Letícia Zilli Vieira, Dr. Enéas Martins de Oliveira Lima e Dra. Isabela Carlos Back Giuliano, pelo exemplo de dedicação e excelência.

Aos meus queridos amigos e colegas da Unidade de Medicina Interdisciplinar em Cardiologia, Dra. Luciana Savoy Fornari, Dr. Dimas Tadahiro Ikeoka, Fernanda Reis de Azevedo, Adriana F. Pastana e Aline Barbara de Oliveira, pela convivência e incentivo diário, sem os quais a conclusão deste trabalho não seria possível.

Ao Dr. João Carlos Prandini, pela sua ajuda nas análises estatísticas do estudo. 
Ao Prof. Dr. Raul Dias dos Santos Filho, ao Dr. Fábio Santana Machado e ao Dr. Pedro Sílvio Farsky, pelas sugestões realizadas no exame de qualificação que certamente enriqueceram para o aprimoramento do trabalho.

À Fundação de Amparo à Pesquisa do Estado de São Paulo (FAPESP), pela concessão do auxílio à pesquisa e o apoio financeiro para a realização desta pesquisa.

À Sociedade de Cardiologia do Estado de São Paulo (SOCESP), por contemplar o projeto para o Programa de Bolsa de Estudo da SOCESP. 


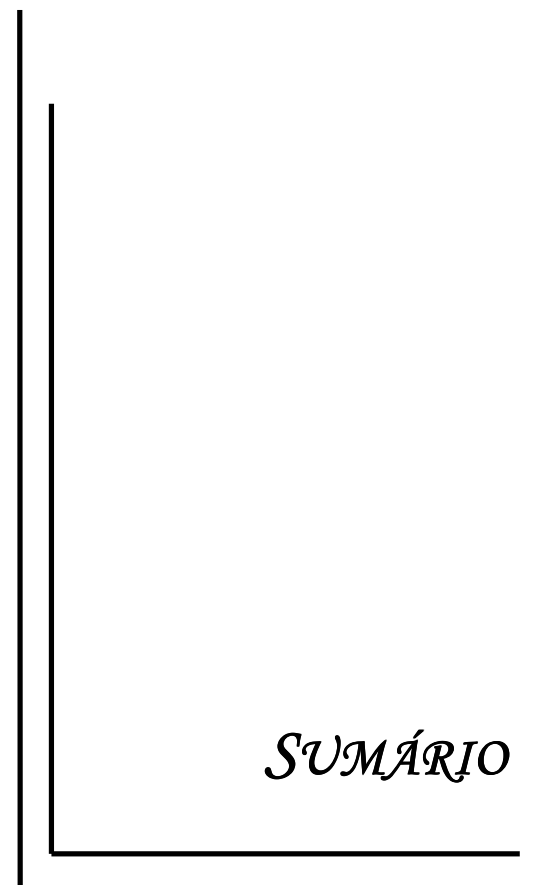




\section{SUMÁRIO}

\section{LISTA DE SIGLAS E ABREVIATURAS}

LISTA DE SÍMBOLOS

LISTA DE TABELAS

LISTA DE FIGURAS

LISTA DE GRÁFICOS

RESUMO

SUMMARY

1. REVISÃO DE LITERATURA ....................................................... 25

1.1. Cirurgia e medicina perioperatória .............................................. 26

1.2. Cirurgia e co-morbidades clínicas .......................................................... 34

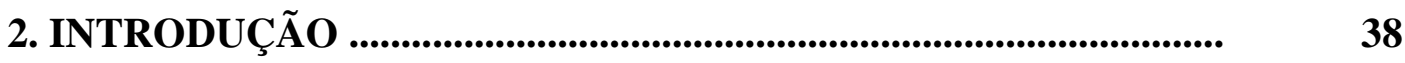

3. HIPÓTESE ..................................................................................... 42

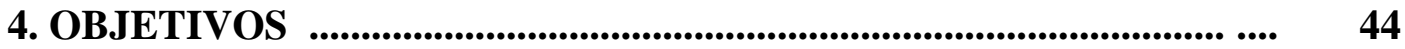

5. METODOLOGIA _................................................................................. 46

5.1. Casuística e métodos ............................................................................ 47

5.2. Análise de resultados ....................................................................... 49

5.2.1. Análise estatística ............................................................. 52

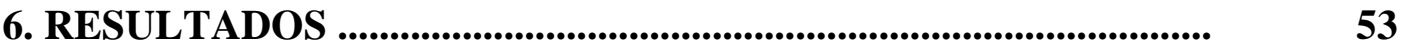

6.1. Análise global ................................................................................... 54

6.2. Análise por especialidades cirúrgicas ............................................. $\quad 57$

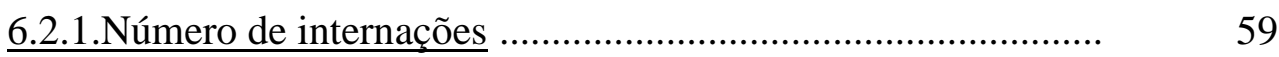

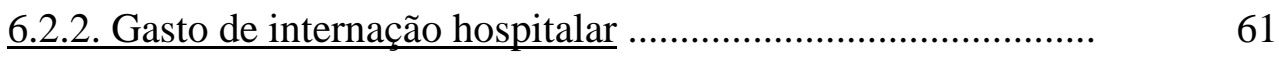

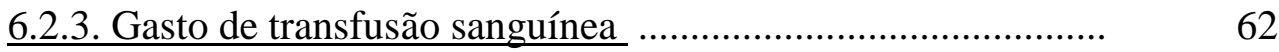


6.2.4. Tempo de internação hospitalar …....................................... 63

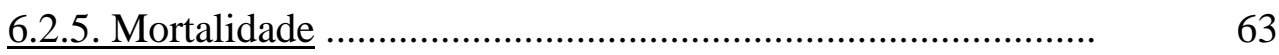

6.3. Análise por procedimentos cirúrgicos ............................................... $\quad 65$

6.3.1. Número de internações ....................................................... 65

6.3.2. Gasto médio por internação ……......................................... 66

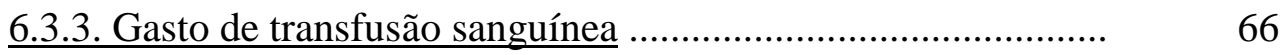

6.3.4. Tempo de internação hospitalar …….................................. 67

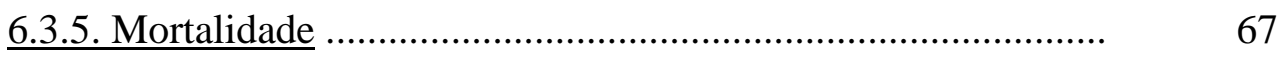

6.4. Análise de tendências ................................................................. $\quad 70$

6.4.1 Análise global ...................................................................

6.4.2 Análise por especialidades ….............................................. 72

6.4.2.1.Número de internações cirúrgicas .........................

6.4.2.2. Tempo médio de internação ................................. 73

6.4.2.3. Mortalidade ........................................................

6.5. Análise econômica ......................................................................

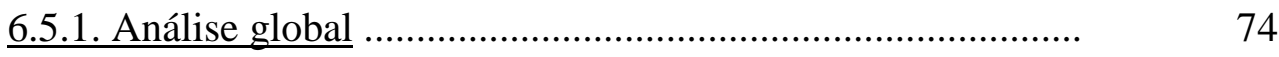

6.5.2. Análise por especialidades ............................................. 77

6.5.2.1. Gasto médio por internação ................................... 77

6.5.2.2. Gasto médio de transfusão .................................... $\quad 78$

7. DISCUSSÃ O ...................................................................................

Considerações finais ............................................................................ 87

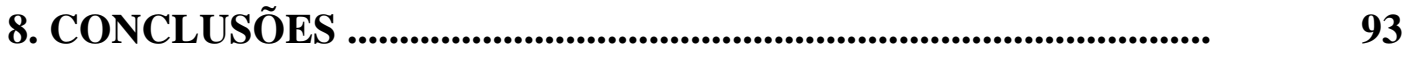

9. REFERÊNCIAS BIBLIOGRÁFICAS ............................................... 96

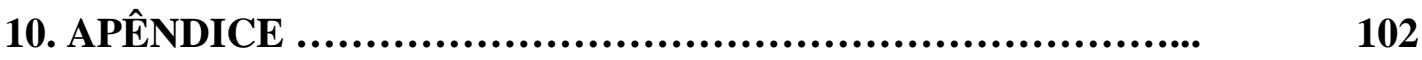

Apêndice A - Tabelas ............................................................................. 103

Apêndice B - Gráficos ................................................................................ 110 


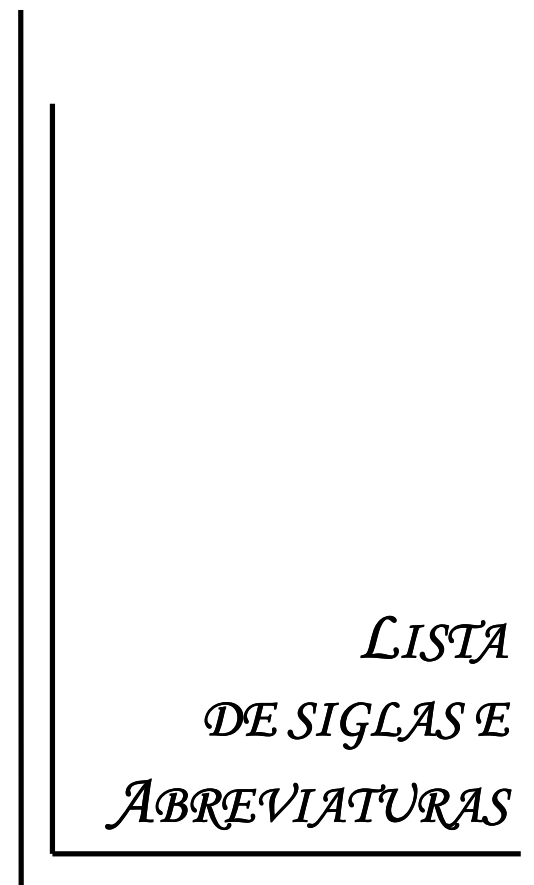




\section{LISTA DE SIGLAS E ABREVIATURAS}

ACC

$\mathrm{ACP}$

AHA

ASA

BNP

$\mathrm{Cr}$

DAC

DATASUS

ECG

EMAPO

ESC

HCFMUSP

IAM

IBGE

ICC

INPC

OMS

POISE

SPSS

SUS

$\mathrm{U}$
American College of Cardiology

American College of Physicians

American Heart Association

American Society of Anesthesiology

Brain Natriuretic Peptide

Creatinina

Doença Arterial Coronária

Departamento de Informática do Sistema Único de Saúde

Eletrocardiograma

Estudo Multicêntrico de Avaliação Perioperatória

European Society of Cardiology

Hospital das Clínicas da Faculdade de Medicina da Universidade de

São Paulo

Infarto Agudo do Miocárdio

Instituto Brasileiro de Geografia e Estatística

Insuficiência Cardíaca Congestiva

Índice Nacional de Preço ao Consumidor

Organização Mundial de Saúde

Perioperative Ischemic Evaluation Study

Statistical Package for the Social Sciences

Sistema Único de Saúde

Uréia 


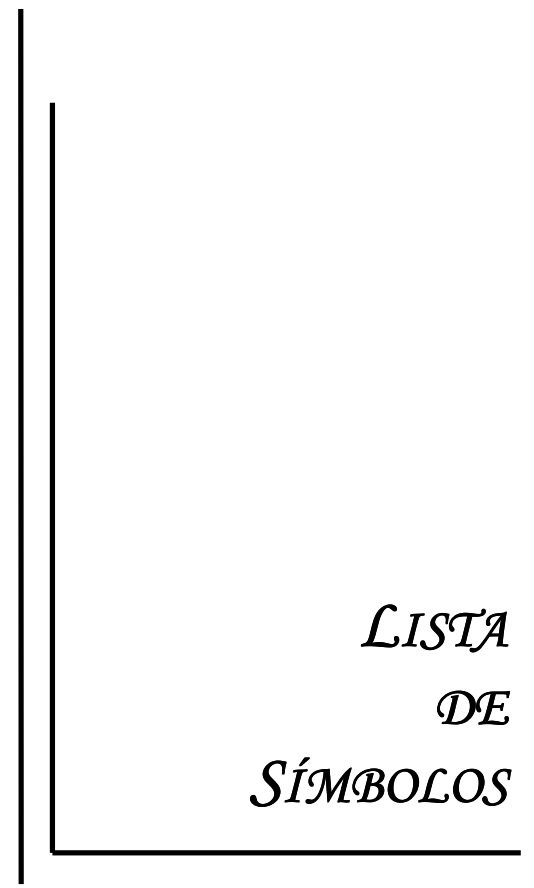




\section{LISTA DE SÍMBOLOS}

$\begin{array}{ll}\mathrm{mg} / \mathrm{dl} & \text { miligrama por decilitro } \\ < & \text { menor } \\ \geq & \text { maior } \\ = & \text { maior ou igual a } \\ \pm & \text { igual a } \\ \% & \text { mais ou menos } \\ \mathrm{x} & \text { porcentagem } \\ \mathrm{r}^{2} & \text { versus } \\ & \text { r ao quadrado }\end{array}$




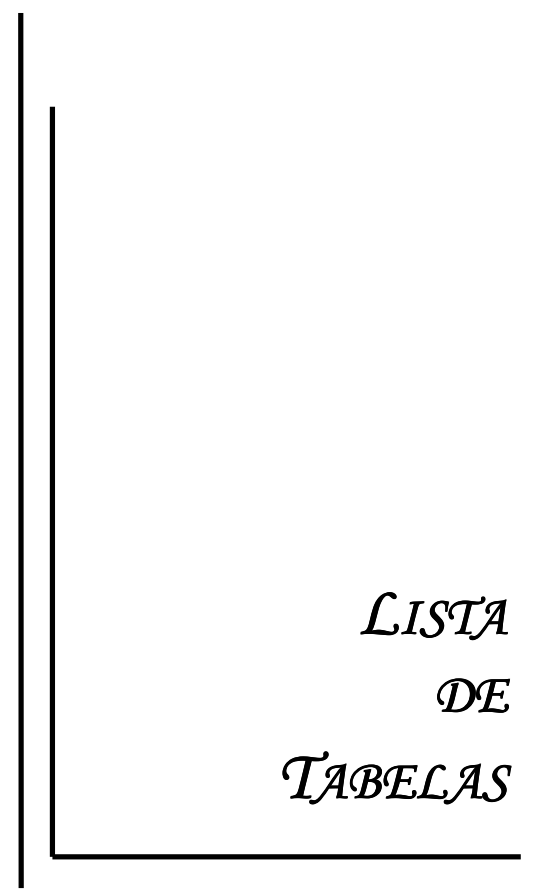




\section{LISTA DE TABELAS}

Tabela 1. Classificação de risco cardiovascular de acordo com tipo de cirurgia .....

Tabela 2. Resultados das cinco variáveis do estudo relacionadas às internações cirúrgicas no período de 1995 a 2007

Tabela 3. "Ranking" decrescente das especialidades cirúrgicas conforme as variáveis estudadas, ordenado por seus valores médios \pm desvio padrão das médias de todos anos

Tabela 4. Procedimentos cirúrgicos de cada especialidade que ocuparam topo do "ranking" nas variáveis estudadas no período de 1995 a 2007 68

Tabela 5. Resultado da análise de tendência do número de internações por 1.000 habitantes conforme especialidade cirúrgica no período de 1995 a 2007

Tabela 6. Resultado da análise de tendência do tempo de internação por especialidade cirúrgica no período de 1995 a 2007

Tabela 7. Resultado da análise de tendência da mortalidade por especialidade cirúrgica no período de 1995 a 2007

Tabela 8. Valores de gastos hospitalares por internação cirúrgica e por transfusão, corrigidos anualmente para inflação do período

Tabela 9. Resultado de análise de tendências do gasto de internação corrigido para inflação, no período de 1995 a 2007, por especialidade cirúrgica ..... 
Tabela 10. Resultado de análise de tendências do gasto de transfusão corrigido para inflação, no período de 1995 a 2007, por especialidade cirúrgica ......................................................

Tabela 11. Número de internações por 1.000 habitantes em cada especialidade cirúrgica no período de 1995 a 2007 Apêndice A, 103

Tabela 12. Gasto médio em reais por internação hospitalar conforme as diferentes especialidades cirúrgicas - 1995 a 2007

Apêndice A, 104

Tabela 13. Gasto médio em reais com a transfusão sanguínea por internação conforme especialidades cirúrgicas - 1995 a 2007 Apêndice A, 105

Tabela 14. Tempo médio de internação hospitalar (em dias) conforme especialidade cirúrgica - 1995 a 2007

Apêndice A, 106

Tabela 15. Taxa de mortalidade em porcentagem de cada especialidade cirúrgica no período de 1995 a 2007 Apêndice A, 107

Tabela 16. Valores de gastos médios em reais por internação de cada especialidade cirúrgica corrigidos para inflação do período de 1995 a 2007

Apêndice A, 108

Tabela 17. Valores de gastos médios em reais de transfusão sanguínea por procedimento de cada especialidade cirúrgica corrigidos para inflação do período de 1995 a 2007

Apêndice A, 109 


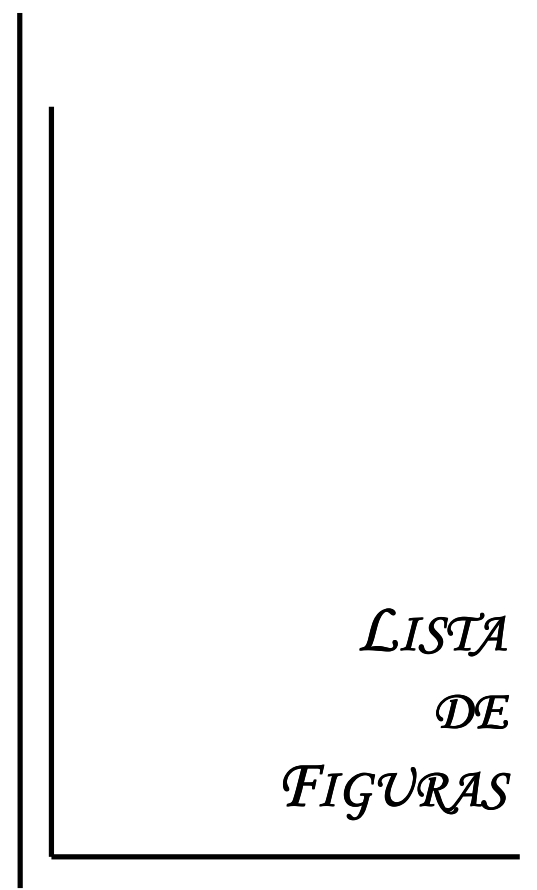




\section{LISTA DE FIGURAS}

Figura 1. Número de internações de cirurgias não cardíacas a cada 1000 habitantes - período de 1995 a 2007

Figura 2. Distribuição do número de internações cirúrgicas em porcentagens de cada especialidade no período de 1995 a 2007

Figura 3. Representação da taxa de mortalidade cirúrgica por especialidade em escala logarítmica - período de 1995 a 2007

Figura 4. Número de leitos hospitalares disponíveis pelo sistema público de saúde e seus regimes hospitalares 


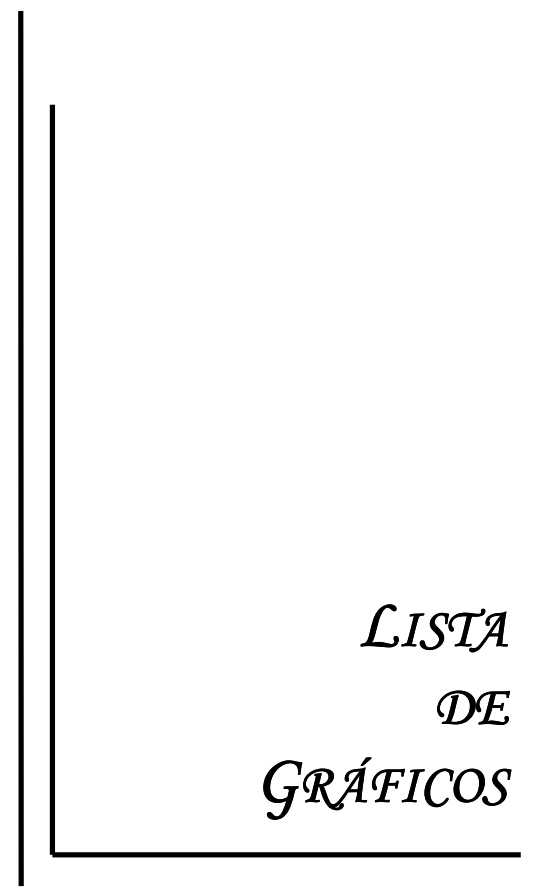




\section{LISTA DE GRÁFICOS}

Gráfico 1. Resultados da análise de tendências das variáveis (dados globais) no período de 1995 a 2007

Gráfico 2. Resultados da análise de tendências das variáveis econômicas, gastos hospitalares e de transfusão, corrigidos para inflação, no período de 1995 a 2007

Gráfico 3. Resultado gráfico da análise de tendências do número de internações em diversas especialidades

Gráfico 4. Resultado gráfico da análise de tendências do tempo médio de internação em diversas especialidades

Apêndice B, 112

Gráfico 5. Resultado gráfico da análise de tendências da mortalidade cirúrgica em diversas especialidades

Apêndice B, 114 


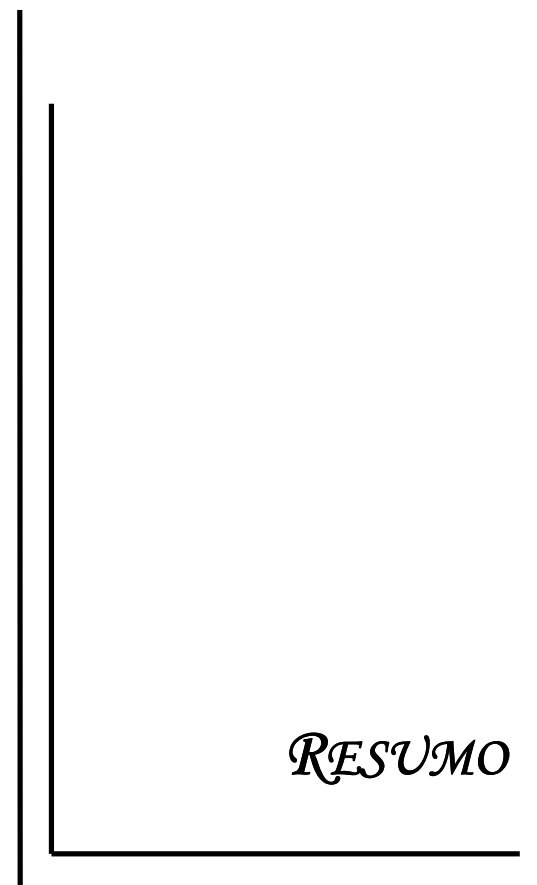


Yu, PC. Registro nacional de operações não cardíacas: aspectos clínicos, cirúrgicos, epidemiológicos e econômicos [Tese]. São Paulo: Universidade de São Paulo, Faculdade de Medicina, 2010.

Anualmente são realizadas mais de 234 milhões de cirurgias no mundo com taxas de morbi e mortalidade relativamente elevadas. Os dados nacionais disponíveis de registros de operações não cardíacas são escassos e deficientes. $\mathrm{O}$ objetivo do nosso estudo foi avaliar o perfil epidemiológico dos pacientes submetidos a operações não cardíacas e a sua evolução nos últimos anos no Brasil. Selecionamos a partir do banco de dados de DATASUS, as informações de sistema público de saúde em caráter nacional para descrição epidemiológica de operações não cardíacas realizadas no país. As variáveis estudadas foram: número total de internações, gasto total por internação, gasto com transfusões sanguíneas, número de óbitos e tempo de internação hospitalar. O período estudado compreendeu os anos de 1995 a 2007 . No período de 13 anos, foram realizadas 32.659.513 operações não cardíacas no país e houve um incremento de $20,42 \%$ no número de procedimentos realizados. De forma semelhante, os gastos hospitalares relacionados a estas cirurgias apresentaram aumento importante neste período ( 200\%), com gasto anual superior a 2 bilhões de reais. As despesas relacionadas às transfusões sanguíneas no perioperatório tiveram um aumento superior a 100\%, com um gasto anual acima de 17 milhões de reais ao ano. A mortalidade hospitalar encontrada é bastante elevada no nosso país, com média de $1,77 \%$ e o aumento registrado foi mais de $30 \%$ no período. A única variável que apresentou redução ao longo dos últimos anos foi o tempo de internação hospitalar, com a média de permanência de 3,83 dias. Concluímos que há uma tendência no aumento de intervenções cirúrgicas no país. Apesar do aumento dos gastos hospitalares relacionados a estas cirurgias, a taxa de mortalidade encontrada ainda é bastante elevada. Estudos futuros são necessários para maior investigação e elaboração de estratégias complementares para melhorar os resultados cirúrgicos.

Descritores: assistência perioperatória, cirurgia, epidemiologia, mortalidade, morbidade, economia médica 


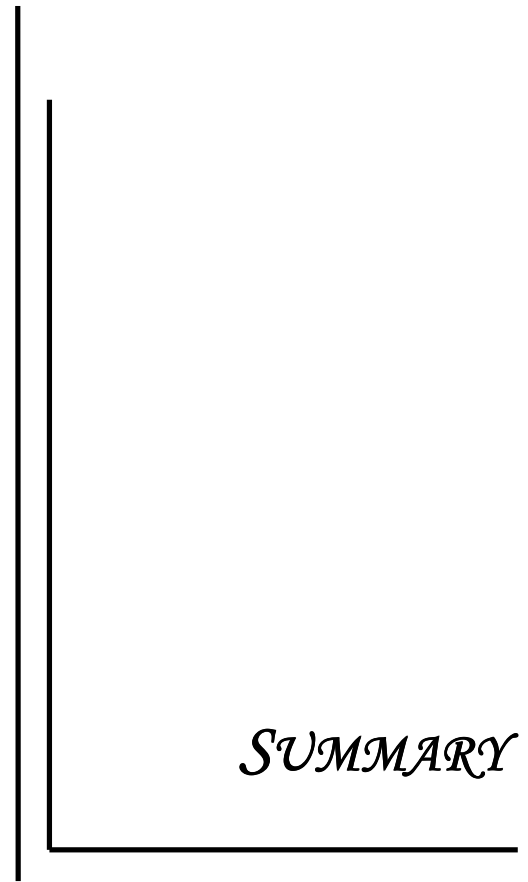


Yu, PC. National registry of non-cardiac surgery: clinical, surgical, epidemiological aspects and economical opportunities. [Thesis]. Sao Paulo: University of Sao Paulo Medical School, 2010 .

Worldwide, there were performed about 234 millions of surgeries annually with a relatively high surgical morbidity and mortality. Registry and information about non-cardiac operations in Brazil are scarce and deficient. The purpose of our study was to describe the epidemiological data of non-cardiac surgeries performed in Brazil in the last years. This is a retrospective cohort study that investigated the time-window from 1995 to 2007 . We collected information from DATASUS, a national public health system database. The variables studied were: number of surgeries, in-hospital expenses, blood transfusion related costs, length of stay and case fatality rates. There were 32.659.513 non-cardiac surgeries performed in Brazil in thirteen years. An increment of $20.42 \%$ was observed in the number of surgeries in this period. The cost of these procedures has increased tremendously in the last years. The increment of surgical cost was almost $200 \%$ and the yearly cost of surgical procedures to public health system was superior to 1.2 billions of dollars ( 2 billions of reais). The cost of blood transfusion had an increment superior to $100 \%$ and annually approximately 10 millions of dollars (17 millions of reais) were spent in perioperative transfusion. Actually, in 2007, the surgical mortality in Brazil was $1.77 \%$ and it had an increment of $31.11 \%$ in the period of 1995 to 2007. The length of stay was the unique variable which had a reduction of its numbers in the period. In average, the mean time of surgical hospitalization was 3.83 days. We concluded that the volume of surgical procedures has increased substantially in Brazil through the past years. The expenditure related to these procedures and its mortality has also increased as the number of operations. Better planning of public health resource and strategies of investment are needed to supply the crescent demand of surgery in Brazil.

Descriptors: perioperative care, surgery, epidemiology, mortality, morbidity, medical economics. 


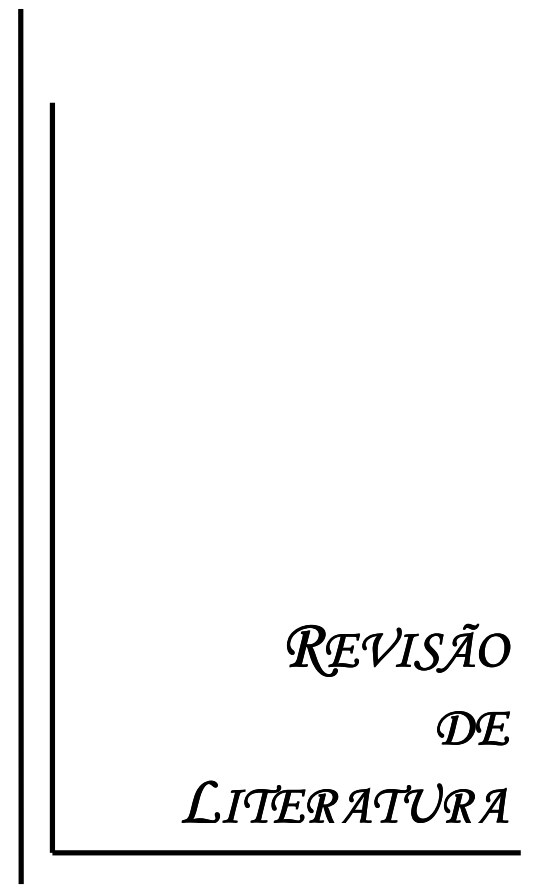




\section{REVISÃO DE LITERATURA}

\subsection{Cirurgia e medicina perioperatória}

Os conhecimentos científicos no campo de cirurgia apresentaram grandes evoluções ao longo do tempo. As inúmeras descobertas da medicina nas últimas décadas permitiram uma melhoria nos resultados de intervenções cirúrgicas em decorrência de avanços tanto no aspecto científico como no aspecto tecnológico. Os conhecimentos médicos adquiridos associados ao aprimoramento de técnicas cirúrgicas foram essenciais para a redução de taxas de morbi-mortalidade perioperatória. Atualmente, sabemos que boa parte das complicações e mortalidades relacionadas aos procedimentos podem ser reduzidas ou até mesmo evitadas por meio de medidas específicas direcionadas para cuidados perioperatórios. A probabilidade de ocorrência de eventos e complicações está diretamente relacionada aos diversos fatores determinantes do risco cirúrgico. Entre os fatores já conhecidos, podemos citar as condições clínicas e co-morbidades do paciente, tipo e caráter da operação proposta, a experiência da equipe cirúrgica e do hospital onde ocorrerá a cirurgia e a equipe interdisciplinar envolvida nos cuidados do paciente.

A medicina perioperatória, dedicada aos cuidados de pacientes no período perioperatório de um procedimento cirúrgico, apresentou grandes evoluções e melhorias nestas últimas décadas. Inúmeros novos conhecimentos e estratégias foram desenvolvidos com objetivos de redução de risco de complicações no período perioperatório. Entre as condutas já amplamente conhecidas e preconizadas na medicina perioperatória, podemos citar, a realização de uma boa avaliação clínica cardiológica pré-operatória, com intuito em identificar fatores de risco ou condições clínicas que potencialmente podem estar relacionadas 
com um risco cardíaco elevado. Esta avaliação ainda tem o objetivo de sugerir e implementar medidas que possam contribuir para a redução do risco de eventos no pós operatório. Entre elas estão incluídas, a indicação de exames complementares para uma melhor estratificação de risco do paciente, a instituição de estratégias de farmacoproteção perioperatória visando exclusivamente e diretamente à redução de risco de eventos, e a recomendação de medidas de monitorizações hemodinâmica e cardíaca tanto no período intra como no pós operatório.

Os primórdios de medicina perioperatório tiveram início na década de 1960, quando a Sociedade Americana de Anestesiologia (ASA) estabeleceu um método de avaliação de risco anestésico para avaliação de pacientes cirúrgicos ${ }^{(1)}$. A avaliação de ASA procurou estabelecer a estimativa de risco anestésico dos pacientes conforme o seu estado clínico. A divisão de ASA em cinco categorias procurou classificar os pacientes de acordo com a presença de outras doenças exceto a cirúrgica e a gravidade destas condições clínicas associadas.

$\mathrm{Na}$ década de anos 70, tivemos a publicação do primeiro índice de avaliação de risco cardíaco para cirurgias não cardíacas. Este índice proposto por Goldman e colaboradores foi publicado em 1977 e o objetivo dos autores era determinar fatores que poderiam estar associados ao risco de desenvolvimento de complicações cardíacas no pós operatório ${ }^{(2)}$. Os autores identificaram e estabeleceram nove variáveis clínicas que estariam associadas a um aumento de risco cardíaco e de possíveis complicações perioperatórias. De acordo com a presença das variáveis, os pacientes eram divididos em quatro classes de risco cirúrgico conforme a pontuação obtida. Este foi o primeiro índice multifatorial que procurou normatizar e padronizar a avaliação pré operatória visando a predição de risco cardíaco perioperatório.

Sucessivamente, nos anos seguintes, foram elaborados e apresentados outros índices e algoritmos de avaliação de risco cirúrgico para operações não cardíacas. Todos estes índices e algoritmos foram estabelecidos para auxiliar a estratificação de risco cardíaco de forma 
prática, mas sempre considerando a peculiaridade de cada paciente, prevalecendo sempre a opinião e experiência do médico assistente. Entre os índices de avaliação do risco e algoritmos disponíveis, podemos citar o índice modificado de $\operatorname{Detsky}^{(3)}$, índice cardíaco revisado de Lee ${ }^{(4)}$, algoritmos de American College of Cardiology/American Heart Association (ACC/AHA) ${ }^{(5)}$ e de American College of Physicians (ACP) ${ }^{(6 ; 7)}$, e um algoritmo nacional dirigido à população brasileira, o Estudo Multicêntrico de Avaliação Perioperatória $(\mathrm{EMAPO})^{(8)}$.

O índice de Detsky foi publicado em 1986 a partir de modificações do índice original de Goldman, com adição de novas variáveis e redivisão em três classes de risco ${ }^{(3)}$. Este índice serviu de base e foi incorporado posteriormente para a formação do algoritmo de avaliação de risco proposto por $\mathrm{ACP}$, um algoritmo bastante difundido para uso na prática clínica como ferramenta para estratificação de risco cardíaco perioperatório.

$\mathrm{Na}$ década de anos 90, a medicina perioperatória ganhou maior visibilidade com a publicação de guidelines de avaliação de risco cirúrgico por duas sociedades renomadas: ACC/AHA em $1996^{(5)}$ e ACP em $1997^{(6 ; 7)}$, respectivamente. A avaliação de risco do paciente para procedimento cirúrgico conforme algoritmo de ACC/AHA foi baseada na presença de preditores clínicos que juntamente com a avaliação da capacidade funcional e porte cirúrgico determinaria o risco do paciente para procedimento proposto ${ }^{(5)}$. $\mathrm{O}$ algoritmo de $\mathrm{ACP}^{(6 ; 7)}$ utiliza basicamente o índice de Detsky modificado com complementação da avaliação mediante a presença de variáveis de baixo risco estabelecidos por Eagle e Vanzetto ${ }^{(9 ; 10)}$ para classificação de risco cardíaco e a respectiva probabilidade da ocorrência de complicações.

Em 1999, Lee e colaboradores elaboraram um índice de avaliação de risco cardíaco simplificado, onde foram identificadas seis fatores preditores independentes de risco de complicações e que servem como variáveis para classificação do risco cardíaco 
pré operatório $^{(4)}$. Este índice tornou-se bastante utilizado na prática clínica perioperatória nos últimos anos pela sua simplicidade e praticidade e foi recentemente incorporado na última atualização de guideline de avaliação perioperatória de ACC/AHA de $2007^{(11)}$, como parte da estratégia de estratificação de risco cirúrgico.

Nesta linha de pesquisa, com objetivo de melhorar a avaliação pré operatória com inclusão de novas variáveis clínicas excluídas de algoritmos disponíveis e melhorar a avaliação de risco cirúrgico, Pinho e colaboradores elaboraram o EMAPO ${ }^{(8)}$, um algoritmo nacional de avaliação perioperatória, dirigido à população brasileira que foi validado e comparado a um algoritmo internacional - ACP. Os autores encontraram uma acurácia semelhante entre os dois métodos de avaliação (EMAPO x ACP) e identificaram novas variáveis de risco: insuficiência renal $(\mathrm{Cr} \geq 2,3 \mathrm{mg} / \mathrm{dl}$ ou $\mathrm{U} \geq 50 \mathrm{mg} / \mathrm{dl})$, cirurgia de emergência e cirurgias de grande porte.

Além das variáveis clínicas, as determinantes cirúrgicas também estão relacionadas à taxa de complicações perioperatórias. Cada procedimento cirúrgico apresenta um risco intrínseco relacionado à probabilidade de ocorrência de complicações cardiovasculares. Segundo a nova classificação de AHA/ACC ${ }^{(11)}$ e European Society of Cardiology (ESC) ${ }^{(12)}$, as operações não cardíacas são divididas em três classes de risco: alto, intermediário ou de baixo risco cirúrgico. Tabela 1. Outra variável cirúrgica importante a ser considerada em relação à morbi-mortalidade perioperatória é a experiência do cirurgião e o local onde será realizado o procedimento cirúrgico. Numa análise retrospectiva de dados de Medicare nos Estados Unidos, a mortalidade cirúrgica foi inversamente proporcional ao volume de operações realizadas por cirurgião e ao volume cirúrgico do hospital onde era realizado o procedimento $^{(13 ; 14)}$. Não houve relação entre a idade do cirurgião e a mortalidade cirúrgica $^{(15)}$. 
Tabela 1 - Classificação de risco cardiovascular de acordo com tipo de cirurgia. Adaptado de guidelines de $\mathrm{ACC} \mathrm{AHA}^{(11)}$ e $\mathrm{ESC}^{(12)}$

\begin{tabular}{|c|c|c|}
\hline Alto risco (>5\%) & Intermediário (1 a 5\%) & Baixo risco $(<1 \%)$ \\
\hline $\begin{array}{l}\text { Operações de } \\
\text { aorta e vasculares } \\
\text { Operações de } \\
\text { revascularizações } \\
\text { periféricas }\end{array}$ & 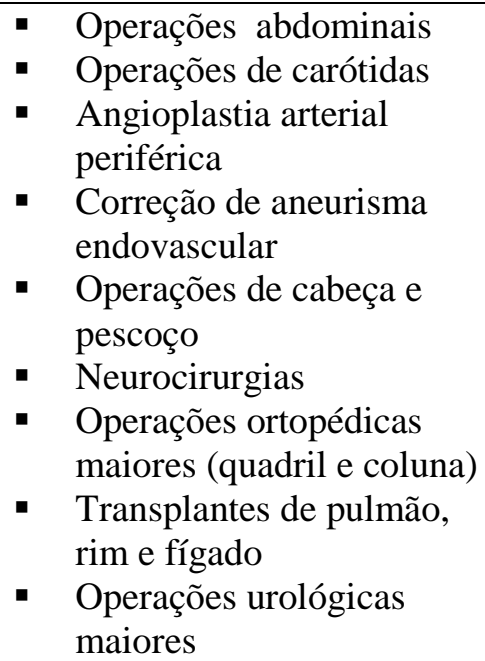 & $\begin{array}{l}\text { - } \text { Operações de mama } \\
\text { Procedimentos } \\
\text { odontógicos } \\
\text { - Operações endócrinas } \\
\text { Operações } \\
\text { oftalmológicas } \\
\text { Procedimentos } \\
\text { ginecológicos } \\
\text { Operações } \\
\text { reconstrutivas } \\
\text { Operações } \\
\text { ortopédicas menores } \\
\text { (joelho) } \\
\text { Operações urológicas } \\
\text { menores }\end{array}$ \\
\hline
\end{tabular}

Grandes avanços se desenvolveram a partir da década de 90 sobretudo em relação às medidas de farmacoproteção no ambiente perioperatório. Em 1996, Mangano e colaboradores foram pioneiros ao mostrar o benefício do uso de beta bloqueadores como estratégia específica instituída para redução de complicações perioperatórias em cirurgias não cardíacas $^{(16)}$. Os autores encontraram uma redução de mortalidade cardiovascular de até $65 \%$ em seguimento clínico de dois anos. Benefício ainda maior, foi encontrado no grupo de pacientes com alto risco cardíaco submetido a operações vasculares ${ }^{(17)}$. Neste segundo estudo, realizado por Poldermans e colaboradores, o grupo de pacientes que recebeu beta-bloqueador apresentou uma redução de $91 \%$ da taxa de infarto agudo do miocárdio (IAM) comparado ao grupo placebo $(3,4 \%$ x $34 \%, \mathrm{p}<0,001)$. A partir destes dois estudos, o uso de beta bloqueador foi bastante difundido como uma ferramenta para redução de eventos isquêmicos perioperatórios.

Diversos trabalhos subsequentes sobre este tema apresentaram resultados divergentes, e suscitaram discussões sobre o real efeito protetor do beta bloqueador e sua indicação no 
perioperatório $^{(18 ; 19)}$. Num levantamento retrospectivo com grande número de pacientes, Lindenauer avaliou, numa série de 782.969 pacientes, o uso de beta bloqueador no perioperatório de cirurgias não cardíacas ${ }^{(20)}$. Os autores encontraram o benefício do beta bloqueador na redução de mortalidade, principalmente nos pacientes com estimativa de risco moderado a alto, e sem proteção com potencial malefício nos pacientes de baixo risco. Os dados nos levam a concluir que o beta bloqueador não deve ser indicado indiscriminadamente para todos, mas sim conforme a estimativa do risco cardíaco dos pacientes.

Último grande trabalho realizado a respeito do uso de beta bloqueador no perioperatório de cirurgias não cardíacas foi o estudo POISE ${ }^{(21)}$, publicado em maio de 2008. Este estudo clínico randomizado, prospectivo e multicêntrico teve a participação do maior número de pacientes (8.351 indivíduos) entre todos os estudos sobre este tema realizados até hoje. Os resultados do POISE mostraram o efeito benéfico do beta bloqueador em reduzir taxa de complicações cardiovasculares no contexto perioperatório, $(5,8 \%$ x 6,9\%, p=0,039), desfecho primário definido por combinação de IAM não fatal, morte cardíaca e parada cardiorrespiratória revertida. Entretanto, o grupo de pacientes que recebeu metoprolol teve uma mortalidade global maior que o grupo placebo $(3,1 \% \times 2,3 \%, \mathrm{p}=0,031)$ e foi observada ainda uma maior incidência de casos de acidente vascular cerebral no grupo beta bloqueador. Este resultado insatisfatório pode ser decorrente da dose fixa e elevada de metoprolol (200mg) utilizada no estudo, sugerido pela grande parcela de pacientes com bradicardias e hipotensões registradas no grupo de intervenção e justifica a ocorrência de mais eventos cerebrovasculares encontrados neste grupo. Uma análise cuidadosa dos resultados e das limitações do POISE e dos estudos anteriores com beta-bloqueador no ambiente perioperatório permite concluir que permanece a indicação do beta bloqueador para proteção perioperatória como uma medida favorável para redução de risco cirúrgico. Entretanto, esta indicação deve ser acompanhada de 
monitorização clínica rigorosa para obtenção de beta bloqueio efetivo e titulação da dose utilizada.

As estatinas, classicamente indicadas para tratamento de hipercolesterolemia e utilizadas na prevenção da doença arterial coronária, ganharam outras indicações de uso clínico além da sua ação hipolipemiante devido aos seus efeitos pleiotrópicos. No contexto perioperatório, a estatina mostrou-se eficaz em reduzir eventos e complicações cardiovasculares provavelmente devido a sua ação antitrombótica, estabilizadora de placas ateromatosas e proporcionar melhora da função endotelial.

O primeiro trabalho prospectivo que estudou o uso de estatina no perioperatório de cirurgias vasculares eletivas foi desenvolvido pelo Instituto do Coração e Cirurgia Vascular do Hospital das Clínicas da Faculdade de Medicina da Universidade de São Paulo (HCFMUSP). Os autores randomizaram 98 pacientes para receberem, por período de 45 dias, atorvastatina $20 \mathrm{mg}$ ou placebo no perioperatório de cirurgia vascular eletiva ${ }^{(22)}$. Neste estudo, foi observada a redução de $68 \%$ de eventos cardiovasculares no grupo tratado com atorvastatina no seguimento de seis meses, independentemente do nível sérico de colesterol. Diversos outros trabalhos retrospectivos também encontraram a associação do efeito protetor de estatina em cirurgias vasculares ${ }^{(23 ; 24)}$. Num estudo retrospectivo envolvendo grande número de pacientes, Lindenauer e colaboradores sugerem que o benefício do uso perioperatório de estatina não se restringem somente a cirurgias vasculares ${ }^{(25)}$. Na análise de prontuários de 780.591 pacientes submetidos a diversos tipos de procedimentos, aqueles que receberam estatina nos dois primeiros dias da internação apresentaram uma menor taxa de mortalidade $(2,13 \% \times 3,05 \%, \mathrm{p}<0,001)$.

Entre os outros cuidados de manejo perioperatório que podem resultar em redução de risco, inclui a indicação de monitorização intensiva no período perioperatório de pacientes 
com risco moderado a alto para apresentar complicações cardiovasculares. A monitorização ativa e intensiva de possíveis eventos por meio de eletrocardiograma (ECG) seriada e curva enzimática deve ser realizada por um período de 72 horas após a operação, onde concentra maior probabilidade de ocorrência de eventos isquêmicos. O racional destas medidas é procurar identificar a ocorrência de complicações cardíacas precocemente, pois a isquemia miocárdica perioperatória apresenta alta mortalidade e o diagnóstico clínico é difícil devido à manifestação clínica muitas vezes incaracterística.

O uso de marcadores de necrose miocárdica tem seu papel crucial no auxílio diagnóstico de eventos isquêmicos no perioperatório. Destacamos especialmente o uso de troponina sérica por ser um marcador de necrose com maior sensibilidade e especificidade em relação às outras, e a sua elevação no pós operatório de cirurgias não cardíacas implica num pior efeito prognóstico a longo prazo ${ }^{(26 ; 27)}$. Outros marcadores utilizados habitualmente para estratificação de doença cardíaca, tais como proteína $\mathrm{C}$ reativa ultra-sensível e peptídeo natriurético tipo B (BNP), tem sido estudados para aplicação clínica no ambiente de operações não cardíacas. Os pequenos estudos realizados sugerem que estes marcadores poderiam apresentar uma informação prognóstica adicional para predição de risco de eventos cardiovasculares no pós operatório, porém ainda necessita de estudos maiores para a comprovação $^{(28-32)}$.

$\mathrm{Na}$ busca de novos métodos de estratificação de risco cirúrgico, Calderaro e colaboradores avaliaram a função endotelial dos pacientes vasculopatas, na expectativa de identificar novas técnicas de aprimorar a avaliação pré operatória. Numa casuística de 96 pacientes em programação de cirurgias vasculares eletivas, os pacientes realizaram avaliação da função endotelial pelo método de análise de fluxo mediada por vasodilatação por meio de ultrassonografia com doppler de artéria braquial, na fase pré e pós operatória. A taxa de 
complicações perioperatórias encontrada foi de $28,1 \%$ e mortalidade global de $17 \%$. E os autores encontraram que a baixa velocidade de fluxo na hiperemia reativa foi preditora de eventos perioperatórios ${ }^{(33)}$. Estes achados sugerem que nesta população específica, a avaliação de função endotelial poderia ser um método adicional para avaliação de risco cirúrgico.

\subsection{Cirurgia e co-morbidades clínicas}

Nos últimos anos, houve uma mudança importante no perfil da população. Com o avanço de conhecimentos médicos, houve o envelhecimento natural da população. Atualmente a população é formada por maior número de indivíduos idosos, portadores de comorbidades e que representa uma boa parcela de pacientes submetidos a procedimentos cirúrgicos. Até há poucos anos, a realização de procedimentos cirúrgicos em indivíduos idosos era bastante rara. Porém, nos últimos anos, com a melhoria de técnicas cirúrgicas e anestésicas, possibilidade de utilização de estratégias cirúrgicas menos invasivas, o número de operações vem crescendo nos pacientes nas faixas etárias mais avançadas. Este novo grupo apresenta um perfil de risco cardíaco muito mais elevado, devido à idade mais avançada e à presença de co-morbidades. Estas duas situações estão relacionadas ao risco cirúrgico mais elevado e contribuem para aumento da morbi-mortalidade perioperatória com uma maior taxa de complicações mais comumente observadas nesta população.

A idade isoladamente é um fator importante e determinante de pior evolução perioperatória. Está relacionada a maior taxa de mortalidade, maior risco de desenvolvimento de complicações perioperatórias e maior tempo de internação hospitalar ${ }^{(34 ; 35)}$. Num estudo de coorte prospectiva com 4.315 pacientes acima de 50 anos, os autores procuraram avaliar o impacto da idade nas complicações perioperatórias de cirurgias não cardíacas $^{(34)}$. Os resultados foram analisados conforme a faixa etária dos pacientes: 50 a 59 anos, 60 a 69 anos, 
70 a 79 anos e $\geq 80$ anos. As taxas de mortalidade intra-hospitalar crescem conforme aumenta a faixa etária. A mortalidade registrada foi respectivamente de $0,3 \%$ nos pacientes com idade entre 50-59 anos, 0,8\% nos pacientes de 60-69 anos, $0,9 \%$ nos pacientes de $70-79$ anos e 2,6\% nos pacientes $\geq 80$ anos $(\mathrm{p}=0,002)$. A mesma associação também foi encontrada entre a faixa etária e a ocorrência de complicações pós operatórias. As taxas de complicações registradas foram respectivamente, 4,3\% no grupo de 50-59 anos, 5,7\% no grupo de 60-69 anos, 9,6\% no grupo de $70-79$ anos e $12,5 \%$ no grupo $\geq 80$ anos $(\mathrm{p}<0,001)$. Na análise ajustada para as potenciais variáveis de confusão, a idade permaneceu como preditor relacionado ao maior tempo de internação, maior risco de desenvolvimento de complicações perioperatórias e de mortalidade intra-hospitalar ( idade >70anos).

No estudo semelhante para avaliar a influência da idade na morbi e mortalidade de pacientes submetidos a operações não cardíacas, Hamel e colaboradores dividiram os pacientes em dois grupos: $<80$ anos e $>80 \operatorname{anos}^{(35)}$. Os autores encontraram uma maior taxa de mortalidade perioperatória em 30 dias no grupo de pacientes maiores de 80 anos. $(8,2 \% \mathrm{x}$ 2,8\%, p<0,001), assim como também a morbidade cirúrgica. Em 20\% dos pacientes $>80$ anos, foram registradas pelo menos uma ou mais complicações no período pós operatório e a mortalidade em 30 dias foi superior no grupo de pacientes que apresentaram algum tipo de complicação quando comparado ao grupo sem complicação $(26,1 \%$ x 3,7\%, p<0,001). Na análise multivariada do estudo, a idade e a presença de co-morbidades foram fatores identificados como preditores independentes de mortalidade perioperatória em 30 dias.

A presença de co-morbidades como preditores de pior evolução perioperatória também já foi evidenciada por diversos estudos na literatura. Segundo estudo de Tao e colaboradores, $27 \%$ dos pacientes diabéticos submetidos a procedimentos cirúrgicos apresentaram complicações cardiovasculares e 9\% tiveram infecções de ferida cirúrgica ${ }^{(36)}$. A presença de 
doença arterial coronária (DAC) está relacionada ao maior risco de complicações cardiovasculares no perioperatório, principalmente a ocorrência de eventos isquêmicos, como já previamente demonstrado em diversos estudos ${ }^{(2-4 ; 8 ; 37)}$. Outra doença crônica com alta prevalência na população idosa é a insuficiência cardíaca congestiva (ICC). Esta condição clínica representa um preditor de risco perioperatório muito mais grave e importante que as outras variáveis preditoras de risco como idade, diabetes mellitus ou DAC.

No maior estudo já realizado em pacientes portadores de insuficiência cardíaca, os autores procuraram avaliar o impacto de ICC em perioperatório de cirurgias não cardíacas maiores. Hammill e colaboradores, por meio de levantamento de dados de Medicare, incluíram nesta análise, pacientes acima de 65 anos que foram submetidos a algum procedimento cirúrgico maior, cujo desfecho primário do estudo foi a mortalidade operatória e reinternação em 30 dias $^{(38)}$. Na série de 159.327 procedimentos cirúrgicos analisados, os pacientes foram divididos em 3 grupos: portadores de ICC, portadores de DAC ou grupo controle. O grupo de pacientes portadores de ICC tinha o perfil de risco cirúrgico mais grave - 55\% dos pacientes deste grupo apresentavam três ou mais fatores de risco do índice cardíaco de Lee, enquanto que somente $10 \%$ no grupo DAC tinham este perfil e menos de $1 \%$ no grupo controle. A mortalidade perioperatória foi maior no grupo de pacientes com ICC quando comparado aos outros dois grupos ( $8 \%$ no grupo ICC x 3,1\% no grupo DAC x 2,4\% no grupo controle, $\mathrm{p}<0,001)$. A readmissão hospitalar em 30 dias também foi maior no grupo de pacientes com diagnóstico prévio de ICC $(17,1 \%$ no grupo ICC x $10,8 \%$ no grupo DAC x $8,1 \%$ no grupo controle, $\mathrm{p}<0,001)$. Na análise por regressão logística, após ajuste para as potenciais variáveis de confusão, o resultado permaneceu significativo. A mortalidade operatória do grupo de paciente com ICC foi $63 \%$ maior que o grupo controle e $51 \%$ maior que o grupo DAC. A taxa de reinternação também foi $51 \%$ maior nos pacientes com ICC 
quando comparado ao grupo controle e $30 \%$ superior na comparação em relação ao grupo de pacientes com DAC.

Um estudo nacional multicêntrico, prospectivo e observacional procurou avaliar a epidemiologia e desfecho de pacientes cirúrgicos não cardíacos em unidades de terapia intensiva no país ${ }^{(39)}$. Dos 587 pacientes incluídos neste estudo, a presença de co-morbidades pré-existentes foi bastante frequente: $59 \%$ dos pacientes apresentavam hipertensão arterial, $35 \%$ cardiopatias, $32 \%$ neoplasias, $21 \%$ diabetes mellitus, $20 \%$ tabagismo e $19 \%$ tinham baixa capacidade funcional. Para os procedimentos cirúrgicos de grande porte ou aqueles realizados em caráter de urgência, as taxas de mortalidade foram superiores no grupo de pacientes portadores de condição clínica pré-existente quando comparado com o grupo de pacientes sem outras co-morbidades, com um risco relativo $>3$ e $p<0,05$. Ainda mais, a taxa de mortalidade foi diretamente proporcional ao número de co-morbidades apresentadas. Isto é, quanto maior número de condições clínicas pré-existentes, maior a taxa de mortalidade perioperatória.

Este trabalho mostra que a população brasileira segue a tendência internacional e apresenta o perfil de risco cardíaco semelhante, formado por população mais idosa, com mais co-morbidades associadas e que representa um grupo de pacientes com risco elevado para procedimentos cirúrgicos. Intuitivamente, acredita-se que quanto maior o risco cirúrgico, maior deve ser a taxa de morbi-mortalidade perioperatória, assim como o tempo de internação e o custo hospitalar. De fato, a ocorrência de complicações pós operatórias está relacionada ao aumento do período de internação hospitalar ${ }^{(40)}$, assim como inúmeras outras variáveis clínicas e cirúrgicas que também são preditores de uma internação cirúrgica prolongada. 


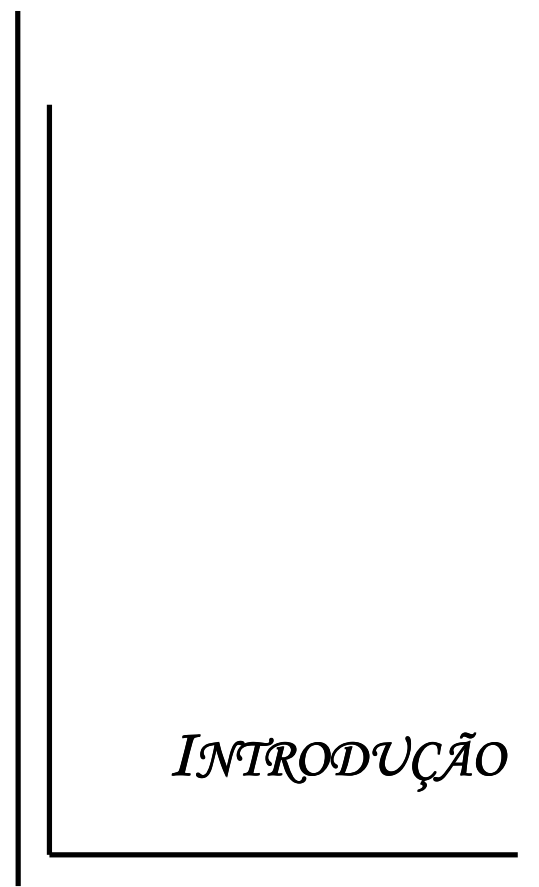




\section{INTRODUÇÃO}

Os dados existentes da literatura indicam que, apesar de todos conhecimentos adquiridos nestes últimos anos, a taxa de morbi e mortalidade relacionada a intervenções cirúrgicas ainda é bastante elevada e variada. Em países desenvolvidos, a morbidade cirúrgica chega a 3-16\% em todos procedimentos realizados em ambiente hospitalar, com uma taxa de mortalidade que varia de 0,4 a $0,8 \%$. Enquanto que nos países em desenvolvimento, esta taxa chega a ser 10 vezes superior, com números que variam entre 5 a $10 \% .^{(41)}$

Os dados disponíveis de registros de operações são escassos e deficientes. Estima-se que em média são realizados 234,2 milhões de cirurgias por ano no mundo ${ }^{(41)}$. Estes números podem estar subestimados, pois segundo levantamento obtido a partir de registro de 192 países membros de Organização Mundial de Saúde (OMS), apenas 29\% dos países tinham registro de informações relacionadas aos procedimentos cirúrgicos realizados. Este grande número de operações realizadas anualmente e sua elevada morbi-mortalidade constituem um problema de saúde pública que vem adquirindo sua importância nos últimos anos. A mudança do perfil da população nos últimos anos, decorrente do envelhecimento e aumento da expectativa de vida, elevou o número de indivíduos idosos, portadores de co-morbidades que são submetidos a procedimentos cirúrgicos. Estas modificações de perfil clínico da população podem ser responsáveis pelas altas taxas de complicações perioperatórias observadas no país.

Os poucos trabalhos brasileiros existentes sobre as operações não cardíacas são direcionados principalmente para avaliação de risco cardíaco e taxa de complicações perioperatórias. O enfoque principal dos estudos nacionais publicados até então visa

principalmente estabelecer e identificar preditores e determinantes clínicos relacionadas à detecção de morbi-mortalidade perioperatória e validação de algoritmos e índices de 
avaliação $^{(42 ; 43)}$ Outros procuraram melhorar a forma de estratificação pré operatória e avaliar novos métodos e técnicas de predição de eventos perioperatórios ${ }^{(8 ; 33)}$, além de propor novas medidas de farmacoproteção perioperatório ${ }^{(22)}$. No entanto, os trabalhos existentes são, geralmente, estudos com pequenos números de pacientes em grupos populacionais selecionados e direcionados a desfechos específicos. A mortalidade perioperatória nacional registrada nestes estudos varia de 3,4 a $17 \%$ e a taxa de complicações de 9,1 a $38,3 \%$ em cirurgias não cardíacas eletivas ${ }^{(8 ; 22 ; 33 ; 37 ; 39 ; 43)}$. Estas taxas elevadas de morbi-mortalidade perioperatória implicam em internações hospitalares prolongadas, aumento de custos hospitalares com maior demanda de recursos do sistema de saúde.

Os dados nacionais disponíveis sobre a morbi - mortalidade cirúrgica, o custo de internações cirúrgicas e a sua repercussão no gasto público no sistema de saúde são escassos e não conclusivos. Os avanços tecnológicos associados à mudança do perfil da população brasileira devem ter resultado em modificações no cenário nacional em relação ao número de cirurgias realizadas no país e sua morbi-mortalidade. Intuitivamente, a evolução de conhecimentos médicos junto com as novas tecnologias adquiridas ao longo de últimos anos, devem ter contribuído para melhores resultados cirúrgicos com a consequente redução de mortalidade cirúrgica e de tempo de internação hospitalar. Entretanto, o uso de novos equipamentos, materiais específicos e próteses nas operações podem ter acarretado também um custo hospitalar mais elevado. O perfil clínico atual dos pacientes submetidos a operações, composto por indivíduos mais idosos com presença de mais co-morbidades, pode estar associado a maior incidência de complicações perioperatórias. Desta forma, espera-se um aumento nos gastos relacionados às internações hospitalares e maior tempo de internação. 
No contexto perioperatório de operações não cardíacas, não são disponíveis dados nacionais referentes à epidemiologia, dados clínicos, gastos de internações hospitalares e o impacto econômico destes no sistema de saúde do país. 


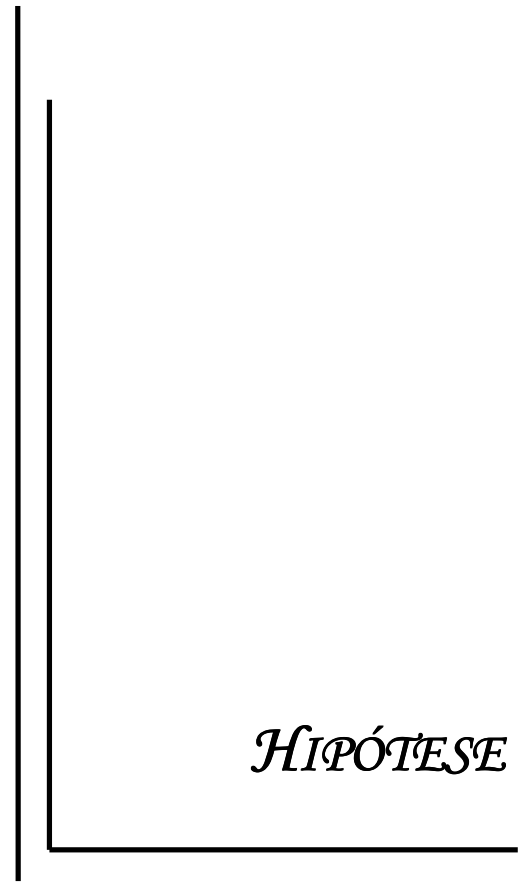




\section{HIPÓTESE}

O aumento da expectativa de vida da população, associado aos avanços tecnológicos utilizados nas cirurgias podem ter um impacto na alteração do perfil dos resultados cirúrgicos no Brasil. Isso pode estar relacionado com modificações nas taxas de complicações, de mortalidade perioperatória, do tempo de internação e de gastos hospitalares. 


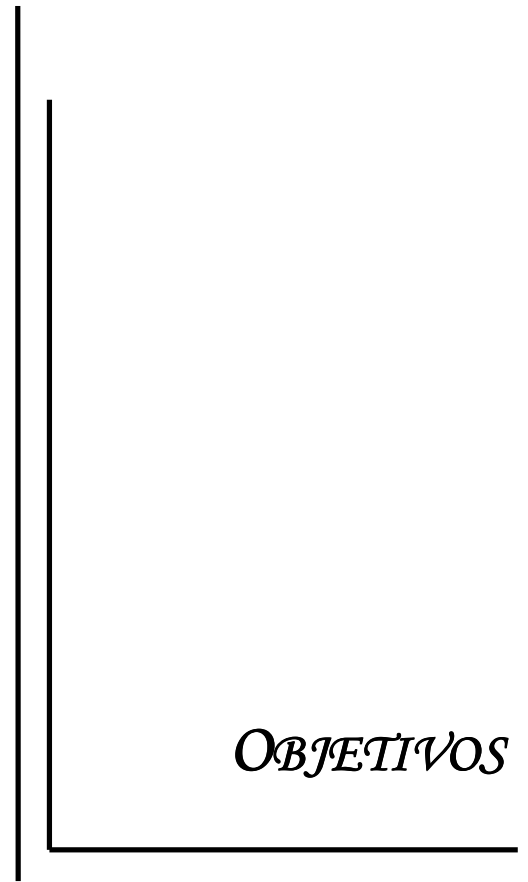




\section{OBJETIVOS}

Avaliar o perfil epidemiológico dos pacientes submetidos a operações não cardíacas nos últimos anos no Brasil.

$\checkmark$ Procurar identificar entre as especialidades cirúrgicas, fatores ou procedimentos que possam estar associadas à maior taxa de mortalidade.

$\checkmark$ Estabelecer um "ranking” entre os procedimentos cirúrgicos estudados, aqueles relacionados a maiores números de internações, maiores taxas de mortalidade, maiores períodos de internação hospitalar e maiores gastos de internações.

Analisar a relação entre o gasto com internações cirúrgicas e a variação do mesmo na área de saúde nos últimos anos e a sua relação com os índices econômicos do país no período estudado. 


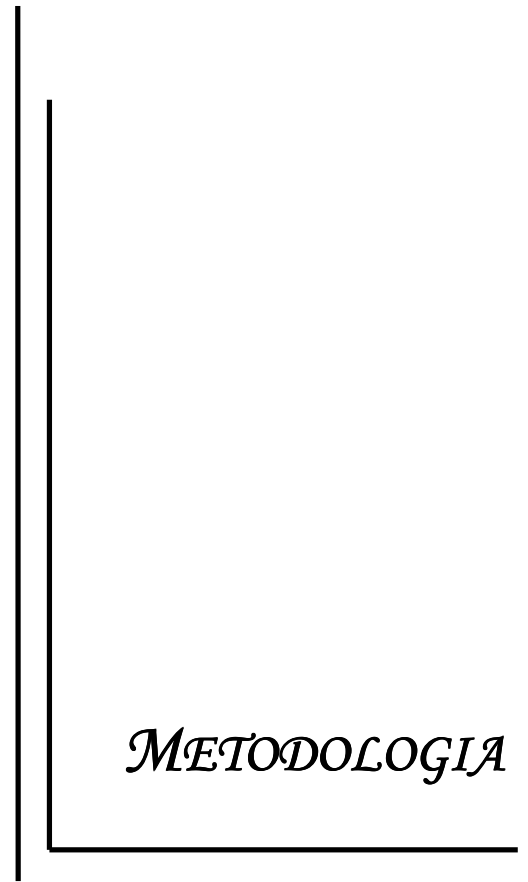

METODOLOGIA 


\section{METODOLOGIA}

\subsection{Casuística e métodos}

Trata-se de um estudo epidemiológico, retrospectivo, descritivo e analítico, cujo objetivo principal do estudo é avaliar os dados nacionais no contexto perioperatório de operações não cardíacas e a sua evolução nos últimos anos. O projeto foi aprovado pela Comissão de Ética em Pesquisa do Hospital das Clínicas (n 0952/09). Não foi obtido o termo de consentimento livre e esclarecido para este estudo, pois a resolução 196/96 não se aplica a este projeto, no que se refere ao item IV - obtenção do Consentimento Livre e Esclarecido, uma vez que as informações necessárias para o estudo foram obtidas por meio de levantamento de banco de dados do Departamento de Informática do Sistema Único de Saúde (DATASUS) ${ }^{(44)}$ que é de domínio público. Desta forma, não há vínculo de informações entre sujeito da pesquisa e dados coletados.

A coleta de dados e variáveis do estudo foi realizada inteiramente a partir do banco de dados e informações disponibilizadas pelo governo via sistema de DATASUS. Para este nosso estudo, selecionamos os dados nacionais referentes às internações hospitalares classificadas como cirúrgicas nos últimos anos. As variáveis de interesse para o estudo foram aquelas que possam fornecer informações e ajudar a conhecer a epidemiologia brasileira e o panorama nacional sobre as operações não cardíacas realizadas no país. Dentre as informações disponíveis no sistema, foram selecionadas as seguintes variáveis: número total de internações, gasto total por internação, gasto relacionado a transfusões sanguíneas, dias de permanência hospitalar e número de óbitos referentes às internações. O período selecionado para estudo foi determinado conforme a disponibilidade das informações no DATASUS no momento do levantamento de dados, que compreendeu os anos de 1992 a 2007. 
Para cada uma das cinco variáveis selecionadas do estudo, foi obtida uma planilha separada com os respectivos dados da variável interesse, onde na linha correspondeu ao procedimento cirúrgico que gerou a internação e na coluna $o$ ano correspondente. Selecionamos informações correpondentes a todas as regiões geográficas do país, de todas as naturezas e regimes hospitalares (público, privado ou universitário) e de todas as gestões (estaduais, municipais e federais). Ao todo, foram obtidas cinco planilhas contendo as informações correspondentes às variáveis selecionadas. Os procedimentos realizados eram descritos por um código em número junto com o nome da cirurgia.

Inicialmente, obtivemos do sistema, planilhas contendo todos os procedimentos que geraram internações hospitalares, compostas ao todo por 3.209 procedimentos. Uma análise detalhada das planilhas permitiu a exclusão das internações de caráter clínico, sendo que 2.424 procedimentos foram considerados como internações de caráter cirúrgico. Da planilha obtida com todos os procedimentos cirúrgicos, excluimos aqueles que não foram objetos do nosso estudo, entre eles, cirurgias ou procedimentos cardíacos, partos, biópsias ou procedimentos classificados como pequenas cirurgias superficiais ou diagnósticas. Após as exclusões de procedimentos descritos, obtivemos uma relação de 1.727 procedimentos cirúrgicos. Este processo foi bastante trabalhoso uma vez que foram observados diversos procedimentos idênticos com nomes repetidos e códigos diferentes, sendo que estes foram agrupados numa mesma categoria. Resultaram, no final, 1.568 procedimentos que constam nas planilhas finais para análise. 
Em seguida, todos os procedimentos cirúrgicos foram classificados conforme a especialidade cirúrgica correspondente, sendo no total de doze especialidades:

\begin{tabular}{ll}
\hline cabeça e pescoço & cirurgia geral \\
cirurgia plástica & gastrocirurgia \\
ginecologia & neurocirurgia \\
otorrinolaringologia & oftalmologia \\
ortopedia & torácica \\
urologia & vascular \\
\hline
\end{tabular}

Optamos pela divisão dos procedimentos em especialidades com objetivo de agrupar operações de mesma natureza e permitir a realização de análises de forma organizada e separada. A classificação dos procedimentos em especialidades correspondentes foi realizada por um único pesquisador, com base na $5^{\circ}$ edição da Classificação Brasileira Hierarquizada de Procedimentos Médicos da Associação Médica Brasileira e na tabela de procedimentos do Sistema Único de Saúde (SUS).

\subsection{Análise de resultados}

Inicialmente foi realizada uma análise global descritiva dos dados conforme as variáveis selecionadas, ano a ano, no período estudado. Todos dados obtidos foram apresentados em variáveis contínuas e expressas em números totais e médias. O número total de internações, gasto total de internações cirúrgicas, gasto em transfusão sanguínea foram apresentadas no formato de soma total dos valores. O tempo de internação (em dias) por procedimento foi apresentado em média, obtido por meio da divisão de total de dias de permanência hospitalar por número total de internações. A taxa de mortalidade foi calculada por meio da divisão de número total de óbitos por número total de internações e representada em percentagem. 
Os dados obtidos no período entre 1992 a 1994 foram excluídos da análise final, pois o sistema monetário utilizado no período anterior ao ano de 1995 era diferente e mesmo após a conversão dos valores de Cruzeiros e Cruzeiros Reais para Reais (utilizado a partir de 1995), os valores de custos se mostraram muito discrepantes, impossibilitando a análise fidedigna de dados econômicos.

$\mathrm{Na}$ análise de dados obtidos, observamos na planilha composta por todas variáveis estudadas com todos procedimentos incluídos, um grande número de dados missing no banco de dados originado de DATASUS. Desta forma, para evitar a limitação da análise fidedigna dos resultados, optamos por realizar as análises das variáveis somente com os procedimentos que tinham as informações disponíveis. Isto é, para análise de cada variável selecionada do estudo, os procedimentos com dados missing foram desconsiderados para análise estatística.

A análise descritiva de resultados foi dividida em três etapas. Primeiramente, foram avaliados os resultados de forma global, incluindo todos os procedimentos cirúrgicos estudados. Num segundo momento, realizamos a análise das variáveis por especialidades cirúrgicas e finalmente, a mesma análise foi repetida para os procedimentos cirúrgicos dentro de cada especialidade.

Realizamos inicialmente uma comparação descritiva de dados absolutos das variáveis obtidas ano a ano, para analisar a evolução temporal do comportamento das variáveis selecionadas no período do estudo. Para análise de tendência da evolução das variáveis ao longo do tempo, utilizamos o modelo de regressão linear.

Após a análise descritiva inicial das variáveis de forma geral, procuramos estudar as informações específicas relacionadas às particularidades de cada especialidade cirúrgica. Para cada especialidade, analisamos o comportamento das variáveis selecionadas e a sua evolução nos últimos anos. De forma semelhante, os resultados das cinco variáveis estudadas foram 
apresentadas para cada especialidade cirúrgica, inicialmente de valores absolutos e posteriormente também a análise de tendências do comportamento da variável ao longo do tempo por meio de modelo de regressão linear.

A análise semelhante foi realizada para descrição de procedimentos cirúrgicos dentro de cada especialidade. Ainda dentro da análise específica por especialidades e procedimentos, procuramos estabelecer o "ranking" de especialidades e de procedimentos cirúrgicos que apresentaram maiores números de internações, maiores taxas de mortalidade, internações mais prolongadas, maiores gastos em internação hospitalar e nas transfusões sanguíneas. Este "ranking" foi estabelecido utilizando o valor médio \pm desvio padrão das médias de todos anos, e ordenado de forma decrescente para cada variável estudada.

$\mathrm{Na}$ análise de dados no aspecto econômico, analisamos as informações obtidas referentes aos gastos de internação hospitalar. Entre eles, os gastos totais das internações cirúrgicas e gastos em transfusões sanguíneas no período estudado. Para isso, realizamos a correção da depreciação dos valores em função da desvalorização da moeda. Os dados obtidos do levantamento foram corrigidos anualmente para os valores de inflação por meio de indicador econômico - INPC (Índice Nacional de Preço ao Consumidor) específico, setorial para custos hospitalares. Utilizamos como base para comparação, o ano de 1995 como referência para a correção dos valores.

Dentro do objetivo em analisar o perfil epidemiológico das operações não cardíacas no país, tinhamos como proposta inicial do estudo, obter e realizar as análises de dados referentes aos aspectos clínicos, cirúrgicos, epidemiológicos e econômicos dos pacientes submetidos a procedimentos cirúrgicos. Entretanto, a análise de perfil clínico dos pacientes nas internações cirúrgicas não foi possível, pois os dados clínicos e demográficos dos pacientes não eram disponibilizados pelo sistema DATASUS. 


\section{$\underline{\text { 5.2.1 Análise Estatística }}$}

Todos dados obtidos foram apresentados em variáveis contínuas e expressas em números totais e médias. A análise de tendências das variáveis ao longo do período estudado foi realizada por meio do modelo de regressão linear.

Todas as análises estatísticas foram realizadas utilizando o programa estatístico denominado R-project for statistical computing (http://www.r-project.org). Os gráficos foram realizados com auxílio do software estatístico SPSS versão 17.0 (SPSS Inc). Adotamos como significância estatística para o nosso estudo, o valor de $p$ bi-caudado $<0,05$. 


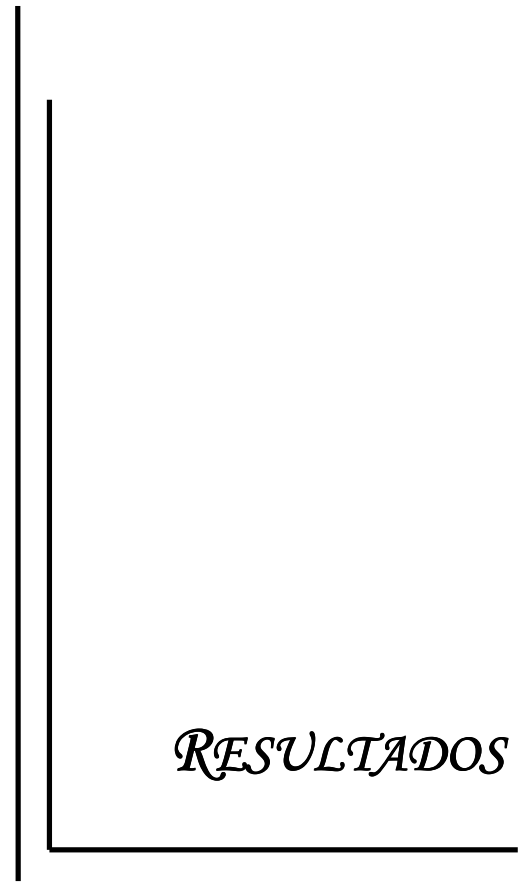




\section{RESULTADOS}

\subsection{Análise global}

Segundo os resultados do nosso estudo, foram realizados no período de 1995 a 2007 , um total de 32.659 .513 operações não cardíacas no país, com um gasto total hospitalar relacionado a estas cirurgias correspondente a $\mathrm{R} \$ 18.170 .700 .897,20$, sendo que somente $\mathrm{R} \$$ 173.838.341,13 foram relacionados a gastos em transfusões perioperatórias. Estas operações apresentaram um tempo médio de internação hospitalar de 4,14 dias e a taxa de mortalidade apresentou média de $1,6 \%$ neste período.

$\mathrm{Na}$ análise global dos resultados, observamos um aumento numérico progressivo das variáveis estudadas, nos últimos anos, com exceção da variável tempo de internação hospitalar. Houve aumento no número absoluto de internações cirúrgicas, no seu gasto total, assim como também o aumento do gasto em transfusão sanguínea. A taxa de mortalidade global no período também apresentou aumento gradativo nestes últimos anos. A única variável que mostrou tendência à redução no período estudado, foi o tempo de internação hospitalar. (Tabela 2) 
Tabela 2. Resultados das cinco variáveis do estudo relacionadas às internações cirúrgicas no período de 1995 a 2007

\begin{tabular}{cccccc}
\hline Ano & $\begin{array}{c}\mathbf{N}^{\circ} \text { de } \\
\text { Internações }\end{array}$ & $\begin{array}{c}\text { Gasto total das } \\
\text { internações (R\$) }\end{array}$ & $\begin{array}{c}\text { Gasto total em } \\
\text { transfusão (R\$) }\end{array}$ & $\begin{array}{c}\text { Tempo Médio de } \\
\text { Internação (dias) }\end{array}$ & Mortalidade \\
\hline 1995 & 2.374 .785 & $758.320 .580,67$ & $8.544 .341,07$ & 4,36 & $1,35 \%$ \\
1996 & 2.240 .815 & $770.830 .683,62$ & $8.395 .958,50$ & 4,46 & $1,46 \%$ \\
1997 & 2.152 .741 & $765.270 .078,55$ & $9.069 .315,60$ & 4,37 & $1,53 \%$ \\
1998 & 2.205 .637 & $915.201 .835,55$ & $11.023 .418,40$ & 4,34 & $1,54 \%$ \\
1999 & 2.359 .313 & $1.187 .971 .727,80$ & $12.803 .971,55$ & 4,31 & $1,57 \%$ \\
2000 & 2.505 .951 & $1.228 .607 .055,82$ & $13.360 .206,58$ & 4,07 & $1,53 \%$ \\
2001 & 2.412 .859 & $1.286 .563 .205,86$ & $13.737 .955,43$ & 4,16 & $1,61 \%$ \\
2002 & 2.578 .830 & $1.450 .449 .748,70$ & $13.744 .479,41$ & 4,12 & $1,58 \%$ \\
2003 & 2.672 .604 & $1.647 .980 .257,53$ & $13.628 .511,68$ & 4,06 & $1,65 \%$ \\
2004 & 2.748 .461 & $1.871 .908 .988,81$ & $15.904 .000,24$ & 3,99 & $1,68 \%$ \\
2005 & 2.750 .971 & $2.007 .295 .868,49$ & $18.260 .051,90$ & 3,91 & $1,78 \%$ \\
2006 & 2.796 .745 & $2.039 .263 .812,00$ & $17.518 .246,95$ & 3,82 & $1,74 \%$ \\
2007 & 2.859 .801 & $2.241 .037 .053,80$ & $17.847 .883,81$ & 3,83 & $1,77 \%$ \\
\hline Total & 32.659 .513 & $18.170 .700 .897,20$ & $173.838 .341,13$ & 4,14 & $1,6 \%$ \\
\hline
\end{tabular}

Os resultados do levantamento do banco de dados nos mostraram que houve um crescente aumento de número de internações cirúrgicas ao longo dos últimos anos. Houve um incremento de 20,42\% no número de procedimentos realizados no período estudado de 1995 a 2007. Para avaliar estes resultados em relação ao número total da população brasileira e a proporção do seu crescimento no mesmo período, obtivemos os dados corrigidos para o número de internações a cada 1.000 habitantes. (Figura 1) Observa-se que, no período entre 1995 e 1998, houve uma queda no número de internações cirúrgicas, que voltou a crescer principalmente a partir de 2001 . No último ano de dados disponíveis, foram registradas 15,24 internações cirúrgicas a cada 1000 habitantes. 


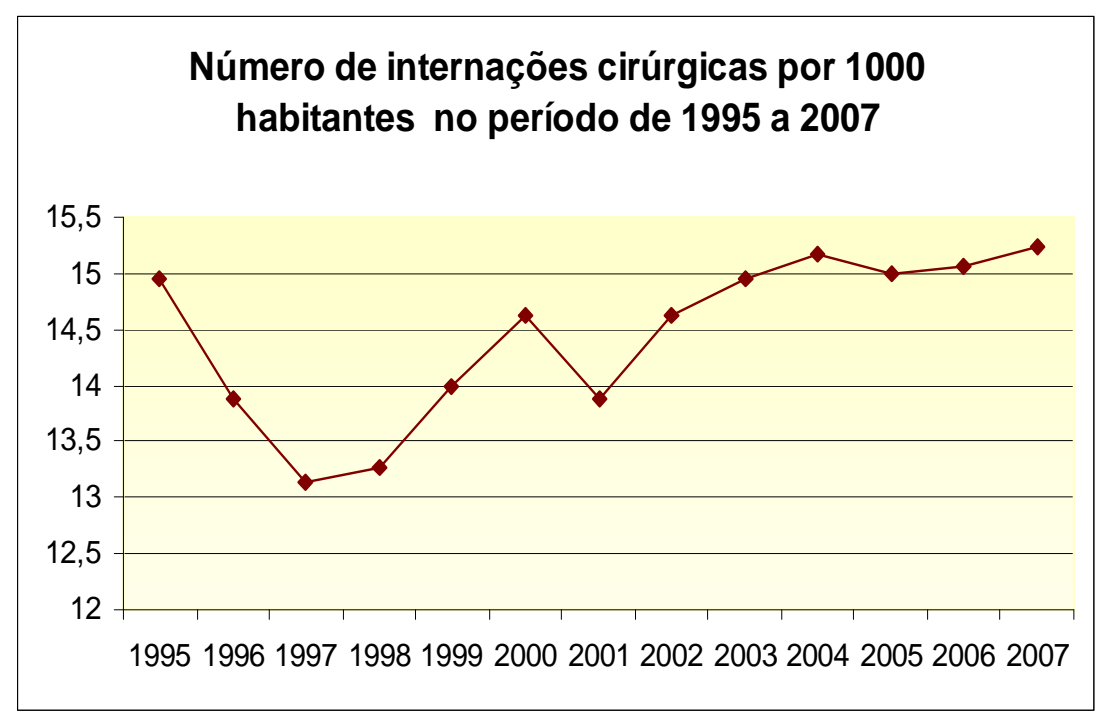

Fig.1. Número de internações de cirurgias não cardíacas a cada 1000 habitantes - período de 1995 a 2007

Em relação aos gastos de internações cirúrgicas, observamos que houve um aumento de quase $200 \%$ nos gastos num intervalo de 13 anos. Em 2007, o gasto anual em internações cirúrgicas registrado pelo DATASUS foi superior a dois bilhões de reais e vem aumentando rapidamente nos últimos anos. O mesmo comportamento se observa quanto aos gastos relacionados às transfusões sanguíneas perioperatórias, que também apresentaram um aumento importante neste período. $\mathrm{O}$ aumento dos gastos em transfusão sanguínea apresentou uma variação de 108,88\% no período de 1995 a 2007, sendo que foram gastos mais de 17 milhões de reais somente em transfusões sanguíneas nas internações de 2007, aproximadamente $0,8 \%$ do gasto total em internações cirúrgicas daquele ano.

Paralelamente ao número elevado e crescente de cirurgias realizadas anualmente, a mortalidade cirúrgica hospitalar registrada também foi cada vez mais elevada no decorrer dos anos, chegando a uma taxa de $1,77 \%$ no ano de 2007 . O incremento da taxa de mortalidade cirúrgica no período estudado foi de $31,11 \%$. A única variável estudada que mostrou redução 
de seus valores ao longo dos anos foi o tempo de internação hospitalar. Em média, o tempo de internação hospitalar caiu de 4,36 dias de 1995 para 3,83 dias em 2007, com redução de $12,15 \%$ no tempo médio de permanência hospitalar.

\subsection{Análise por especialidades cirúrgicas}

$\mathrm{Na}$ análise dos resultados divididos por especialidades cirúrgicas, observamos que há uma grande variabilidade das variáveis estudadas entre as especialidades. Os resultados das variáveis selecionadas foram organizadas conforme a especialidade cirúrgica e estão resumidos na Tabela 3. Os dados estão apresentados em médias \pm desvios-padrão dos valores médios de todos anos e estão organizados em "ranking" decrescente para cada variável analisada.

De uma forma geral, há três especialidades cirúrgicas - cirurgia torácica, neurocirurgia e gastrocirurgia, que ocuparam os primeiros lugares dos "rankings", destacando-se como as especialidades que apresentaram maiores gastos hospitalares, com tempos de internação hospitalar mais prolongadas e também como aquelas com as maiores taxas de mortalidade. Por outro lado, oftalmologia, otorrinolaringologia e ginecologia foram as especialidades que registraram os menores gastos hospitalares, com menores tempos de internação e apresentaram também as menores taxas de mortalidade. 
Tabela 3. "Ranking"decrescente das especialidades cirúrgicas conforme as variáveis estudadas, ordenado por seus valores médios \pm desvio padrão das médias de todos anos. A. Número de internações cirúrgicas; B.Gasto por internação cirúrgica; C.Gasto de transfusão sanguínea; D.Tempo de internação hospitalar; E. Mortalidade cirúrgica.

A- Número de internações cirúrgicas

\begin{tabular}{lc}
\hline Especialidade & $\begin{array}{c}\text { Número de } \\
\text { internações }\end{array}$ \\
\hline ginecologia & $681.851 \pm 38.156$ \\
cirurgia geral & $500.989 \pm 34.724$ \\
ortopedia & $408.269 \pm 78.133$ \\
gastrocirurgia & $228.830 \pm 39.814$ \\
urologia & $162.365 \pm 20.243$ \\
cirurgia plástica & $125.824 \pm 12145$ \\
vascular & $89.107 \pm 33835$ \\
oftalmologia & $89.097 \pm 25453$ \\
neurocirurgia & $73.269 \pm 16698$ \\
otorrino & $57.519 \pm 15632$ \\
cabeça pescoço & $48.137 \pm 5525$ \\
torácica & $47.012 \pm 7068$ \\
\hline
\end{tabular}

C - Gasto de transfusão sanguínea

\begin{tabular}{lc} 
Especialidade & $\begin{array}{c}\text { Gasto de } \\
\text { transfusão }(\mathbf{R} \$)\end{array}$ \\
\hline torácica & $26,37 \pm 5,92$ \\
gastrocirurgia & $14,31 \pm 1,52$ \\
neurocirurgia & $13,20 \pm 2,18$ \\
vascular & $8,07 \pm 2,25$ \\
cirurgia geral & $5,89 \pm 0,75$ \\
ortopedia & $4,72 \pm 0,85$ \\
urologia & $4,71 \pm 0,95$ \\
cabeça pescoço & $1,69 \pm 0,24$ \\
cirurgia plástica & $1,69 \pm 0,23$ \\
ginecologia & $1,58 \pm 0,36$ \\
otorrino & $0,29 \pm 0,09$ \\
oftalmologia & $0,07 \pm 0,04$ \\
\hline
\end{tabular}

B- Gasto por internação cirúrgica

\begin{tabular}{lc}
\hline Especialidade & $\begin{array}{c}\text { Gasto por } \\
\text { internação }(\mathbf{R} \$ \mathbf{)}\end{array}$ \\
\hline neurocirurgia & $1.928,97 \pm 702,30$ \\
torácica & $1.320,25 \pm 433,72$ \\
gastrocirurgia & $785,02 \pm 182,88$ \\
vascular & $697,72 \pm 179,96$ \\
ortopedia & $667,68 \pm 172,08$ \\
urologia & $656,78 \pm 183,77$ \\
cabeça pescoço & $500,93 \pm 171,34$ \\
cirurgia geral & $461,57 \pm 107,02$ \\
oftalmologia & $415,40 \pm 74,45$ \\
cirurgia plástica & $366,40 \pm 96,14$ \\
otorrino & $303,53 \pm 101,07$ \\
ginecologia & $256,12 \pm 56,49$ \\
\hline
\end{tabular}

D - Tempo de internação hospitalar

\begin{tabular}{lc}
\hline Especialidade & $\begin{array}{c}\text { Tempo } \\
\text { internação (dias) }\end{array}$ \\
\hline torácica & $11,99 \pm 0,24$ \\
neurocirurgia & $10,27 \pm 0,41$ \\
gastrocirurgia & $6,37 \pm 0,58$ \\
ortopedia & $5,25 \pm 0,46$ \\
urologia & $4,46 \pm 0,6$ \\
cirurgia geral & $3,92 \pm 0,3$ \\
vascular & $3,82 \pm 0,85$ \\
cabeça pescoço & $3,75 \pm 0,32$ \\
cirurgia plástica & $3,33 \pm 0,55$ \\
ginecologia & $2,50 \pm 0,22$ \\
otorrino & $1,48 \pm 0,21$ \\
oftalmologia & $1,34 \pm 0,19$ \\
\hline
\end{tabular}




\begin{tabular}{lc}
\multicolumn{2}{l}{ E - Mortalidade cirúrgica } \\
\hline torácica & Mortalidade $(\%)$ \\
neurocirurgia & $10,16 \pm 0,47 \pm 1,99$ \\
gastrocirurgia & $4,01 \pm 0,18$ \\
vascular & $2,30 \pm 0,87$ \\
cirurgia geral & $1,77 \pm 0,08$ \\
ortopedia & $1,01 \pm 0,04$ \\
urologia & $0,71 \pm 0,04$ \\
cirurgia plástica & $0,35 \pm 0,05$ \\
cabeça pescoço & $0,28 \pm 0,02$ \\
ginecologia & $0,06 \pm 0,01$ \\
otorrino & $0,04 \pm 0,01$ \\
oftalmologia & $0,03 \pm 0,02$ \\
\hline
\end{tabular}

\subsubsection{Número de internações}

Analisando detalhadamente cada variável do estudo separadamente, em relação ao número de internações de cada especialidade cirúrgica, notamos uma grande diferença entre elas. A especialidade responsável pelo maior número de internações cirúrgicas em todos anos foi a ginecologia com 8.864.065 operações realizadas no período de 1995 a 2007, correspondente a $27,14 \%$ do número total de internações cirúrgicas. A cirurgia torácica foi a especialidade que registrou menor número de procedimentos cirúrgicos (611.158 operações), responsável por apenas $1,87 \%$ do número total de internações cirúrgicas no período. Figura 2. 


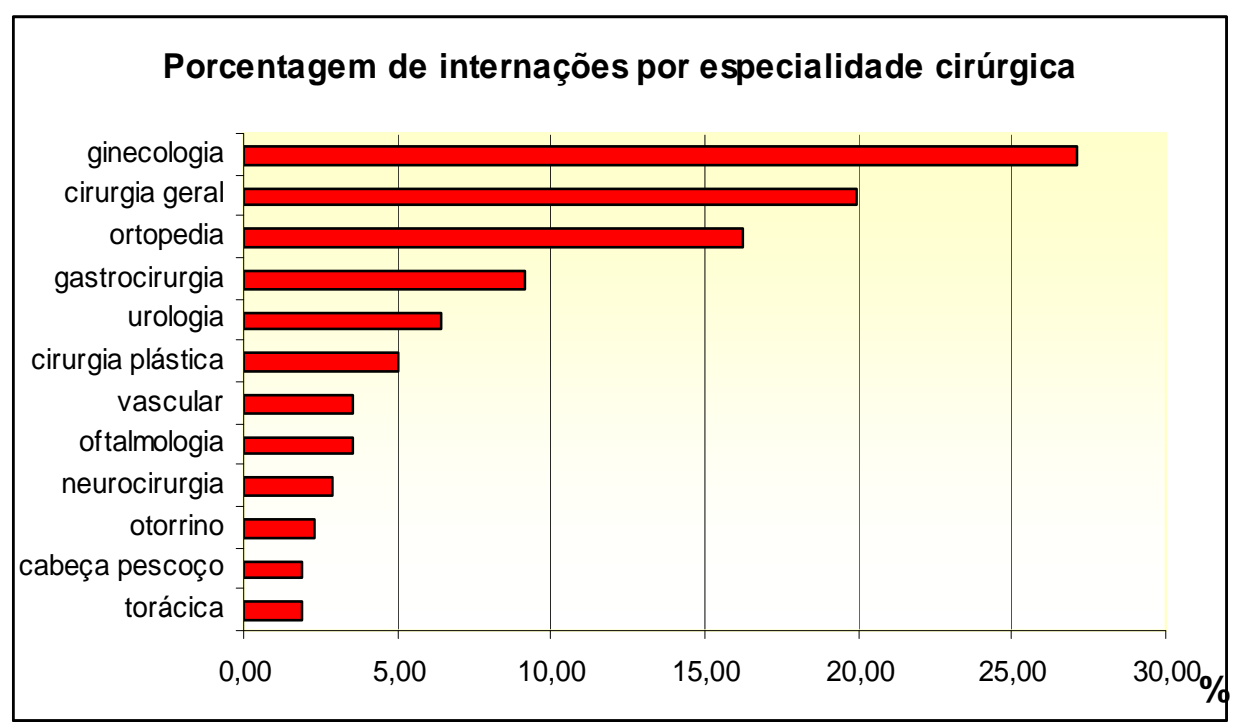

Fig 2. Distribuição do número de internações cirúrgicas em porcentagens de cada especialidade no período de 1995 a 2007

A análise do comportamento das variáveis estudadas no período de acordo com as diferentes especialidades mostrou que, na maioria das especialidades, houve um aumento progressivo do número total de internações nos últimos anos, com exceção da ginecologia e oftalmologia. Comparando os dados de anos 1995 e 2007, observamos que estas duas especialidades foram as únicas que registraram redução do número de internações neste período, com redução de 13,68\% para internações em ginecologia e uma redução mais acentuada de $38,84 \%$ nas internações oftalmológicas. Todas as outras especialidades cirúrgicas apresentaram aumento de número de internações ao longo do tempo, diferindo apenas na proporção de seus aumentos.

$\mathrm{Na}$ análise de número de internações a cada 1.000 habitantes, observamos que as internações cirúrgicas apresentaram três comportamentos distintos nas diferentes especialidades. Em algumas especialidades, o número de internações manteve estável ao 
longo do período estudado, como foram observados em cabeça pescoço, cirurgia geral, cirurgia plástica e urologia. As especialidades que apresentaram aumento de internações cirúrgicas foram gastrocirurgia, neurocirurgia, ortopedia, otorrinolaringologia, cirurgia torácica e cirurgia vascular. As duas especialidades cirúrgicas que apresentaram redução de números de internações foram ginecologia e oftalmologia. (Apêndice A - Tabela 11).

\subsubsection{Gasto de internação hospitalar}

Em relação aos gastos hospitalares, utilizamos para nossa análise o valor calculado de gasto médio por internação. Os dados mostraram que todas as especialidades apresentaram aumento de seus gastos ao longo dos anos, porém a proporção deste aumento ocorreu de forma diferenciada entre as especialidades. Algumas especialidades apresentaram aumento mais expressivo dos seus gastos de seus procedimentos no período, como foi o exemplo de neurocirurgia (aumento de 224,19\%), otorrinolaringologia (222,19\%), cirurgia torácica $(185,38 \%)$, cabeça e pescoço $(159,64 \%)$ e cirurgia vascular $(142,46 \%)$. As outras especialidades apresentaram elevação de gasto hospitalar em menor grau quando comparada com as anteriores, mas também um aumento considerável, como observado em urologia $(118,35 \%)$, ortopedia $(114,24 \%)$, cirurgia plástica $(112,42 \%)$, cirurgia geral $(101,26 \%)$, gastrocirurgia (101,15\%), ginecologia $(92,06 \%)$ e oftalmologia $(59,43 \%)$. As duas especialidades cirúrgicas com maiores gastos por internação foram a neurocirurgia, seguida por cirurgia torácica, com gasto médio por internação de $\mathrm{R} \$ 1.928,97$ e $\mathrm{R} \$ 1.320,25$, respectivamente. As três especialidades com menores gastos hospitalares foram ginecologia, otorrinolaringologia e cirurgia plástica. Os valores de gasto médio por internação de cada especialidade estão representados na Tabela 12 - Apêndice A. 


\subsubsection{Gasto de transfusão sanguínea}

Em relação aos gastos relacionados à transfusão sanguínea, observamos um aumento do gasto em todas as especialidades cirúrgicas ao longo dos anos. As três especialidades que mais gastaram com a transfusão sanguínea no perioperatório foram cirurgia torácica, gastrocirurgia e neurocirurgia. A cirurgia torácica foi de longe a especialidade que apresentou maior gasto em transfusões, com valor médio de $\mathrm{R} \$ 26,37$ por procedimento, um gasto quase duas vezes maior que o valor gasto em gastrocirurgia, que ocupa o segundo lugar do “ranking" com valor médio de $\mathrm{R} \$ 14,31$. As outras especialidades apresentaram valores intermediários conforme mostrado na Tabela 3. As duas especialidades com menor gasto em transfusão foram otorrinolaringologia e oftalmologia (valores médios de $\mathrm{R} \$ 0,29$ e $\mathrm{R} \$ 0,07$ respectivamente).

O aumento do gasto em transfusão entre todas especialidades foi bastante expressivo e a porcentagem do aumento ocorreu da seguinte maneira: oftalmologia $(379,62 \%)$, cirurgia torácica $(99,18 \%)$, ginecologia $(88,32 \%)$, ortopedia $(68,27 \%)$, neurocirurgia $(66,95 \%)$, urologia $(66,02 \%)$, otorrinolaringologia $(63,99 \%)$, cirurgia geral $(43 \%)$, cabeça pescoço $(38,72 \%)$, cirurgia plástica $(26,11 \%)$, cirurgia vascular $(23,11 \%)$ e gastrocirurgia $(12,82 \%)$. Nota-se que apesar do aumento no gasto de transfusão em algumas especialidades, como a oftalmologia, o seu gasto médio em transfusão ainda é muito baixo, menor entre todas as especialidades.

A distribuição dos gastos com a transfusão sanguínea de cada especialidade ao longo do tempo está resumida na Apêndice A - Tabela 13. 


\subsubsection{Tempo de internação hospitalar}

Quanto ao tempo de internação hospitalar, houve uma tendência na redução do tempo médio de permanência em todas as especialidades, exceto a cirurgia torácica e neurocirurgia, que mantiveram seus períodos de internação relativamente estáveis. Estas duas especialidades cirúrgicas foram responsáveis pelos maiores tempos de internação hospitalar, com tempo médio de 11,99 e 10,27 dias, respectivamente. As duas especialidades com menor tempo de internação hospitalar foram otorrinolaringologia e oftalmologia, com média de internação de 1,48 e 1,34 dias, respectivamente.

De maneira geral, a maioria das especialidades apresentaram reduções do tempo de internação hospitalar, com pequenas variações entre elas. A oftalmologia foi a especialidade que apresentou maior porcentagem na redução do tempo de internação, de 36,34\%, seguida por cirurgia plástica $35,93 \%$, otorrinolaringologia $32,58 \%$, urologia $32,47 \%$, gastrocirurgia $24,65 \%$, ginecologia $23,25 \%$, cirurgia geral $19,53 \%$, ortopedia $17,55 \%$, cirurgia vascular $17,17 \%$ e cabeça pescoço com $14,25 \%$.

A Tabela 14 do Apêndice A apresenta os resultados do tempo médio de internação de cada especialidade de cada ano no período estudado.

\subsubsection{Mortalidade}

Em relação à mortalidade cirúrgica, a maioria das especialidades manteve a taxa de mortalidade relativamente estável. A especialidade que registrou um aumento expressivo da mortalidade $(46,76 \%)$ foi a cirurgia torácica; a cirurgia vascular apresentou variações da sua taxa de mortalidade ao longo dos anos, com um período de leve aumento da mortalidade até 1998 e período de redução no período de 2000 a 2004; enquanto que a cirurgia plástica 
teve uma tendência à queda da taxa de mortalidade ao longo do tempo. As duas especialidades com maiores taxas de mortalidades foram a cirurgia torácica e a neurocirurgia $(13,82 \%$ e $10,16 \%$, respectivamente); as três especialidades com menor taxa de mortalidade $(<0,1 \%)$ foram ginecologia, otorrinolaringologia e oftalmologia; as outras especialidades apresentaram taxas de mortalidade intermediárias. As especialidades cirúrgicas que apresentaram taxa de mortalidade entre 0,1 a $1 \%$ foram: cabeça pescoço, cirurgia plástica e urologia; enquanto que as seguintes especialidades - ortopedia, cirurgia geral, cirurgia vascular e gastrocirurgia apresentaram a taxa de mortalidade entre 1 a 5\%. (Tabela 3) Representamos a evolução da mortalidade conforme a especialidade cirúrgica no período estudado na Figura 3, na escala logarítmica. As taxas de mortalidade de cada especialidade cirúrgica estão resumidas na Tabela 15 - Apêndice A.

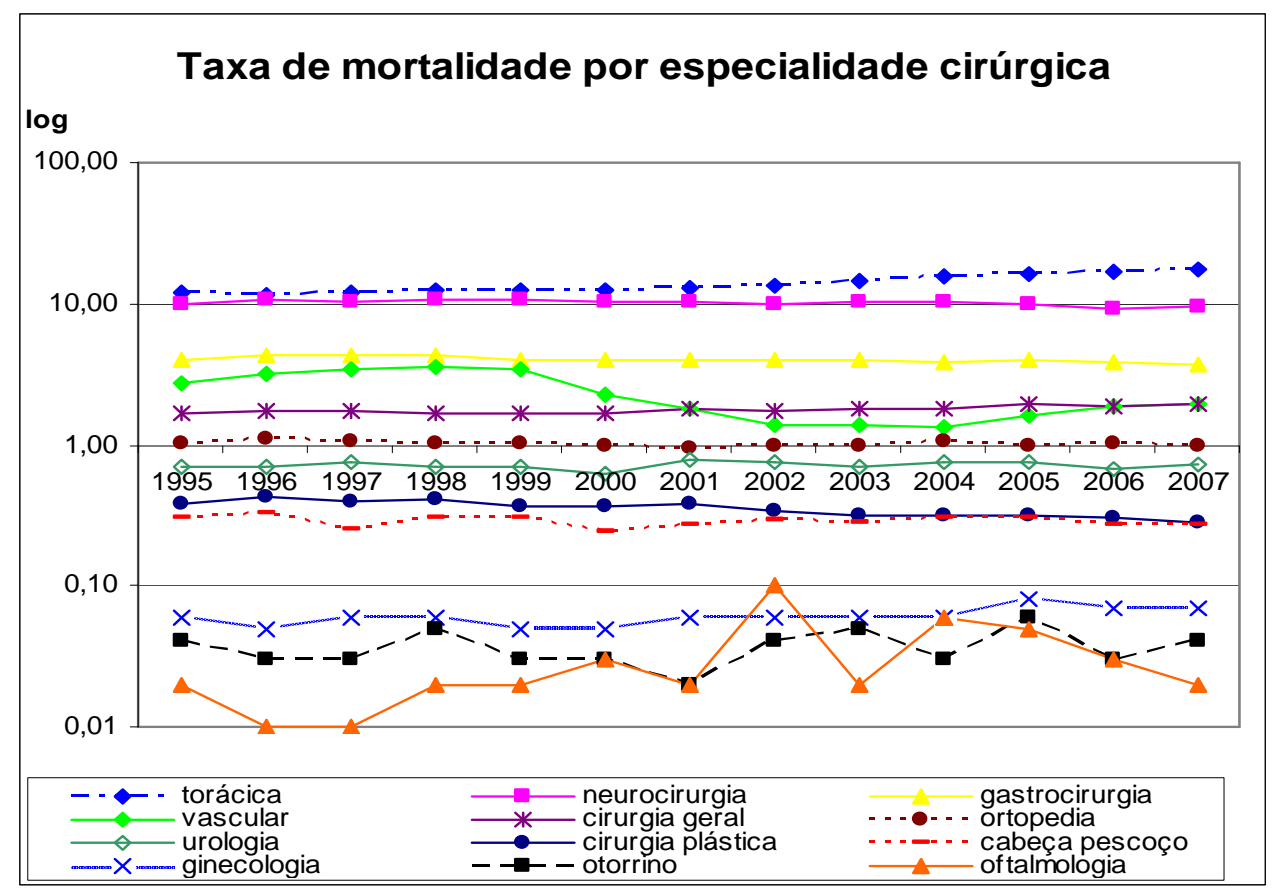

Fig. 3 - Representação da taxa de mortalidade cirúrgica por especialidade em escala logarítmica período de 1995 a 2007 


\subsection{Análise por procedimentos cirúrgicos}

Dos 1.568 procedimentos cirúrgicos incluídos na análise, estes foram divididos em doze especialidades. A especialidade com maior número de procedimentos cadastrados pelo SUS foi a ortopedia com 509 diferentes tipos de cirurgias. As outras especialidades apresentaram os seguintes números de procedimentos na tabela do SUS: 176 em neurocirurgia, 133 em cirurgia vascular, $126 \mathrm{em}$ urologia, $110 \mathrm{em}$ gastrocirurgia, $85 \mathrm{em}$ cirurgia plástica, 84 em oftalmologia, 78 tanto em cirurgia geral como em ginecologia, 74 em cabeça e pescoço, 66 em cirurgia torácica e 49 em otorrinolaringologia.

De acordo com os procedimentos estudados, estabelecemos o "ranking" de cirurgias relacionado ao maior número de internações, à maior taxa de mortalidade, ao maior período de internação hospitalar e aos maiores gastos na internação. Destacamos abaixo, os cinco procedimentos cirúrgicos que ocuparam os primeiros lugares dos "rankings", em cada variável estudada englobando todas as especialidades.

\subsubsection{Número de internações}

$\mathrm{Na}$ análise global de todos procedimentos cirúrgicos, os cinco procedimentos responsáveis pelo maior número de internações no período estudado foram:

1. Curetagem pós aborto

2. Herniorrafia inguinal unilateral

3. Colecistectomia

4. Colpoperioneoplastia

5. Apendicectomia
238.646

138.508

92.931

90.493

71.075 


\subsubsection{Gasto médio por internação}

Os cinco primeiros do "ranking" de procedimentos cirúrgicos que apresentaram maiores gastos por internação em todas as especialidades foram:

1. Implante coclear

2. Transplante hepático receptor - doador vivo

3. Transplante renal receptor (doador cadáver)

4. Transplante renal receptor (doador vivo)

5. Embolização de aneurismas cerebrais com espirais destacáveis
$\mathrm{R} \$ 32.612,36$

$\mathrm{R} \$ 28.373,19$

$\mathrm{R} \$ 15.435,60$

$\mathrm{R} \$ 13.569,73$

$\mathrm{R} \$ 10.003,16$

\subsubsection{Gasto de transfusão sanguínea}

Os cinco procedimentos cirúrgicos com maior gasto médio de transfusão por internação foram:

1. Anastomose porto cava

$\mathrm{R} \$ 288,48$

2. Desarticulação inter-ilio abdominal

$\mathrm{R} \$ 186,71$

3. Anastomose espleno renal ou outra derivação central

$\mathrm{R} \$ 149,66$

4. Hemipelvectomia

$\mathrm{R} \$ 115,13$

5. Pancreatoduodenectomia

$\mathrm{R} \$ 111,05$ 


\subsubsection{Tempo de internação hospitalar}

Os cinco procedimentos cirúrgicos com maior tempo médio de internação hospitalar foram:

1. Microcirurgia do tumor cerebral com laser

2. Desarticulação inter-ilio abdominal

3. Esofagectomia

4. Esofagocoloplastia

5. Pancreatoduodenectomia
25,68 dias

23,94 dias

19,91 dias

19,75 dias

18,97 dias

\subsubsection{Mortalidade}

Os cinco procedimentos cirúrgicos com maiores taxas de mortalidade ao longo dos últimos anos foram:

1. Tratamento cirúrgico do hematoma intracerebral

2. Traqueotomia (inclusive curativos)

3. Desarticulação ao nível de coxo femoral

4. Drenagem ventricular contínua externa

5. Craniotomia descompressiva
$42,04 \%$

$34,35 \%$

$28,77 \%$

$28,28 \%$

$27,79 \%$

Resumimos na tabela abaixo (Tabela 4), o "ranking" de procedimentos cirúrgicos de cada especialidade que apresentaram maior número de internações, maiores gastos hospitalares - por internação e por transfusão sanguínea, maior tempo médio de internação e maior taxa de mortalidade. 
Tabela 4. Procedimentos cirúrgicos de cada especialidade que ocuparam topo do "ranking" nas variáveis estudadas no período de 1995 a 2007

\begin{tabular}{|c|c|c|c|c|c|}
\hline Especialidade & $\mathbf{N}^{\circ}$ internações & Gasto por internação & Gasto de transfusão & Tempo de internação & Mortalidade \\
\hline $\begin{array}{l}\text { Cabeça } \\
\text { pescoço }\end{array}$ & tireoidectomia parcial - 6.654 & $\begin{array}{l}\text { pelvi gloso mandibulectomia } \\
\text { - R\$ 3.091,27 }\end{array}$ & $\begin{array}{l}\text { pelvi gloso mandibulectomia - } \\
\mathrm{R} \$ 21,62\end{array}$ & timectomia - 13,41 dias & $\begin{array}{l}\text { Pelvi gloso } \\
\text { mandibulectomia - } \\
2,77 \%\end{array}$ \\
\hline Cirurgia geral & $\begin{array}{l}\text { herniorrafia inguinal } \\
\text { unilateral - } 138.508\end{array}$ & $\begin{array}{l}\text { ressecção de tumor } \\
\text { retroperitonial com ressecção } \\
\text { de órgão(s) contíguo(s) - } \\
\mathrm{R} \$ 3.206,72\end{array}$ & $\begin{array}{l}\text { anastomose porto cava - } \\
\mathrm{R} \$ 288,48\end{array}$ & $\begin{array}{l}\text { anastomose espleno renal } \\
\text { ou outra derivação central } \\
\text { - } 14,18 \text { dias }\end{array}$ & $\begin{array}{l}\text { anastomose porto cava - } \\
22,27 \%\end{array}$ \\
\hline $\begin{array}{l}\text { Cirurgia } \\
\text { plástica }\end{array}$ & $\begin{array}{l}\text { extirpação e supressão de } \\
\text { lesão da pele e do tecido - } \\
20.991\end{array}$ & $\begin{array}{l}\text { ressecção de partes moles das } \\
\text { extremidades com } \\
\text { reconstrução - } \mathrm{R} \$ 2.749,88\end{array}$ & $\begin{array}{l}\text { reconstrução por microcirurgia } \\
\text { (qualquer parte) em cirurgia } \\
\text { oncológica - } R \$ 14,58\end{array}$ & $\begin{array}{l}\text { homoenxertia ato cirúrgico } \\
\text { pré e pós operatórios - } \\
9,11 \text { dias }\end{array}$ & $\begin{array}{l}\text { tratamento cirúrgico da } \\
\text { elefantíase ao nível do pé } \\
-1,98 \%\end{array}$ \\
\hline Gastrocirurgia & hemorroidectomia - 35.274 & $\begin{array}{l}\text { transplante de figado receptor } \\
\text { - doador vivo - } \mathrm{R} \$ 28.373,19\end{array}$ & $\begin{array}{l}\text { pancreato duodenectomia - } \\
\mathrm{R} \$ 111,05\end{array}$ & esofagectomia - 19,91dias & $\begin{array}{l}\text { esofagorrafia torácica - } \\
23,6 \%\end{array}$ \\
\hline Ginecologia & $\begin{array}{l}\text { curetagem pós aborto - } \\
238.646\end{array}$ & $\begin{array}{l}\text { histerectomia com ressecção } \\
\text { de órgão(s) contíguo(s) - } \\
\mathrm{R} \$ 2.520,01\end{array}$ & $\begin{array}{l}\text { histerectomia puerperal - } \\
\mathrm{R} \$ 88,47\end{array}$ & $\begin{array}{l}\text { vulvectomia ampliada com } \\
\text { linfadenectomia - } \\
\text { 13,81 dias }\end{array}$ & $\begin{array}{l}\text { histerectomia puerperal - } \\
7,13 \%\end{array}$ \\
\hline Neurocirurgia & $\begin{array}{l}\text { tratamento cirúrgico da } \\
\text { hematoma subdural }-6.222\end{array}$ & $\begin{array}{l}\text { embolização de aneurismas } \\
\text { cerebrais com espirais } \\
\text { destacáveis - R\$10.003,16 }\end{array}$ & $\begin{array}{l}\text { anastomose espino facial - } \\
\mathrm{R} \$ 89,64\end{array}$ & $\begin{array}{l}\text { microcirurgia do tumor } \\
\text { cerebral com laser - } \\
25,68 \text { dias }\end{array}$ & $\begin{array}{l}\text { tratamento cirúrgico do } \\
\text { hematoma intracerebral } \\
42,04 \%\end{array}$ \\
\hline
\end{tabular}


Tabela 4 . Procedimentos cirúrgicos de cada especialidade que ocuparam topo do "ranking" nas variáveis estudadas no período de 1995 a 2007 (Continuacão)

\begin{tabular}{|c|c|c|c|c|c|}
\hline Especialidade & $\mathbf{N}^{\circ}$ internações & Custo por internação & Custo de transfusão & Tempo de internação & Mortalidade \\
\hline Oftalmologia & $\begin{array}{l}\text { facectomia com lente intra- } \\
\text { ocular - } 37.139\end{array}$ & $\begin{array}{l}\text { transplante de córnea em } \\
\text { cirurgias combinadas - } \\
\mathrm{R} \$ 1.006,85\end{array}$ & $\begin{array}{l}\text { exenteração de órbita - } \\
\mathrm{R} \$ 4,28\end{array}$ & $\begin{array}{l}\text { exenteração de órbita - } \\
7,33 \text { dias }\end{array}$ & $\begin{array}{l}\text { exenteração de órbita - } \\
1,13 \%\end{array}$ \\
\hline Ortopedia & $\begin{array}{l}\text { tratamento cirúrgico da } \\
\text { fratura diafisária dos ossos do } \\
\text { antebraço - } 29.017\end{array}$ & $\begin{array}{l}\text { ressecção de tumores ósseos } \\
\text { com substituição } \\
\text { (endoprótese) - R } \$ 3.987,85\end{array}$ & $\begin{array}{l}\text { desarticulação inter ilio } \\
\text { abdominal - R\$ 186,71 }\end{array}$ & $\begin{array}{l}\text { desarticulação inter ilio } \\
\text { abdominal - 23,94 dias }\end{array}$ & $\begin{array}{l}\text { desarticulação ao nivel da } \\
\text { coxo femoral }-28,77 \%\end{array}$ \\
\hline $\begin{array}{l}\text { Otorrinolarin- } \\
\text { gologia }\end{array}$ & $\begin{array}{l}\text { amigdalectomia com ou sem } \\
\text { adenoidectomia - } 20.158\end{array}$ & $\begin{array}{l}\text { implante coclear - } \\
\mathrm{R} \$ 32.612,36\end{array}$ & $\begin{array}{l}\text { ressecção do glomo jugular - } \\
\mathrm{R} \$ 13,59\end{array}$ & $\begin{array}{l}\text { neurectomia vestibular } \\
\text { trans-labiríntica sem } \\
\text { audição - 7,4 dias }\end{array}$ & $\begin{array}{l}\text { plástica transpalatina para } \\
\text { atresia coanal }-2,58 \%\end{array}$ \\
\hline Torácica & $\begin{array}{l}\text { toracotomia com drenagem } \\
\text { fechada - } 24.860\end{array}$ & $\begin{array}{l}\text { toracectomia com ressecção } \\
\text { de estruturas intra torácicas - } \\
\mathrm{R} \$ 2.890 .03\end{array}$ & $\begin{array}{l}\text { mediastinotomia } \\
\text { (exploradora) trans-esternal - } \\
\mathrm{R} \$ 100,80\end{array}$ & $\begin{array}{l}\text { traqueotomia (inclusive } \\
\text { curativos) - } 17,08 \text { dias }\end{array}$ & $\begin{array}{l}\text { traqueotomia (inclusive } \\
\text { curativos) }-34,35 \%\end{array}$ \\
\hline Urologia & $\begin{array}{l}\text { postectomia (circuncisão) - } \\
23.633\end{array}$ & $\begin{array}{l}\text { transplante renal receptor - } \\
\text { doador cadáver - } \\
\mathrm{R} \$ 15.435,60\end{array}$ & $\begin{array}{l}\text { cistectomia total e derivação } \\
\text { em um só tempo - } \mathrm{R} \$ 77,77\end{array}$ & $\begin{array}{l}\text { cistoenteroplastia - } \\
17,45 \text { dias }\end{array}$ & $\begin{array}{l}\text { nefrostomia sem ou com } \\
\text { drenagem }-12,63 \%\end{array}$ \\
\hline Vascular & $\begin{array}{l}\text { tratamento cirúrgico de } \\
\text { varizes da safena interna } \\
\text { unilateral }-1.942\end{array}$ & $\begin{array}{l}\text { correção endovascular de } \\
\text { aneurisma ou dissecção da } \\
\text { aorta abdominal e ilíaca - } \\
\text { R } \$ 7.121,93\end{array}$ & $\begin{array}{l}\text { aneurismectomia toraco- } \\
\text { abdominal - } \mathrm{R} \$ 99,32\end{array}$ & $\begin{array}{l}\text { bypass ou endarterectomia } \\
\text { renal - } 10,88 \text { dias }\end{array}$ & $\begin{array}{l}\text { interrupção da veia cava } \\
\text { ou filtro da veia cava - } \\
26,06 \%\end{array}$ \\
\hline
\end{tabular}




\subsection{Análise de tendências}

\subsubsection{Análise global}

Realizamos a avaliação da tendência das variáveis estudadas ao longo do tempo de forma global e por especialidades. Na avaliação geral, observamos que todas as variáveis se modificaram no decorrer dos anos. As variáveis, número de internação e mortalidade apresentaram um crescimento linear ao longo do tempo, no período estudado. A variável tempo médio de internação foi a única que apresentou redução relacionada ao tempo.

No caso da variável número de internações, utilizamos para análise de tendências, o número de internações por 1.000 habitantes e observamos uma tendência fraca de aumento em relação ao tempo, mas estatisticamente significativa $\left(r^{2}\right.$ linear de 0,447 e $\left.p=0,012\right)$. A relação entre a taxa de mortalidade e o ano correspondente teve um $r^{2}$ linear de 0,907 e p = 0,0055 , enquanto que a relação entre o tempo médio de internação e o ano teve $\mathrm{r}^{2}$ linear de 0,928 e $\mathrm{p}=0,0011$. Nos gráficos seguintes, estão representados os resultados das análises. Gráfico 1. Os resultados das análises de tendências dos gastos hospitalares estão localizados na seção de análise econômica. 
Gráfico 1 - Resultados da análise de tendências das variáveis (dados globais) no período de 1995 a 2007. A. Número de internações por 1000 habitantes; B - Mortalidade; C - Tempo de internação hospitalar

A. Número de internações por 1000 habitantes

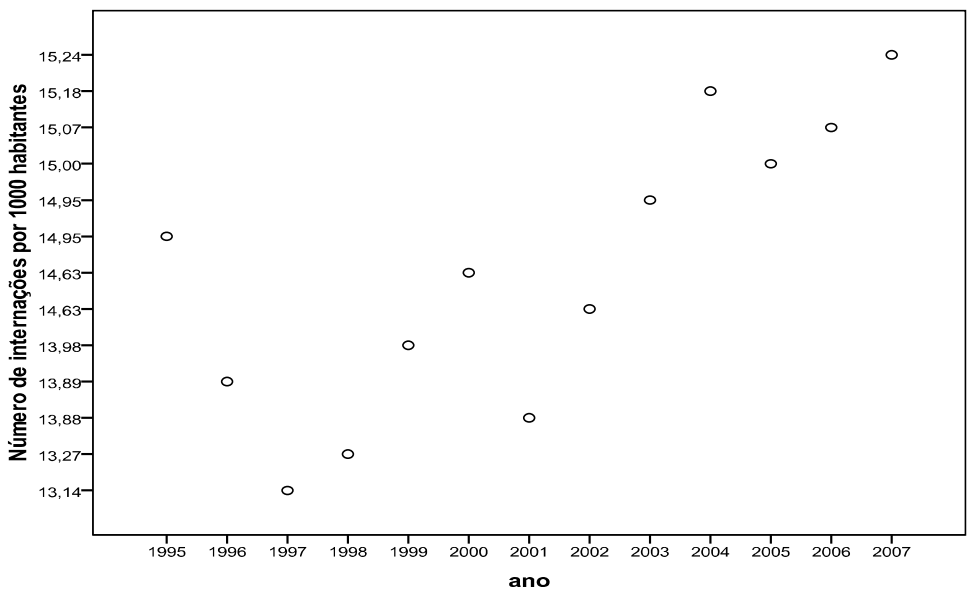

B. Mortalidade

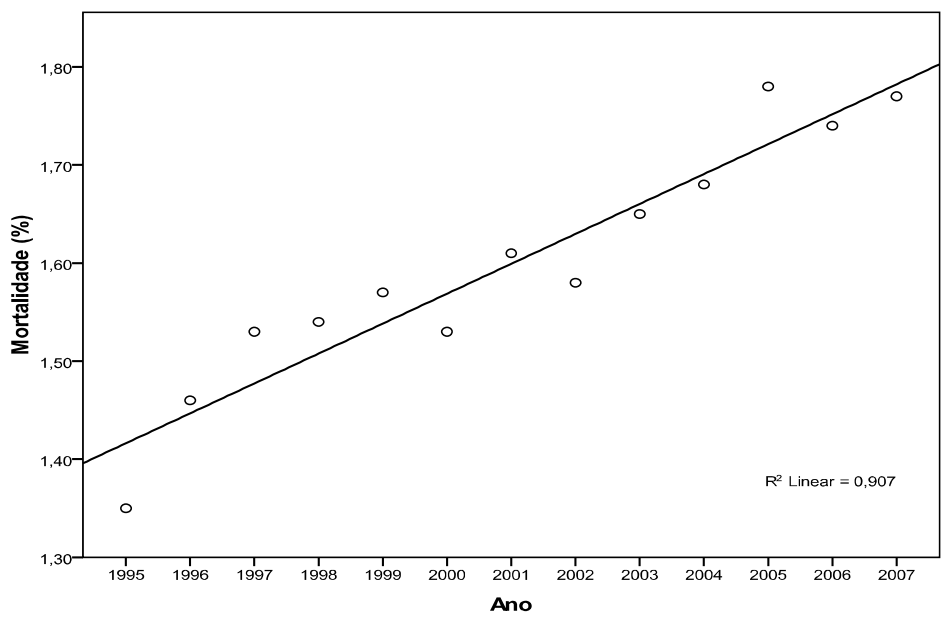

C - Tempo de internação hospitalar

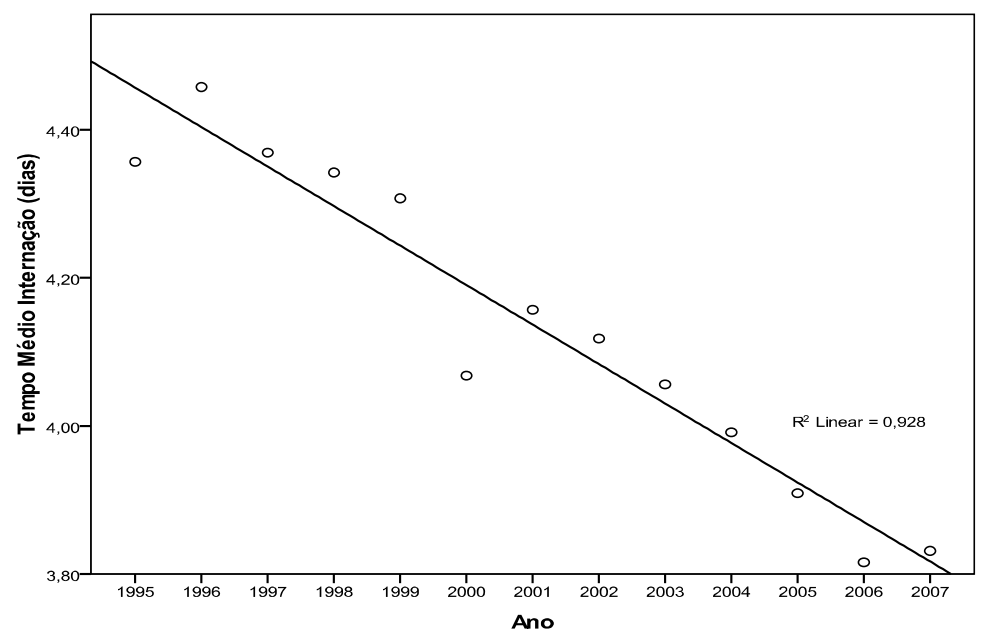




\subsubsection{Análise por especialidades}

$\mathrm{Na}$ análise de tendência das variáveis separadas por especialidade cirúrgica, observamos que algumas especialidades apresentaram uma relação linear direta entre a variável estudada e o tempo, enquanto que outras apresentaram uma relação mais fraca. Os resultados das análises de tendências das variáveis divididas por especialidades cirúrgicas foram representados em tabelas seguintes, organizadas de acordo com a variável estudada. Para as especialidades onde há uma tendência fortemente linear da variação ao longo do tempo, representamos graficamente os resultados da análise. Apêndice B - Gráficos 3 a 5.

\subsubsection{Número de internações cirúrgicas}

As especialidades que mais apresentaram aumento de números de internações relacionado ao tempo foram: ortopedia, gastrocirurgia, cirurgia torácica, otorrinolaringologia e neurocirurgia, todas com $\mathrm{r}^{2}$ acima de 0,9 e valores de $\mathrm{p}$ estatisticamente significativos. As outras especialidades apresentaram relações menos importantes, mas também significativos, como pode ser observado na Tabela 5. A única especialidade cirúrgica que não apresentou relação na análise de tendência foi a cirurgia geral com $\mathrm{r}^{2}$ linear de 0,085 e p=0,33. Todas as análises foram realizadas com os números de internação corrigidos para 1.000 habitantes. As representações gráficas dos resultados mais importantes estão no Gráfico 3 - Apêndice B. 
Tabela 5. Resultado da análise de tendência do número de internações por 1.000 habitantes conforme especialidade cirúrgica no período de 1995 a 2007

\begin{tabular}{lccccccc}
\hline Especialidade & $\mathbf{r}^{2}$ linear & $\mathbf{p}$ & & & Especialidade & $\mathbf{r}^{2}$ linear & $\mathbf{p}$ \\
\cline { 1 - 2 } ortopedia & 0,964 & 0,0003 & & vascular & & 0,717 & 0,0003 \\
gastrocirurgia & 0,946 & 0,0009 & & ginecologia & & 0,545 & 0,004 \\
torácica & 0,914 & 0,003 & & urologia & & 0,485 & 0,008 \\
otorrinolaringologia & 0,914 & 0,003 & & cirurgia plástica & 0,461 & 0,011 \\
neurocirurgia & 0,904 & 0,006 & & cabeça pescoço & 0,414 & 0,018 \\
oftalmologia & 0,786 & 0,037 & & cirurgia geral & & 0,085 & 0,33 \\
\hline
\end{tabular}

\subsubsection{Tempo médio de internação}

Em todas as especialidades cirúrgicas, houve tendência na redução do tempo de internação hospitalar no período de 1995 a 2007. Em algumas especialidades, a relação entre as duas variáveis foi acima de $90 \%$ com p estatisticamente significativo. Abaixo, na Tabela 6, estão os resultados da análise de regressão e as representações gráficas das especialidades que apresentaram maiores relações entre as duas variáveis, podem ser encontradas no Gráfico 4 -

\section{Apêndice B.}

Tabela 6. Resultado da análise de tendência do tempo de internação por especialidade cirúrgica no período de 1995 a 2007

\begin{tabular}{lcc}
\hline Especialidade & $\mathbf{r}^{2}$ linear & $\mathbf{p}$ \\
\hline gastrocirurgia & 0,987 & 0,00002 \\
cirurgia geral & 0,958 & 0,0008 \\
cirurgia plástica & 0,947 & 0,0008 \\
otorrinolaringologia & 0,936 & 0,002 \\
ginecologia & 0,929 & 0,001 \\
ortopedia & 0,903 & 0,006 \\
\hline
\end{tabular}

\begin{tabular}{lcc}
\hline Especialidade & $\mathbf{r}^{2}$ linear & $\mathbf{p}$ \\
\hline urologia & 0,898 & 0,008 \\
neurocirurgia & 0,877 & 0,006 \\
cabeça pescoço & 0,754 & 0,0001 \\
vascular & 0,52 & 0,005 \\
torácica & 0,498 & 0,007 \\
oftalmologia & 0,467 & 0,01 \\
\hline
\end{tabular}




\subsubsection{Mortalidade}

Em relação à mortalidade cirúrgica, apenas duas especialidades chamaram nossa atenção na análise de tendências. A relação mais forte encontrada foi na cirurgia torácica onde observamos um nítido aumento da taxa de mortalidade ao longo dos últimos anos. Enquanto que a cirurgia plástica apresentou uma tendência na redução de mortalidade registrada no período. Entre as outras especialidades cirúrgicas, houve uma relação mais fraca entre a variável mortalidade e tempo, como pode ser observada na Tabela 7. Os resultados gráficos destas análises divididas por especialidades estão no Gráfico 5- Apêndice B.

Tabela 7. Resultado da análise de tendência da mortalidade por especialidade cirúrgica no período de 1995 a 2007

\begin{tabular}{lcc}
\hline Especialidade & $\mathbf{r}^{2}$ linear & $\mathbf{p}$ \\
\hline torácica & 0,907 & 0,0046 \\
cirurgia plástica & 0,847 & 0,02 \\
cirurgia geral & 0,727 & 0,0002 \\
gastrocirurgia & 0,611 & 0,0016 \\
vascular & 0,559 & 0,0033 \\
ginecologia & 0,468 & 0,0099 \\
\hline
\end{tabular}

\begin{tabular}{lcc}
\hline Especialidade & $\mathbf{r}^{2}$ linear & $\mathbf{p}$ \\
\hline neurocirurgia & 0,44 & 0,013 \\
ortopedia & 0,227 & 0,1 \\
oftalmologia & 0,181 & 0,15 \\
otorrinolaringologia & 0,12 & 0,25 \\
cabeça pescoço & 0,065 & 0,4 \\
urologia & 0,018 & 0,66 \\
\hline
\end{tabular}

\subsection{Análise econômica}

\subsubsection{Análise global}

Realizamos as análises de gastos hospitalares corrigidos para inflação registrada no período estudado. Após a correção dos dados econômicos de acordo com a inflação setorial (saúde), observamos que houve uma redução dos gastos hospitalares em comparação com o ano de 1995, usado como referência para cálculo. A redução de gastos por internação ocorreu principalmente nos dois primeiros anos subseqüentes, em 1996 e 1997, e voltou a apresentar 
um aumento progressivo dos gastos a partir de 1998. A análise de tendência do gasto de internação corrigido mostrou um $\mathrm{r}^{2}$ linear de 0,439 e p=0,014. Gráfico 2A.

Em relação ao gasto médio de transfusão, de forma semelhante, os valores obtidos após a correção da inflação também apresentaram redução do gasto em relação ao ano-base. A análise de tendência desta variável em função do tempo não mostrou nenhuma relação entre elas: $\mathrm{r}^{2}$ linear de 0,014 e p estatisticamente não significante de 0,30. Gráfico 2B.

Os resultados dos gastos de internações hospitalar e de gasto de transfusão sanguínea perioperatória, após a correção da inflação, estão dispostos na Tabela 8.

Gráfico 2 - Resultados da análise de tendências das variáveis econômicas, gastos hospitalares e de transfusão, corrigidos para inflação, no período de 1995 a 2007. A - Gasto médio por internação; B Gasto médio de transfusão

A - Gasto médio por internação

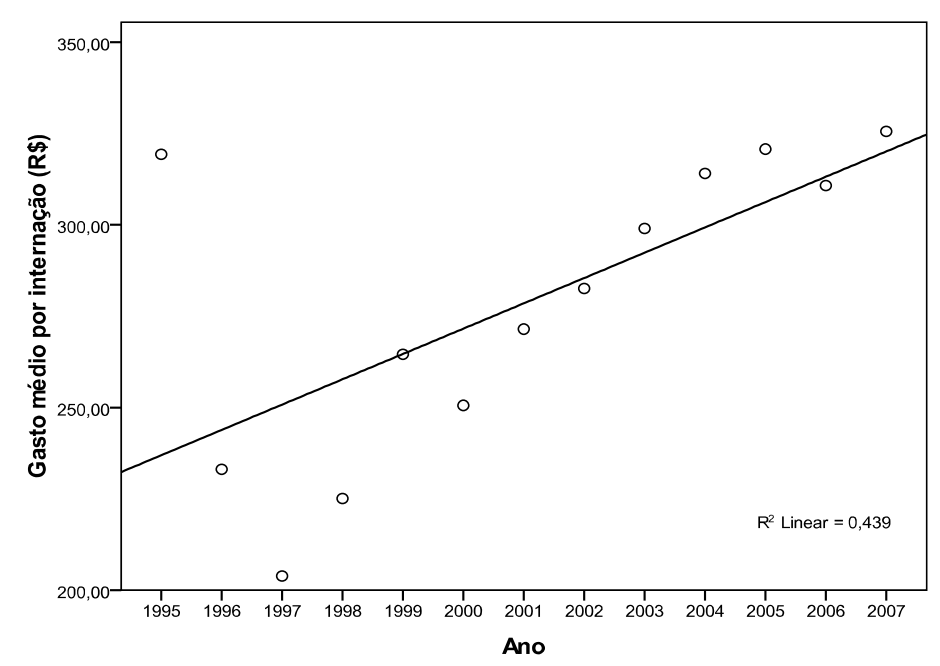


B - Gasto médio de transfusão

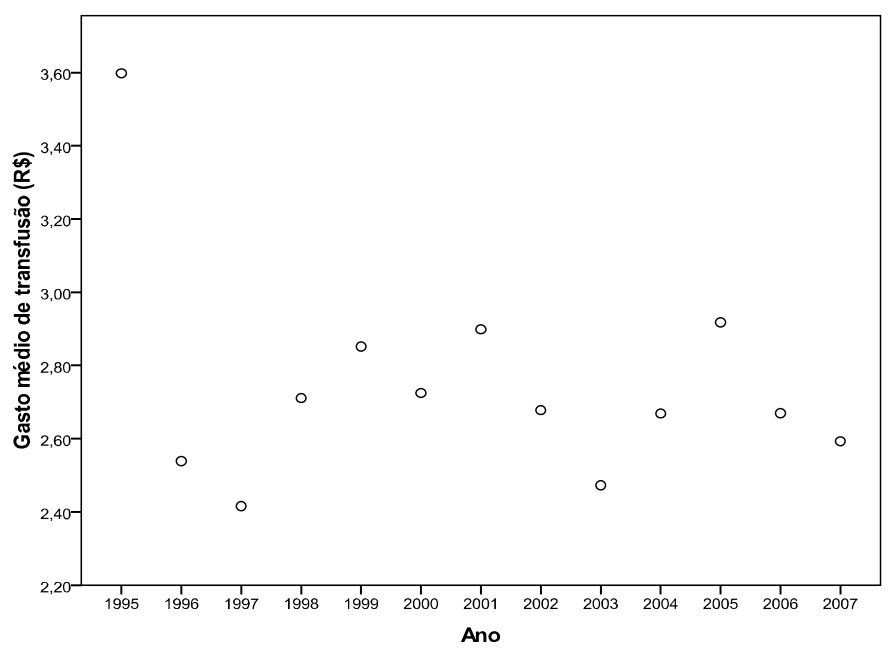

Tabela 8. Valores de gastos hospitalares por internação cirúrgica e por transfusão, corrigidos anualmente para inflação do período.

\begin{tabular}{lcc}
\hline Ano & $\begin{array}{c}\text { Gasto médio } \\
\text { internação R(\$) }\end{array}$ & $\begin{array}{c}\text { Gasto médio de } \\
\text { transfusão R(\$) }\end{array}$ \\
\hline 1995 & 319,32 & 3,60 \\
1996 & 233,09 & 2,54 \\
1997 & 203,86 & 2,42 \\
1998 & 225,08 & 2,71 \\
1999 & 264,58 & 2,85 \\
2000 & 250,58 & 2,72 \\
2001 & 271,46 & 2,90 \\
2002 & 282,59 & 2,68 \\
2003 & 299,01 & 2,47 \\
2004 & 314,12 & 2,67 \\
2005 & 320,75 & 2,92 \\
2006 & 310,77 & 2,67 \\
2007 & 325,59 & 2,59
\end{tabular}

Nota: $\overline{1995, \text { ano-base, utilizado como referência para correção da inflação }}$ 


\subsubsection{Análise por especialidades}

\subsubsection{Gasto médio por internação}

$\mathrm{Na}$ análise de gasto de internação corrigido para inflação por especialidades, observamos o comportamento semelhante ao apresentado na análise de gastos de forma global. Em todas as especialidades cirúrgicas, os gastos médios de internação apresentaram redução de seus valores com a correção para inflação, principalmente no período de 1996 a 1997. A partir de 1998, os gastos voltaram a apresentar aumento progressivo ao longo dos últimos anos. Os valores de gasto por internação por especialidade de cada ano estão resumidos na Tabela 16 - Apêndice A.

A análise de tendências entre os valores de gasto de internação corrigidos e o tempo não mostrou relações muito fortes entre as duas variáveis na divisão por especialidades. Apenas quatro especialidades cirúrgicas apresentaram resultados da análise de tendência com p significativo, apesar de baixa relação de $\mathrm{r}^{2}$ linear (Tabela 9).

Tabela 9. Resultado de análise de tendências do gasto de internação corrigido para inflação, no período de 1995 a 2007, por especialidade cirúrgica

\begin{tabular}{lccccccc}
\hline Especialidade & $\mathbf{r}^{2}$ linear & $\mathbf{p}$ & & Especialidade & $\mathbf{r}^{2}$ linear & $\mathbf{p}$ \\
\cline { 1 - 3 } \cline { 7 - 8 } neurocirurgia & 0,7 & 0,0003 & & ortopedia & & 0,166 & 0,17 \\
otorrinolaringologia & 0,627 & 0,001 & & vascular & 0,108 & 0,27 \\
cabeça pescoço & 0,553 & 0,003 & & oftalmologia & 0,082 & 0,34 \\
torácica & 0,528 & 0,005 & & gastrocirurgia & 0,077 & 0,36 \\
urologia & 0,202 & 0,12 & & cirurgia geral & & 0,047 & 0,48 \\
cirurgia plástica & 0,18 & 0,15 & & ginecologia & & 0,021 & 0,64 \\
\hline
\end{tabular}




\subsubsection{Gasto médio de transfusão}

Em relação ao gasto de transfusão sanguínea, os valores corrigidos por inflação também foram menores em relação ao ano-base, semelhante ao observado na análise de gastos de internação hospitalar. Entretanto, na análise de tendências, esta variável apresentou menor relação com a variável tempo, como pode ser notado por $\mathrm{r}^{2}$ baixos e somente significativos em poucas especialidades. (Tabela 10). Os dados absolutos de gasto médio de transfusão sanguínea de cada especialidade estão disponíveis na Tabela 17, Apêndice A.

Tabela 10. Resultado de análise de tendências do gasto de transfusão corrigido para inflação, no período de 1995 a 2007, por especialidade cirúrgica

\begin{tabular}{|c|c|c|c|c|c|}
\hline Especialidade & $\mathbf{r}^{2}$ linear & $\mathbf{p}$ & Especialidade & $\mathbf{r}^{2}$ linear & $\mathbf{p}$ \\
\hline gastrocirurgia & 0,694 & 0,0004 & neurocirugia & 0,177 & 0,15 \\
\hline cirurgia plástica & 0,668 & 0,0006 & ortopedia & 0,067 & 0,39 \\
\hline vascular & 0,659 & 0,0007 & ginecologia & 0,019 & 0,65 \\
\hline oftalmologia & 0,597 & 0,0019 & torácica & 0,014 & 0,7 \\
\hline cirurgia geral & 0,35 & 0,033 & urologia & 0,012 & 0,72 \\
\hline cabeça pescoço & 0,289 & 0,058 & otorrinolaringologia & 0,002 & 0,9 \\
\hline
\end{tabular}




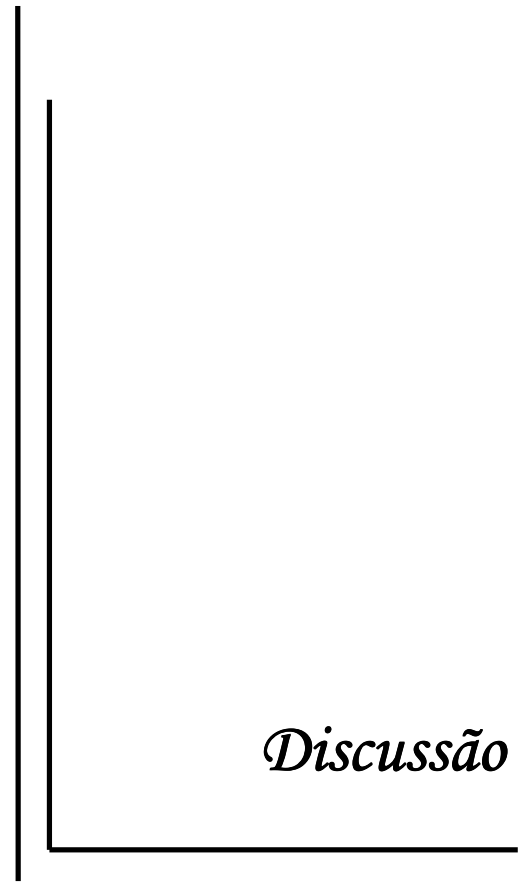




\section{DISCUSSÃO}

Neste estudo, procuramos caracterizar o perfil epidemiológico das operações não cardíacas realizadas no Brasil conforme registro de DATASUS. Segundo os nossos resultados, foram realizados no período de 1995 a 2007, um total de 32.659 .513 operações não cardíacas no país, distribuídos em 1.568 tipos de procedimentos cirúrgicos cadastrados no Sistema Único de Saúde. O gasto total relacionado a internações hospitalares destas cirurgias foi mais de 18 bilhões de reais neste período de 13 anos, sendo que o gasto anual em internações cirúrgicas é superior a 2 bilhões de reais, segundos dados dos últimos anos. Os gastos relacionadas a transfusões sanguíneas perioperatórias foram superiores a 173 milhões de reais para todas as operações realizadas no período estudado, e um gasto anual atual superior a 17 milhões de reais . Estas operações apresentaram um tempo médio de internação hospitalar de 4,14 dias e a média da mortalidade registrada no período do estudo foi de 1,6\%. Os resultados do estudo ainda mostraram uma tendência no aumento do número de operações não cardíacas realizadas no Brasil, dos gastos hospitalares relacionadas às internações cirúrgicas, além da taxa de mortalidade cirúrgica ao longo dos últimos anos.

Ao analisarmos as internações cirúrgicas conforme as especialidades, observamos que o crescimento de números de internações foi associado principalmente ao aumento de procedimentos cirúrgicos de grande volume e de baixo risco. Houve aumento de operações como as cirurgias de varizes, amigdalectomias, herniorrafias, colecistectomias, postectomias e correções de fraturas. A redução de número de internações na oftalmologia foi decorrente à diminuição das internações por facectomias, provavelmente em consequência às campanhas de catarata promovidas pelo governo nos últimos anos e a tendência atual da realização deste tipo de procedimento de baixo risco a nível ambulatorial. Estes dados poderiam sugerir um 
maior acesso da população brasileira às intervenções cirúrgias oferecidas no sistema de saúde. Este aumento progressivo de cirurgias realizadas observado no nosso estudo e seus gastos cada vez mais elevados provavelmente representará um ônus cada vez mais importante no sistema público de saúde com aumento da demanda de seus recursos e necessitará de melhor planejamento e investimentos futuros.

$\mathrm{Na}$ análise de gastos hospitalares de procedimentos cirúrgicos, o aumento de gastos ocorreu em todas as especialidades e pode ser justificado pelo perfil de pacientes mais graves e pelos avanços tecnológicos como utilização de novas técnicas cirúrgicas disponibilizadas pelo SUS nos últimos anos. Os aumentos mais expressivos de gastos hospitalares foram observadas nas especialidades que incorporaram procedimentos cirúrgicos novos nos últimos anos, como as microcirurgias na área de neurocirurgia, utilização de órteses e próteses nos procedimentos, como as implantes cocleares e as endopróteses vasculares. Estes novos procedimentos que entraram na tabela do SUS, principalmente a partir de 2002, apresentam um gasto de internação muito elevado, pois são dependentes de importação de materiais e tecnologias específicas. A oferta de procedimentos novos e mais avançados no sistema de saúde pode em parte melhorar os resultados cirúrgicos, porém ainda está associada a um custo extremamente elevado. Por exemplo, uma correção endovascular de aneurisma de aorta abdominal tem um custo médio de $\mathrm{R} \$ 10.000,00$ por internação enquanto que a cirurgia convencional via aberta tem um custo três vezes menor, de aproximadamente $\mathrm{R} \$ 3.000,00$. Como a maioria das tecnologias e cirurgias novas foram incluídas há pouco tempo na tabela de procedimentos de SUS, ainda faltam estudos de avaliação de custo-efetividade destes novos procedimentos cirúrgicos. Nosso estudo ainda revelou uma diferença considerável nos gastos por internação entre as diferentes especialidades. Por exemplo, em 2007, o gasto de uma internação de neurocirurgia (maior gasto) foi nove vezes superior ao gasto de uma 
internação da ginecologia (menor gasto). Esta variação de gasto provavelmente pode ser atribuído a portes cirúrgicos distintos dos procedimentos entre as diversas especialidades e também à complexidade diferenciada das operações de cada especialidade. Interessante notar que a ginecologia é a especialidade cirúrgica que apresentou maior número de internações em todos anos e, ao mesmo tempo, teve menor gasto por internação quando comparado com outras especialidades. Enquanto que a cirurgia torácica é uma das especialidades que apresentou maior gasto hospitalar e foi a especialidade que registrou menor número de internações.

A redução do tempo de internação hospitalar observada no nosso estudo provavelmente está relacionada à predominância de procedimentos cirúrgicos de baixo risco e que apresentaram grande volume nos últimos anos, e em consequência aos avanços de medicina perioperatória e a melhora de técnicas cirúrgicas que ocorreram nos últimos anos. A melhoria de cuidados perioperatórios aos pacientes cirúrgicos com normatizações de avaliação de risco cirúrgico, implementação de medidas de farmacoproteção e de monitorização perioperatória, evolução de técnicas cirúrgicas, realização de intervenções menos invasivas como a utilização de técnicas endoscópicas, juntamente com instituição da prática de fast track, devem ter contribuído para a redução do tempo de internação hospitalar.

A taxa de mortalidade cirúrgica observada no nosso levantamento foi superior a da literatura internacional e especialmente elevada em duas especialidades, a cirurgia torácica e a neurocirurgia. Este número elevado de óbitos foi associado a operações com altos índices de mortalidade registrada como tratamento de hematomas intracerebrais e traqueostomias, que apresentaram mortalidades de $42,04 \%$ e $34,35 \%$ respectivamente, provavelmente relacionadas à gravidade da própria doença de base e o caráter de urgência dos procedimentos. Em diversas outras especialidades, as maiores taxas de mortalidade também foram observadas em 
operações realizadas em caráter de urgência ou emergência, como por exemplo, histerectomia puerperal - mortalidade de $7,13 \%$, nefrostomias $(12,63 \%)$ e colocação de filtro de veia cava $(26,06 \%)$. Entretanto, também observamos outros procedimentos cirúrgicos com alta taxas de mortalidade realizados de forma eletiva, tais como tratamento cirúrgico de aneurisma de aorta abdominal $20,57 \%$, colectomia total $19,34 \%$, esofagectomia $17,87 \%$, pneumomectomias $12,39 \%$ e pleurodese $10,14 \%$. Estes números encontrados são alarmantes e ressaltam a necessidade de maior aprimoramento e investimento para redução da nossa mortalidade cirúrgica.

Comparado com os dados de estudos prévios, os resultados do nosso levantamento evidenciaram que a epidemiologia de intervenções cirúrgicas no Brasil é muito diferente dos dados internacionais. Apesar do aumento progressivo de operações realizadas no país, o nosso volume cirúrgico ainda é muito inferior quando comparado a países desenvolvidos. Atualmente, são realizadas quase três milhões de operações não cardíacas no Brasil por ano, enquanto que nos Estados Unidos, são realizadas mais de 38 milhões de cirurgias anualmente e estima-se que na Europa, cerca de 7 milhões de procedimentos cirúrgicos são realizados por ano.

Em relação aos gastos hospitalares, tempo de internação e mortalidade cirúrgica, observamos também uma diferença importante entre os nossos resultados e dos países norteamericanos. No estudo de Khan e colaboradores ${ }^{(45)}$, realizado em único centro do Canadá, os autores encontraram um gasto médio por internação de U\$2.094,00, com tempo médio de internação de 3 dias e uma mortalidade de 0,2\%. No estudo americano de Kalish e colaboradores $^{(46)}$, o gasto hospitalar no grupo sem complicações perioperatórias foi de U\$9.239,00, tempo de internação de 5,4 dias e mortalidade de 1\%. E estes valores se elevam significativamente na ocorrência de algum evento ou complicação pós operatória. Segundo os 
resultados do nosso estudo, as operações realizadas no Brasil apresentaram um gasto médio por procedimento de $\mathrm{R} \$ 783,63$ (U\$ 445,24 - taxa de conversão na época do estudo: $1 \mathrm{U} \$=$ $\mathrm{R} \$ 1,76$ ), tempo médio de internação de 3,8 dias e uma taxa de mortalidade de $1,77 \%$ (dados referentes ao ano de 2007). Estes dados mostraram que o gasto por cada internação cirúrgica é muito menor no Brasil quando comparado a outros países e a nossa taxa de mortalidade é muito superior a estatísticas internacionais, com um tempo médio de internação hospitalar intermediária. Estes resultados são bastantes preocupantes uma vez que boa parte das nossas internações cirúrgicas foram decorrentes de procedimentos classificados como de pequeno porte e de baixo risco, como as ginecológicas, oftalmológicas e otorrinolaringológicas. Estes dados sugerem uma pior evolução pós operatórias com altas taxas de complicações de nossas operações e certamente é uma área que merece uma maior atenção do sistema de saúde e maior investimento para estabelecer estratégias e medidas com intuito de melhorar os nossos resultados cirúrgicos.

$\mathrm{Na}$ análise de resultados por especialidades cirúrgicas, os nossos dados mostraram um perfil de risco cirúrgico muito diferente às observadas em algoritmos internacionais, quanto à divisão de classes de risco inerente ao próprio procedimento cirúrgico. De acordo com os resultados do nosso estudo, as duas especialidades que apresentaram as maiores taxas de mortalidade e seriam caracterizadas como cirurgias de alto risco foram a cirurgia torácica e neurocirurgia, que registraram mortalidade de $13,82 \%$ e $10,16 \%$, respectivamente. Enquanto que a cirurgia vascular, habitualmente a especialidade cirúrgica cujos procedimentos são relacionados a altas taxas de complicações, teve na nossa casuística, uma mortalidade de apenas $2,3 \%$. Esta baixa mortalidade observada em nossos dados pode ser justificada pelo grande número de procedimentos de baixo risco, como as cirurgias de varizes enquanto que as cirurgias de maior mortalidade dentro da especialidade, como as aneurismas de aorta, tiveram 
pouca representatividade no número total de cirurgias realizadas. As duas especialidades (cabeça e pescoço e urologia), classificadas como cirurgias de risco intermediário, com taxa de complicação estimada entre 1 a 5\%, também apresentaram mortalidade menor a $1 \%$ na nossa casuística. As outras especialidades tiveram taxas de mortalidade condizentes com a classificação de seus riscos. Entretanto, a interpretação e comparação destes resultados deve ser realizada com cautela, uma vez que os algoritmos de AHA/ACC ${ }^{(11)}$ e de ESC $^{(12)}$ preconizam a classificação de risco cirúrgico baseada na estimativa de ocorrência de complicações cardiovasculares pós operatórias enquanto que os nossos resultados mostraram taxas de mortalidade relacionadas às especialidades cirúrgicas.

$\mathrm{Na}$ análise dos procedimentos por "ranking", nota-se que os maiores números de internações foram relacionados a procedimentos cuja doença apresenta alta prevalência na população como herniorrafias, colecistectomias, perineoplastias e apendicetomias. A curetagem pós aborto foi responsável pelo maior número de internações em todos anos, com mais de 238.000 internações ao ano. As cirurgias de maior gasto hospitalar foram aquelas relacionadas a um suporte tecnológico maior, como emprego de órteses ou próteses nos procedimentos e também operações de alto custo como os transplantes. O maior gasto de transfusão foi observado em cirurgias de grande porte e que apresentavam um grande risco de sangramento. O tempo de internação mais prolongado foi observado em operações de maior complexidade e de maior porte cirúrgico. Os procedimentos que apresentaram maiores taxas de mortalidade foram as neurocirurgias e as traqueostomias que podem ser reflexos da gravidade da doença associada e também aqueles que foram realizados em caráter de urgência e/ou emergência.

De acordo com o nosso estudo, há uma tendência clara do aumento do números de procedimentos cirúrgicos ao longo do tempo. Considerando o crescimento populacional e o 
aumento da expectativa de vida no Brasil, estes números devem crescer cada vez mais nos próximos anos. Isto implica no aumento do gasto relacionado a estes procedimentos e consequente aumento de demanda de recursos apropriados nesta área.

No aspecto econômico, a análise de gastos de internações e de transfusão sanguínea mostrou uma redução de seus valores após a correção para inflação do período, nos primeiros anos estudados essencialmente até 1997. A redução de gastos em internações cirúrgicas nos anos de 1996 e 1997, provavelmente foi correlacionada à redução de número de internações observada neste mesmo período. Estes resultados poderiam corresponder às mudanças econômicas que ocorreram naqueles anos no país e no mundo. Em 1995, foi o ano da instituição de Plano Real no Brasil, quando ocorreu uma valorização da moeda nacional, com aumento do número de importações no período devido a redução de custo de materiais importados. Este fato poderia justificar um número maior de despesas relacionadas aos procedimentos cirúrgicos observado naquele ano. Nos anos subsequentes, observamos uma redução de gastos e números de internações cirúrgicas provavelmente associada à crise cambial instalada no Brasil e no mundo, com seu auge no ano de 1997, quando ocorreu uma grande desvalorização da moeda nacional. A partir de 1998, os gastos de internações hospitalares voltaram a aumentar gradativamente em decorrência da estabilização da economia brasileira. 


\section{Considerações finais}

Pouco se conhecia da epidemiologia de operações não cardíacas realizadas no nosso país quanto ao número de procedimenos realizados anualmente, os gastos relacionados a estas operações ou a taxa de mortalidade cirúrgica. Encontramos apenas um único trabalho na literatura nacional, que procurou analisar os aspectos epidemiológicos de procedimentos cirúrgicos, realizado por Chaves e colaboradores ${ }^{(47)}$. Trata-se de um estudo conduzido no município de Ribeirão Preto do estado de São Paulo, onde os autores procuraram descrever a produção física, definida por número de procedimentos, e financeira das cirurgias realizadas em internações hospitalares em cinco hospitais da região ${ }^{(47)}$. Os autores realizaram levantamento de dados referente a internações cirúrgicas disponibilizadas pela Secretaria Municipal de Saúde de Ribeirão Preto, no período de 1996 a 2003. Os resultados deste estudo mostram que houve um incremento de $73,1 \%$ na produção física e $121,6 \%$ na produção financeira no período estudado. Entretanto, este trabalho tem uma abrangência limitada, pois trata-se de um estudo local, restrito a um município, com cinco hospitais selecionados e os seus resultados não podem ser aplicados para as outras regiões do país. O nosso estudo é o primeiro levantamento de dados que procurou englobar informações cirúrgicas no âmbito nacional com intuito de conhecer e avaliar a epidemiologia nacional referente às operações não cardíacas. Estes resultados são inéditos, pois obtivemos os dados que demonstraram a realidade brasileira no que concerne nos aspectos epidemiológicos e econômicos de operações não cardíacas realizadas no país.

Nas duas últimas décadas, o Brasil apresentou uma melhoria no sistema de saúde, medida por redução da taxa de mortalidade proporcional ${ }^{(48)}$. Houve uma redução de proporção de óbitos em menores de um ano e aumento da proporção na faixa de idade acima de 50 anos. 
Esse fato reflete, provavelmente, o aumento da longevidade da população brasileira. Segundo o relatório de estatística em saúde mundial publicado pela Organização Mundial de Saúde (OMS) em 2009, a expectativa de vida da população brasileira melhorou aumentando de 66 anos em 1990 para 73 anos em $2007^{(49)}$. De acordo com os dados de IBGE disponível no DATASUS, no ano de 2007, a população brasileira é formada por mais de 18 milhões de indivíduos acima de 60 anos, correspondente a 9,6\% da população total ${ }^{(44)}$. No entanto, apesar do aumento da expectativa de vida observada na população, os indicadores de OMS mostram que o nosso país ainda precisa melhorar em medidas de investimento na área de saúde. As estatística mostram que o valor total de despesas destinadas à área de saúde em relação ao produto interno bruto do país teve um aumento de 7,2\% para 7,5\% neste período, mas ainda abaixo do nível global mundial registrada de $8,7 \%$. Ainda mais, aproximadamente $48 \%$ dos gastos em saúde no país eram provenientes de recursos governamentais, e estes valores corresponderam a apenas $7,2 \%$ do total das despesas anuais do governo, valor praticamente metade da taxa global de 14,3\%. Ao analisarmos a despesa total per capita em saúde no Brasil, observa-se que em média U\$ 427,00 foram gastos por habitante anualmente em serviços de saúde enquanto que o gasto investido pelo governo nesta área foi somente de US\$ 204,00 per capita no ano de 2006. Este valor é muito inferior ao gasto global mundial registrado de U\$ 429,00 per capita, ou aos valores investidos pelos governos de países desenvolvidos que chegam a um investimento de U\$ 3.076,00 por habitante nos Estados Unidos ou de U\$ $1.350,00$ nos países europeus ${ }^{(49)}$. Estes números revelam que o investimento do governo brasileiro nas áreas de saúde está aquém do ideal e muito inferior quando comparado a padrões internacionais. 
A análise dos recursos hospitalares existentes no país pelo sistema público de saúde no período do estudo de 1995 a 2007 mostrou dados estatísticos preocupantes (Figura 4). Segundo os registros do DATASUS, 512.105 leitos eram disponibilizados pelo SUS em 1995 para internações hospitalares, sendo que aproximadamente $70 \%$ dos leitos disponíveis eram administrados por hospitais de regime privado. O número total de leitos oferecidos pelo SUS se manteve relativamente estável até 2000. Houve uma redução discreta e gradativa do número total de leitos ao longo destes anos, mantendo sempre o predomínio de hospitais de regime privado sobre os de regime público. A partir de 2001, houve mudanças importantes referentes a recursos hospitalares disponíveis no país. Observou-se uma redução progressiva no número total de leitos disponibilizados pelo SUS, assim como a mudança nos regimes hospitalares. Em 2007, foram computados um total de 370.930 leitos disponibilizados pelo SUS, com uma redução aproximada de $30 \%$ no número total de leitos hospitalares em comparação com o ano de 1995. Ainda mais, houve uma redução importante de leitos oriundos de hospitais de regime privado acompanhado de discreto aumento dos leitos de hospitais de regime público. Em 2007, apenas 56,34\% dos leitos hospitalares disponibilizados pelo SUS eram provenientes de hospitais de regime privado, enquanto que 43,66\% pertenciam à regime pública. 


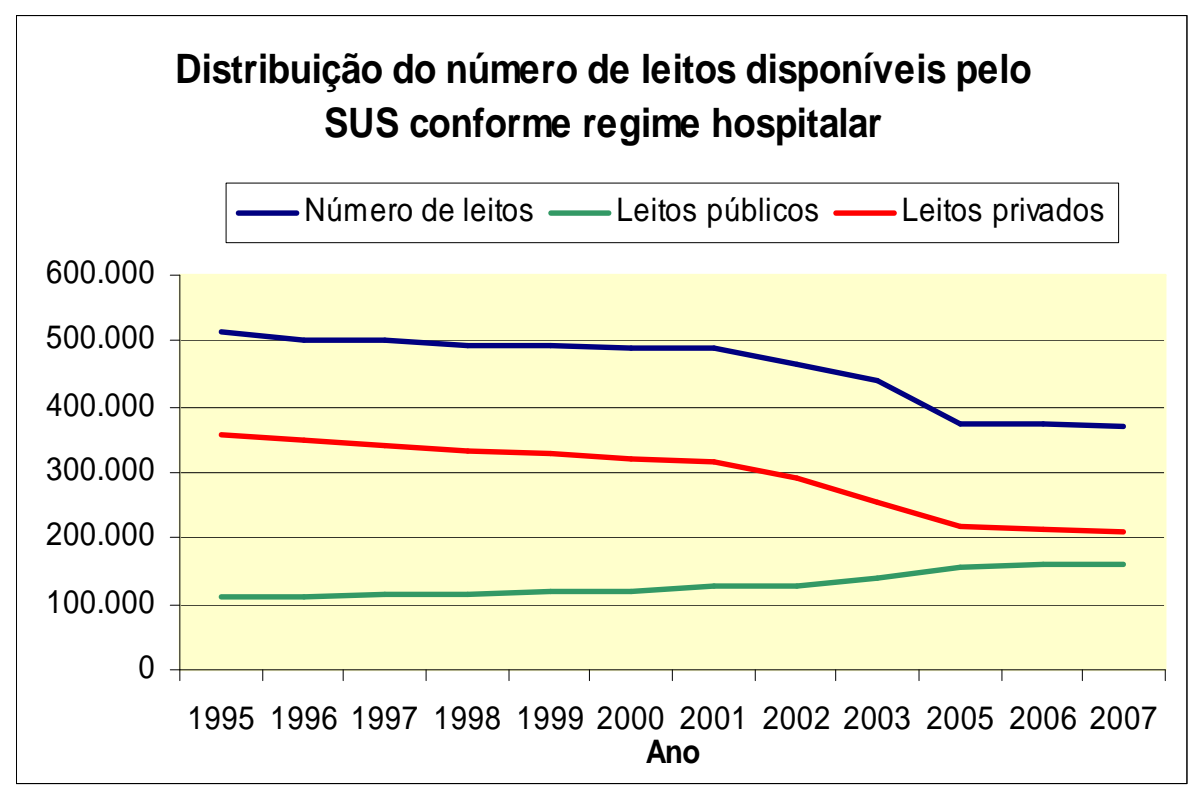

Figura 4 - Número de leitos hospitalares disponíveis pelo sistema público de saúde e seus regimes hospitalares.

Estes dados são bastantes preocupantes se somados a estatísticas de OMS. Além do baixo investimento per capita em saúde no Brasil, os recursos hospitalares existentes também são ineficientes. A redução da participação dos hospitais de regime privado nos serviços de saúde da rede pública ao longo dos últimos anos provavelmente está relacionada abaixo repasse de recursos do SUS aos hospitais privados, não suprindo a real necessidade e os gastos das internações hospitalares. Entretanto, a ocorrência da redução da disponibilidade de leitos de hospitais privados para rede pública não foi associada ao aumento proporcional na oferta de leitos pelos hospitais de regime público, resultando na redução global de leitos disponibilizados pelo SUS ao longo da última década. Isto é bastante preocupante e alarmante, uma vez que a grande maioria da população brasileira, cerca de 75 a $80 \%$ da população do país, utiliza o sistema público como único recurso de tratamento de saúde. O envelhecimento da população, com aumento da expectativa de vida e aumento de 
co-morbidades relacionadas à idade, associados à redução de recursos hospitalares e falta de investimento podem levar ao colapso do sistema público de saúde nos próximos anos.

Estudo prévio de estimativa de volume global de cirurgias realizadas no mundo, utilizando os mesmos dados de levantamento do OMS, mostra que há uma relação entre a taxa de cirurgias realizadas naquele país e o seu gasto per capita em saúde $\left(r^{2}=0,996\right.$; $\mathrm{p}<0,0001)^{(41)}$. De acordo com este estudo, o Brasil se classificaria no grupo de países com gastos intermediários (entre U\$401,00 e U\$1.000,00) e um volume cirúrgico anual estimado de 42,48 cirurgias por 1.000 habitantes $^{(41)}$. Nosso estudo a partir do levantamento de dados de DATASUS mostrou que o número de cirurgias realizadas no país foi apenas de 15,24 procedimentos para cada 1.000 habitantes, com uma média nacional de 1,5\%, número ainda bem abaixo da média mundial que é de cerca de 3,5\%. Estes números encontrados mostraram que o acesso da população às intervenções cirúrgicas no nosso país ainda é deficiente.

Este nosso estudo é pioneiro em fornecer dados de caracterização e descrição da epidemiologia de operações não cardíacas realizadas no Brasil com informações de abrangência nacional. Uma das limitações do estudo é que foi um levantamento baseado no banco de dados disponibilizado pelo DATASUS, e as informações constantes nestas planilhas estão sujeitos a erros de digitação ou falhas no seu preenchimento, como pudemos notar com o achado do grande número de dados em branco (missing). Tentamos minimizar os erros de análise de resultados, excluindo estes dados da análise estatística. Um outro aspecto é que as informações disponíveis no sistema de DATASUS são limitadas. Não tivemos acesso aos dados clínicos e demográficos dos pacientes, nem a taxa de complicações específicas, cuja análise poderia enriquecer o estudo e propiciar uma melhor caracterização do perfil clínico e cirúrgico dos pacientes submetidos a intervenções cirúrgicas no país. O período do nosso 
estudo foi relativamente curto, pois só tivemos acesso a dados cirúrgicos dos últimos 13 anos, o que impossibilitou a realização de estimativas futuras.

O conhecimento de dados epidemiológicos num país é extremamente importante para definir estratégias de planejamento e estabelecer prioridades de investimento de recursos governamentais. O crescente aumento de custos hospitalares, não somente em área cirúrgica, é um problema de sistema de saúde pública que deve ter sua dimensão aumentada nos próximos anos, com o envelhecimento da população. Um estudo interessante realizado em Estados Unidos mostrou, numa análise de registro nacional, que cerca de $62 \%$ das falências declaradas naquele país no período de 2001 a 2007, eram decorrentes de algum problema relacionada a saúde ${ }^{(50)}$. Num país onde o principal acesso aos serviços de saúde ainda é via sistema público para a grande maioria da população como no Brasil, espera-se um aumento de demanda de recursos e necessidade de maior investimento nesta área em decorrência das mudanças demográficas observadas no país.

Os resultados do nosso estudo forneceram dados relevantes e importantes para maior conhecimento dos aspectos epidemiológicas e econômicas relacionados aos procedimentos cirúrgicos realizados no país. Estas informações permitiram traçar o perfil de resultados cirúrgicos a caráter nacional, mais abrangente e também a sua evolução no decorrer do período estudado. O nosso estudo ainda permitiu a determinação de diferenças de comportamento das variáveis estudadas no que se refere ao números de internações, custos hospitalares, tempo de internação e a taxa de mortalidade entre as especialidades cirúrgicas. Estes dados poderão servir para comparações de estudos posteriores, além de auxiliar o planejamento e investimento de recursos públicos para áreas ou especialidades cirúrgicas que merecem maior atenção. 


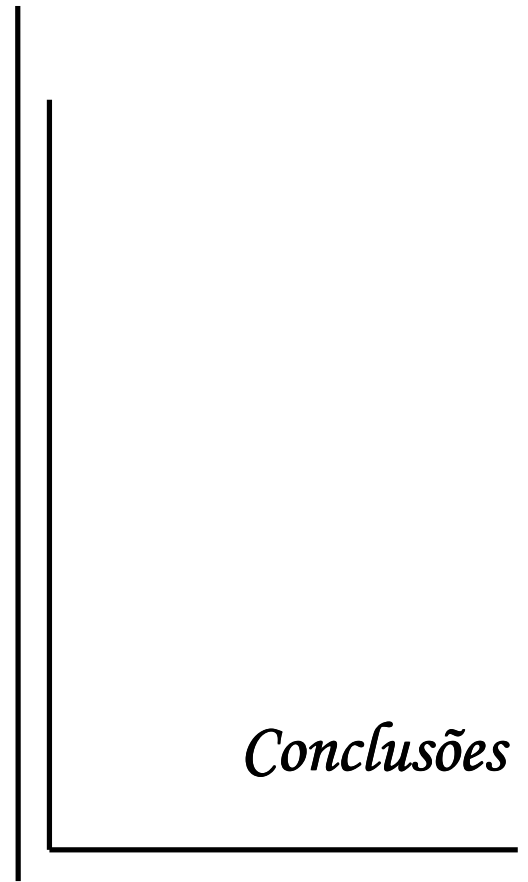




\section{CONCLUSÕES}

O número de internações cirúrgicas, os gastos hospitalares e a mortalidade referentes a procedimentos cirúrgicos aumentaram no Brasil nos últimos anos; houve redução do tempo de internação hospitalar neste mesmo período

$\checkmark$ A ginecologia, cirurgia geral e ortopedia foram especialidades responsáveis pelos maiores números de internações

A neurocirurgia, a cirurgia torácica e a gastrocirurgia foram as três especialidades que apresentaram maiores custos por internação, maiores gastos de transfusão, maiores tempos de internação e maiores taxas de mortalidades

As maiores taxas de mortalidades foram observadas em cirurgias torácicas e neurocirurgias, em procedimentos cirúrgicos que foram associadas a cirurgias de grande porte ou de alta complexidade, de maior gravidade e realizados em caráter de urgência/emergência

A curetagem pós aborto foi o procedimento com maior número de internações; a implante coclear foi responsável pelo maior gasto por internação; a microcirurgia do tumor cerebral com laser teve maior tempo de internação hospitalar e o tratamento cirúrgico do hematoma intracerebral teve maior mortalidade 
$\checkmark$ Os gastos de internações cirúrgicas tiveram variações no período estudado após a correção por indicadores econômicos. A redução de gasto observada nos anos iniciais do estudo deve estar relacionada com as mudanças econômicas do país no período estudado 


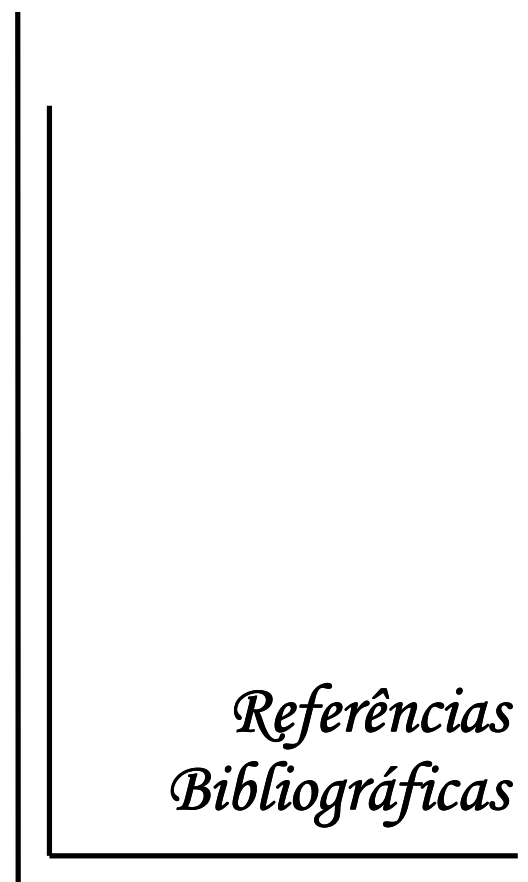
Bibliográficas 


\section{REFERÊNCIAS BIBLIOGRÁFICAS}

(1) American Society of Anesthesiologists. New classification of physical status. Anesthesiology 1963;24:111.

(2) Goldman L, Caldera DL, Nussbaum SR, Southwick FS, Krogstad D, Murray B, et al. Multifactorial index of cardiac risk in noncardiac surgical procedures. $\mathrm{N}$ Engl J Med 1977 Oct 20;297(16):845-50.

(3) Detsky AS, Abrams HB, Forbath N, Scott JG, Hilliard JR. Cardiac assessment for patients undergoing noncardiac surgery. A multifactorial clinical risk index. Arch Intern Med 1986 Nov;146(11):2131-4.

(4) Lee TH, Marcantonio ER, Mangione CM, Thomas EJ, Polanczyk CA, Cook EF, et al. Derivation and prospective validation of a simple index for prediction of cardiac risk of major noncardiac surgery. Circulation 1999 Sep 7;100(10):1043-9.

(5) Eagle KA, Brundage BH, Chaitman BR, Ewy GA, Fleisher LA, Hertzer NR, et al. Guidelines for perioperative cardiovascular evaluation for noncardiac surgery. Report of the American College of Cardiology/American Heart Association Task Force on Practice Guidelines. Committee on Perioperative Cardiovascular Evaluation for Noncardiac Surgery. Circulation 1996 Mar 15;93(6):1278-317.

(6) Guidelines for assessing and managing the perioperative risk from coronary artery disease associated with major noncardiac surgery. American College of Physicians. Ann Intern Med 1997 Aug 15;127(4):309-12.

(7) Palda VA, Detsky AS. Perioperative assessment and management of risk from coronary artery disease. Ann Intern Med 1997 Aug 15;127(4):313-28.

(8) Pinho C, Grandini PC, Gualandro DM, Calderaro D, Monachini M, Caramelli B. Multicenter study of perioperative evaluation for noncardiac surgeries in Brazil (EMAPO). Clinics 2007 Feb;62(1):17-22.

(9) Eagle KA, Coley CM, Newell JB, Brewster DC, Darling RC, Strauss HW, et al. Combining clinical and thallium data optimizes preoperative assessment of cardiac risk before major vascular surgery. Ann Intern Med 1989 Jun 1;110(11):859-66.

(10) Vanzetto G, Machecourt J, Blendea D, Fagret D, Borrel E, Magne JL, et al. Additive value of thallium single-photon emission computed tomography myocardial imaging for prediction of perioperative events in clinically selected high cardiac risk patients having abdominal aortic surgery. Am J Cardiol 1996 Jan 15;77(2):143-8. 
(11) Fleisher LA, Beckman JA, Brown KA, Calkins H, Chaikof E, Fleischmann KE, et al. ACC/AHA 2007 guidelines on perioperative cardiovascular evaluation and care for noncardiac surgery: a report of the American College of Cardiology/American Heart Association Task Force on Practice Guidelines (Writing Committee to Revise the 2002 Guidelines on Perioperative Cardiovascular Evaluation for Noncardiac Surgery): developed in collaboration with the American Society of Echocardiography, American Society of Nuclear Cardiology, Heart Rhythm Society, Society of Cardiovascular Anesthesiologists, Society for Cardiovascular Angiography and Interventions, Society for Vascular Medicine and Biology, and Society for Vascular Surgery. Circulation 2007 Oct 23;116(17):e418-e499.

(12) Poldermans D, Bax JJ, Boersma E, De HS, Eeckhout E, Fowkes G, et al. Guidelines for pre-operative cardiac risk assessment and perioperative cardiac management in non-cardiac surgery: The Task Force for Preoperative Cardiac Risk Assessment and Perioperative Cardiac Management in Non-cardiac Surgery of the European Society of Cardiology (ESC) and endorsed by the European Society of Anaesthesiology (ESA). Eur Heart J 2009; 30:2726-2812.

(13) Birkmeyer JD, Siewers AE, Finlayson EV, Stukel TA, Lucas FL, Batista I, et al. Hospital volume and surgical mortality in the United States. N Engl J Med 2002 Apr 11;346(15):1128-37.

(14) Birkmeyer JD, Stukel TA, Siewers AE, Goodney PP, Wennberg DE, Lucas FL. Surgeon volume and operative mortality in the United States. N Engl J Med 2003 Nov 27;349(22):2117-27.

(15) Waljee JF, Greenfield LJ, Dimick JB, Birkmeyer JD. Surgeon age and operative mortality in the United States. Ann Surg 2006 Sep;244(3):353-62.

(16) Mangano DT, Layug EL, Wallace A, Tateo I. Effect of atenolol on mortality and cardiovascular morbidity after noncardiac surgery. Multicenter Study of Perioperative Ischemia Research Group. N Engl J Med 1996 Dec 5;335(23):1713-20.

(17) Poldermans D, Boersma E, Bax JJ, Thomson IR, van de Ven LL, Blankensteijn JD, et al. The effect of bisoprolol on perioperative mortality and myocardial infarction in high-risk patients undergoing vascular surgery. Dutch Echocardiographic Cardiac Risk Evaluation Applying Stress Echocardiography Study Group. N Engl J Med 1999 Dec 9;341(24):1789-94.

(18) Brady AR, Gibbs JS, Greenhalgh RM, Powell JT, Sydes MR. Perioperative betablockade (POBBLE) for patients undergoing infrarenal vascular surgery: results of a randomized double-blind controlled trial. J Vasc Surg 2005 Apr;41(4):602-9.

(19) Juul AB, Wetterslev J, Kofoed-Enevoldsen A, Callesen T, Jensen G, Gluud C. The Diabetic Postoperative Mortality and Morbidity (DIPOM) trial: rationale and design of a multicenter, randomized, placebo-controlled, clinical trial of metoprolol for patients with diabetes mellitus who are undergoing major noncardiac surgery. Am Heart J 2004 Apr;147(4):677-83. 
(20) Lindenauer PK, Pekow P, Wang K, Mamidi DK, Gutierrez B, Benjamin EM. Perioperative beta-blocker therapy and mortality after major noncardiac surgery. $\mathrm{N}$ Engl J Med 2005 Jul 28;353(4):349-61.

(21) Devereaux PJ, Yang H, Yusuf S, Guyatt G, Leslie K, Villar JC, et al. Effects of extended-release metoprolol succinate in patients undergoing non-cardiac surgery (POISE trial): a randomised controlled trial. Lancet 2008 May 31;371(9627):1839-47.

(22) Durazzo AE, Machado FS, Ikeoka DT, De Bernoche C, Monachini MC, Puech-Leao $\mathrm{P}$, et al. Reduction in cardiovascular events after vascular surgery with atorvastatin: a randomized trial. J Vasc Surg 2004 May;39(5):967-75.

(23) McGirt MJ, Perler BA, Brooke BS, Woodworth GF, Coon A, Jain S, et al. 3-hydroxy3-methylglutaryl coenzyme A reductase inhibitors reduce the risk of perioperative stroke and mortality after carotid endarterectomy. J Vasc Surg 2005 Nov;42(5):82936.

(24) Poldermans D, Bax JJ, Kertai MD, Krenning B, Westerhout CM, Schinkel AF, et al. Statins are associated with a reduced incidence of perioperative mortality in patients undergoing major noncardiac vascular surgery. Circulation 2003 Apr $15 ; 107(14): 1848-51$.

(25) Lindenauer PK, Pekow P, Wang K, Gutierrez B, Benjamin EM. Lipid-lowering therapy and in-hospital mortality following major noncardiac surgery. JAMA 2004 May 5;291(17):2092-9.

(26) Landesberg G, Shatz V, Akopnik I, Wolf YG, Mayer M, Berlatzky Y, et al. Association of cardiac troponin, CK-MB, and postoperative myocardial ischemia with long-term survival after major vascular surgery. J Am Coll Cardiol 2003 Nov 5;42(9):1547-54.

(27) Martinez EA, Nass CM, Jermyn RM, Rosenbaum SH, Akhtar S, Chan DW, et al. Intermittent cardiac troponin-I screening is an effective means of surveillance for a perioperative myocardial infarction. J Cardiothorac Vasc Anesth 2005 Oct;19(5):57782.

(28) Ackland GL, Scollay JM, Parks RW, de B, I, Mythen MG. Pre-operative high sensitivity $\mathrm{C}$-reactive protein and postoperative outcome in patients undergoing elective orthopaedic surgery. Anaesthesia 2007 Sep;62(9):888-94.

(29) Goei D, Hoeks SE, Boersma E, Winkel TA, Dunkelgrun M, Flu WJ, et al. Incremental value of high-sensitivity $\mathrm{C}$-reactive protein and $\mathrm{N}$-terminal pro-B-type natriuretic peptide for the prediction of postoperative cardiac events in noncardiac vascular surgery patients. Coron Artery Dis 2009 May;20(3):219-24.

(30) Choi JH, Cho DK, Song YB, Hahn JY, Choi S, Gwon HC, et al. Preoperative NTproBNP and CRP Predict Perioperative Major Cardiovascular Events in Noncardiac Surgery. Heart 2010 Jan;96(1):56-62. 
(31) Ryding AD, Kumar S, Worthington AM, Burgess D. Prognostic value of brain natriuretic peptide in noncardiac surgery: a meta-analysis. Anesthesiology 2009 Aug;111(2):311-9.

(32) Karthikeyan G, Moncur RA, Levine O, Heels-Ansdell D, Chan MT, onso-Coello P, et al. Is a pre-operative brain natriuretic peptide or N-terminal pro-B-type natriuretic peptide measurement an independent predictor of adverse cardiovascular outcomes within 30 days of noncardiac surgery? A systematic review and meta-analysis of observational studies. J Am Coll Cardiol 2009 Oct 20;54(17):1599-606.

(33) Calderaro D, Monachini MC, Vieira CL, Yu PC, Gualandro DM, Marques AC, et al. Reactive hyperemia revisited. Arterioscler Thromb Vasc Biol 2008 Apr;28(4):e23e24.

(34) Polanczyk CA, Marcantonio E, Goldman L, Rohde LE, Orav J, Mangione CM, et al. Impact of age on perioperative complications and length of stay in patients undergoing noncardiac surgery. Ann Intern Med 2001 Apr 17;134(8):637-43.

(35) Hamel MB, Henderson WG, Khuri SF, Daley J. Surgical outcomes for patients aged 80 and older: morbidity and mortality from major noncardiac surgery. J Am Geriatr Soc 2005 Mar;53(3):424-9.

(36) Tao LS, Mackenzie CR, Charlson ME. Predictors of postoperative complications in the patient with diabetes mellitus. J Diabetes Complications 2008 Jan;22(1):24-8.

(37) Machado AN, Sitta MC, Jacob FW, Garcez-Leme LE. Prognostic factors for mortality among patients above the 6th decade undergoing non-cardiac surgery: cares--clinical assessment and research in elderly surgical patients. Clinics (Sao Paulo) 2008 Apr;63(2):151-6.

(38) Hammill BG, Curtis LH, nett-Guerrero E, O'Connor CM, Jollis JG, Schulman KA, et al. Impact of heart failure on patients undergoing major noncardiac surgery. Anesthesiology 2008 Apr;108(4):559-67.

(39) Lobo SM, Rezende E, Knibel MF, da Silva NB, Páramo JAM, Nácul F, et al. Epidemiologia e desfecho de pacientes cirúrgicos não cardíacos em unidades de terapia intensiva no Brasil. Rev Bras Ter Intensiva 2008;20(4):376-84.

(40) Fleischmann KE, Goldman L, Young B, Lee TH. Association between cardiac and noncardiac complications in patients undergoing noncardiac surgery: outcomes and effects on length of stay. Am J Med 2003 Nov;115(7):515-20.

(41) Weiser TG, Regenbogen SE, Thompson KD, Haynes AB, Lipsitz SR, Berry WR, et al. An estimation of the global volume of surgery: a modelling strategy based on available data. Lancet 2008 Jul 12;372(9633):139-44.

(42) Machado FS. Determinantes clínicos das complicações cardíacas pós-operatórias e de mortalidade geral em até 30 dias após cirurgia não cardíaca. Tese de Doutorado Faculdade de Medicina da Universidade de São Paulo. USP/FM/SBD - 054/01; 2001. 
(43) Heinisch RH, Barbieri CF, Nunes F, Jr., Oliveira GL, Heinisch LM. Prospective assessment of different indices of cardiac risk for patients undergoing noncardiac surgeries. Arq Bras Cardiol 2002 Oct;79(4):327-38.

(44) DATASUS. http://w3.datasus.gov.br/datasus/datasus.php - Informações de saúde assistência a saúde. Acessado em 19-1-2009. Ref Type: Internet Communication

(45) Khan NA, Quan H, Bugar JM, Lemaire JB, Brant R, Ghali WA. Association of postoperative complications with hospital costs and length of stay in a tertiary care center. J Gen Intern Med 2006 Feb;21(2):177-80.

(46) Kalish RL, Daley J, Duncan CC, Davis RB, Coffman GA, Iezzoni LI. Costs of potential complications of care for major surgery patients. Am J Med Qual 1995;10(1):48-54.

(47) Chaves LDP, Anselmi ML, Santos CB. Produção física e financeira dos procedimentos cirúrgicos em hospitais sob gestão municipal em Ribeirão Preto-SP. Texto contexto - Enfermagem 2009;18(3):513-22.

(48) Secretaria de Vigilância em Saúde/MS. Evolução da mortalidade no Brasil. http://portal.saude.gov.br/portal/arquivos/pdf/capitulo3_sb.pdf. 2004. Acessado em 14-11-2009. Ref Type: Internet Communication

(49) World Health Statistics 2009 - World Health Organization. http://whqlibdoc.who.int/publications/2009/9789241563819_eng.pdf . 2009. Acessado em 1-6-2009. Ref Type: Internet Communication

(50) Himmelstein DU, Thorne D, Warren E, Woolhandler S. Medical bankruptcy in the United States, 2007: results of a national study. Am J Med 2009 Aug;122(8):741-6. 


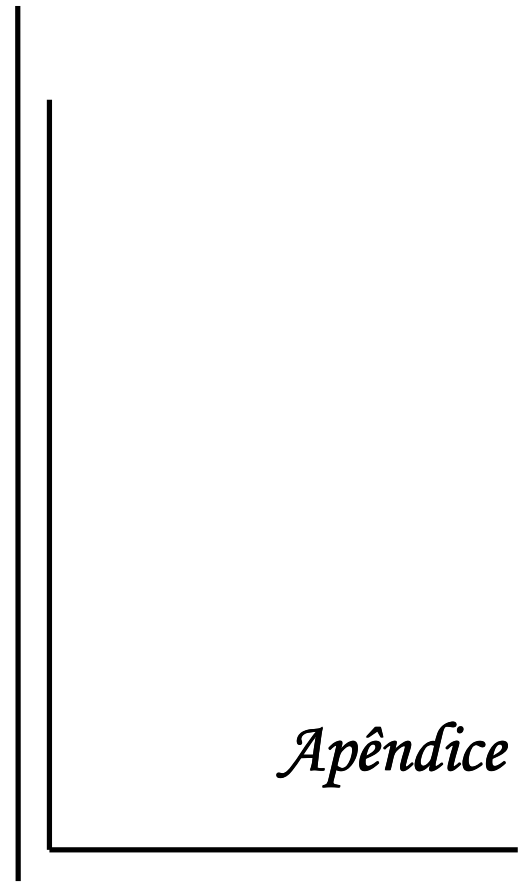




\section{APÊNDICE A}

Tabela 11 - Número de internações por 1.000 habitantes em cada especialidade cirúrgica no período de 1995 a 2007

\begin{tabular}{|c|c|c|c|c|c|c|c|c|c|c|c|c|}
\hline Ano & $\begin{array}{l}\text { Cabeça } \\
\text { pescoço }\end{array}$ & $\begin{array}{c}\text { Cirurgia } \\
\text { geral }\end{array}$ & $\begin{array}{l}\text { Cirurgia } \\
\text { plástica }\end{array}$ & Gastrocirurgia & Ginecologia & Neurocirurgia & Oftalmologia & Ortopedia & Otorrino & Torácica & Urologia & Vascular \\
\hline 1995 & 0,29 & 2,95 & 0,75 & 1,16 & 4,87 & 0,33 & 0,82 & 1,98 & 0,28 & 0,24 & 0,92 & 0,36 \\
\hline 1996 & 0,25 & 2,84 & 0,66 & 1,12 & 4,36 & 0,31 & 0,75 & 1,93 & 0,24 & 0,24 & 0,86 & 0,32 \\
\hline 1997 & 0,24 & 2,70 & 0,68 & 1,12 & 3,83 & 0,32 & 0,73 & 1,95 & 0,24 & 0,24 & 0,83 & 0,27 \\
\hline 1998 & 0,24 & 2,78 & 0,68 & 1,13 & 3,80 & 0,33 & 0,70 & 1,99 & 0,24 & 0,25 & 0,86 & 0,26 \\
\hline 1999 & 0,26 & 2,96 & 0,72 & 1,20 & 3,92 & 0,38 & 0,61 & 2,11 & 0,27 & 0,27 & 0,94 & 0,36 \\
\hline 2000 & 0,29 & 3,03 & 0,73 & 1,26 & 4,07 & 0,41 & 0,52 & 2,25 & 0,31 & 0,26 & 1,00 & 0,49 \\
\hline 2001 & 0,29 & 2,80 & 0,68 & 1,28 & 3,77 & 0,43 & 0,40 & 2,31 & 0,32 & 0,26 & 0,82 & 0,53 \\
\hline 2002 & 0,28 & 2,88 & 0,72 & 1,37 & 3,95 & 0,46 & 0,36 & 2,45 & 0,35 & 0,26 & 0,88 & 0,67 \\
\hline 2003 & 0,28 & 2,89 & 0,76 & 1,40 & 3,88 & 0,48 & 0,35 & 2,56 & 0,36 & 0,28 & 0,99 & 0,71 \\
\hline 2004 & 0,29 & 2,93 & 0,75 & 1,43 & 3,94 & 0,49 & 0,34 & 2,62 & 0,38 & 0,29 & 1,01 & 0,71 \\
\hline 2005 & 0,29 & 2,89 & 0,76 & 1,49 & 3,66 & 0,50 & 0,36 & 2,69 & 0,40 & 0,30 & 0,98 & 0,68 \\
\hline 2006 & 0,29 & 2,92 & 0,75 & 1,52 & 3,63 & 0,50 & 0,41 & 2,72 & 0,43 & 0,30 & 1,01 & 0,59 \\
\hline 2007 & 0,29 & 2,93 & 0,77 & 1,55 & 3,56 & 0,49 & 0,42 & 2,81 & 0,44 & 0,32 & 1,03 & 0,62 \\
\hline
\end{tabular}


Tabela 12 - Gasto médio em reais por internação hospitalar conforme as diferentes especialidades cirúrgicas - 1995 a 2007

\begin{tabular}{|c|c|c|c|c|c|c|c|c|c|c|c|c|c|}
\hline Especialidade & 1995 & 1996 & 1997 & 1998 & 1999 & 2000 & 2001 & 2002 & 2003 & 2004 & 2005 & 2006 & 2007 \\
\hline neurocirurgia & 972,46 & $1.020,51$ & $1.067,14$ & $1.265,60$ & $1.908,08$ & $1.735,96$ & $1.902,88$ & $2.059,40$ & $2.217,26$ & $2.424,46$ & $2.655,60$ & $2.694,63$ & $3.152,64$ \\
\hline torácica & 750,02 & 794,35 & 837,42 & 993,63 & $1.291,80$ & $1.158,98$ & $1.220,94$ & $1.298,73$ & $1.409,05$ & $1.620,86$ & $1.798,99$ & $1.848,08$ & $2.140,40$ \\
\hline vascular & 428,09 & 459,12 & 542,86 & 670,40 & 738,06 & 615,82 & 632,97 & 649,46 & 700,41 & 767,63 & 861,79 & 965,79 & $1.037,95$ \\
\hline gastrocirurgia & 509,27 & 539,35 & 567,12 & 655,79 & 764,69 & 716,74 & 745,65 & 828,30 & 892,97 & 965,63 & $1.007,93$ & 987,47 & $1.024,40$ \\
\hline ortopedia & 431,18 & 462,73 & 468,11 & 539,37 & 615,49 & 610,26 & 629,37 & 651,77 & 743,01 & 838,38 & 877,69 & 888,73 & 923,76 \\
\hline urologia & 380,87 & 404,68 & 414,45 & 481,35 & 588,59 & 602,37 & 828,02 & 800,79 & 758,17 & 813,55 & 846,46 & 787,15 & 831,63 \\
\hline cabeça pescoço & 280,60 & 302,57 & 309,26 & 362,72 & 413,31 & 412,42 & 454,87 & 518,42 & 611,92 & 686,67 & 715,97 & 714,79 & 728,54 \\
\hline cirurgia geral & 311,15 & 334,58 & 318,02 & 365,90 & 442,12 & 433,01 & 460,12 & 476,49 & 514,05 & 555,91 & 584,69 & 578,09 & 626,22 \\
\hline cirurgia plástica & 236,33 & 251,74 & 252,89 & 293,20 & 332,25 & 316,93 & 345,51 & 380,58 & 419,61 & 467,24 & 486,09 & 478,79 & 502,00 \\
\hline oftalmologia & 313,45 & 330,40 & 333,51 & 385,05 & 419,18 & 357,06 & 367,18 & 408,65 & 459,39 & 508,34 & 519,64 & 498,61 & 499,74 \\
\hline otorrinolaringologia & 141,61 & 187,31 & 227,20 & 250,73 & 283,39 & 244,40 & 254,71 & 279,71 & 372,72 & 412,94 & 443,41 & 391,52 & 456,24 \\
\hline ginecologia & 174,19 & 180,62 & 180,04 & 210,85 & 244,55 & 256,35 & 254,85 & 263,95 & 278,54 & 310,55 & 318,96 & 321,53 & 334,54 \\
\hline
\end{tabular}


Tabela 13 - Gasto médio em reais com a transfusão sanguínea por internação conforme especialidades cirúrgicas - 1995 a 2007

\begin{tabular}{lccccccccccccccccc}
\hline Especialidade & $\mathbf{1 9 9 5}$ & $\mathbf{1 9 9 6}$ & $\mathbf{1 9 9 7}$ & $\mathbf{1 9 9 8}$ & $\mathbf{1 9 9 9}$ & $\mathbf{2 0 0 0}$ & $\mathbf{2 0 0 1}$ & $\mathbf{2 0 0 2}$ & $\mathbf{2 0 0 3}$ & $\mathbf{2 0 0 4}$ & $\mathbf{2 0 0 5}$ & $\mathbf{2 0 0 6}$ & $\mathbf{2 0 0 7}$ \\
\hline torácica & 17,55 & 17,16 & 20,23 & 24,30 & 26,12 & 25,75 & 27,53 & 25,60 & 25,32 & 29,47 & 34,82 & 33,99 & 34,97 \\
neurocirurgia & 9,30 & 9,88 & 10,85 & 12,51 & 14,28 & 12,49 & 13,77 & 13,48 & 12,99 & 14,72 & 16,28 & 15,57 & 15,52 \\
gastrocirurgia & 11,82 & 11,96 & 13,15 & 15,68 & 16,22 & 15,96 & 15,86 & 14,59 & 13,25 & 14,59 & 15,55 & 14,09 & 13,33 \\
vascular & 6,55 & 7,78 & 9,94 & 12,31 & 12,09 & 8,17 & 7,74 & 5,78 & 5,04 & 5,63 & 7,46 & 8,41 & 8,07 \\
cirurgia geral & 4,66 & 4,67 & 4,98 & 5,56 & 6,03 & 6,16 & 6,29 & 5,86 & 5,80 & 6,23 & 7,00 & 6,62 & 6,66 \\
ortopedia & 3,42 & 3,51 & 3,68 & 4,44 & 4,68 & 4,58 & 4,74 & 4,76 & 4,54 & 5,42 & 6,05 & 5,74 & 5,76 \\
urologia & 3,36 & 3,37 & 3,47 & 4,18 & 4,41 & 4,31 & 5,42 & 5,31 & 4,60 & 5,49 & 6,17 & 5,58 & 5,59 \\
ginecologia & 1,07 & 1,02 & 1,21 & 1,39 & 1,49 & 1,58 & 1,69 & 1,56 & 1,54 & 1,83 & 2,17 & 2,02 & 2,02 \\
cabeça pescoço & 1,29 & 1,33 & 1,37 & 1,62 & 1,62 & 1,70 & 1,92 & 1,75 & 1,75 & 1,93 & 2,06 & 1,80 & 1,79 \\
cirurgia plástica & 1,29 & 1,46 & 1,48 & 1,84 & 1,90 & 2,03 & 1,96 & 1,75 & 1,40 & 1,66 & 1,86 & 1,65 & 1,62 \\
otorrinolaringologia & 0,23 & 0,19 & 0,20 & 0,22 & 0,27 & 0,28 & 0,34 & 0,26 & 0,27 & 0,25 & 0,52 & 0,36 & 0,38 \\
oftalmologia & 0,02 & 0,02 & 0,03 & 0,03 & 0,08 & 0,04 & 0,08 & 0,07 & 0,08 & 0,12 & 0,15 & 0,08 & 0,11 \\
\hline
\end{tabular}


Tabela 14. Tempo médio de internação hospitalar (em dias) conforme especialidade cirúrgica - 1995 a 2007

\begin{tabular}{lccccccccccccccc}
\hline Especialidade & $\mathbf{1 9 9 5}$ & $\mathbf{1 9 9 6}$ & $\mathbf{1 9 9 7}$ & $\mathbf{1 9 9 8}$ & $\mathbf{1 9 9 9}$ & $\mathbf{2 0 0 0}$ & $\mathbf{2 0 0 1}$ & $\mathbf{2 0 0 2}$ & $\mathbf{2 0 0 3}$ & $\mathbf{2 0 0 4}$ & $\mathbf{2 0 0 5}$ & $\mathbf{2 0 0 6}$ & $\mathbf{2 0 0 7}$ \\
\hline torácica & 12,11 & 11,84 & 11,73 & 11,70 & 11,79 & 11,80 & 11,85 & 11,93 & 11,93 & 12,22 & 12,44 & 12,22 & 12,34 \\
neurocirurgia & 10,57 & 10,85 & 10,74 & 10,71 & 10,58 & 10,21 & 10,25 & 10,24 & 10,20 & 10,06 & 9,82 & 9,54 & 9,73 \\
gastrocirurgia & 7,29 & 7,19 & 7,00 & 6,84 & 6,63 & 6,34 & 6,33 & 6,21 & 6,13 & 6,00 & 5,81 & 5,60 & 5,49 \\
ortopedia & 5,81 & 6,08 & 5,82 & 5,66 & 5,46 & 5,16 & 5,08 & 5,05 & 4,91 & 4,96 & 4,79 & 4,72 & 4,79 \\
vascular & 4,46 & 4,68 & 5,13 & 5,18 & 4,32 & 3,47 & 3,22 & 3,17 & 2,75 & 2,77 & 3,18 & 3,58 & 3,70 \\
cirurgia geral & 4,41 & 4,37 & 4,20 & 4,12 & 4,08 & 3,88 & 3,88 & 3,79 & 3,83 & 3,77 & 3,59 & 3,51 & 3,55 \\
urologia & 5,18 & 5,20 & 5,00 & 4,90 & 4,73 & 4,35 & 4,88 & 4,68 & 4,17 & 3,96 & 3,85 & 3,59 & 3,50 \\
cabeça pescoço & 3,88 & 4,17 & 4,09 & 4,20 & 4,08 & 3,75 & 3,51 & 3,67 & 3,74 & 3,66 & 3,42 & 3,28 & 3,32 \\
cirurgia plástica & 3,84 & 4,13 & 3,86 & 3,88 & 3,72 & 3,41 & 3,42 & 3,33 & 3,10 & 2,92 & 2,73 & 2,54 & 2,46 \\
ginecologia & 2,83 & 2,81 & 2,64 & 2,65 & 2,68 & 2,48 & 2,49 & 2,54 & 2,49 & 2,36 & 2,24 & 2,19 & 2,17 \\
otorrinolaringologia & 1,67 & 1,71 & 1,71 & 1,69 & 1,63 & 1,53 & 1,48 & 1,47 & 1,45 & 1,32 & 1,24 & 1,18 & 1,13 \\
oftalmologia & 1,43 & 1,43 & 1,37 & 1,44 & 1,49 & 1,35 & 1,59 & 1,41 & 1,38 & 1,37 & 1,28 & 1,01 & 0,91 \\
\hline
\end{tabular}


Tabela 15 - Taxa de mortalidade em porcentagem de cada especialidade cirúrgica no período de 1995 a 2007

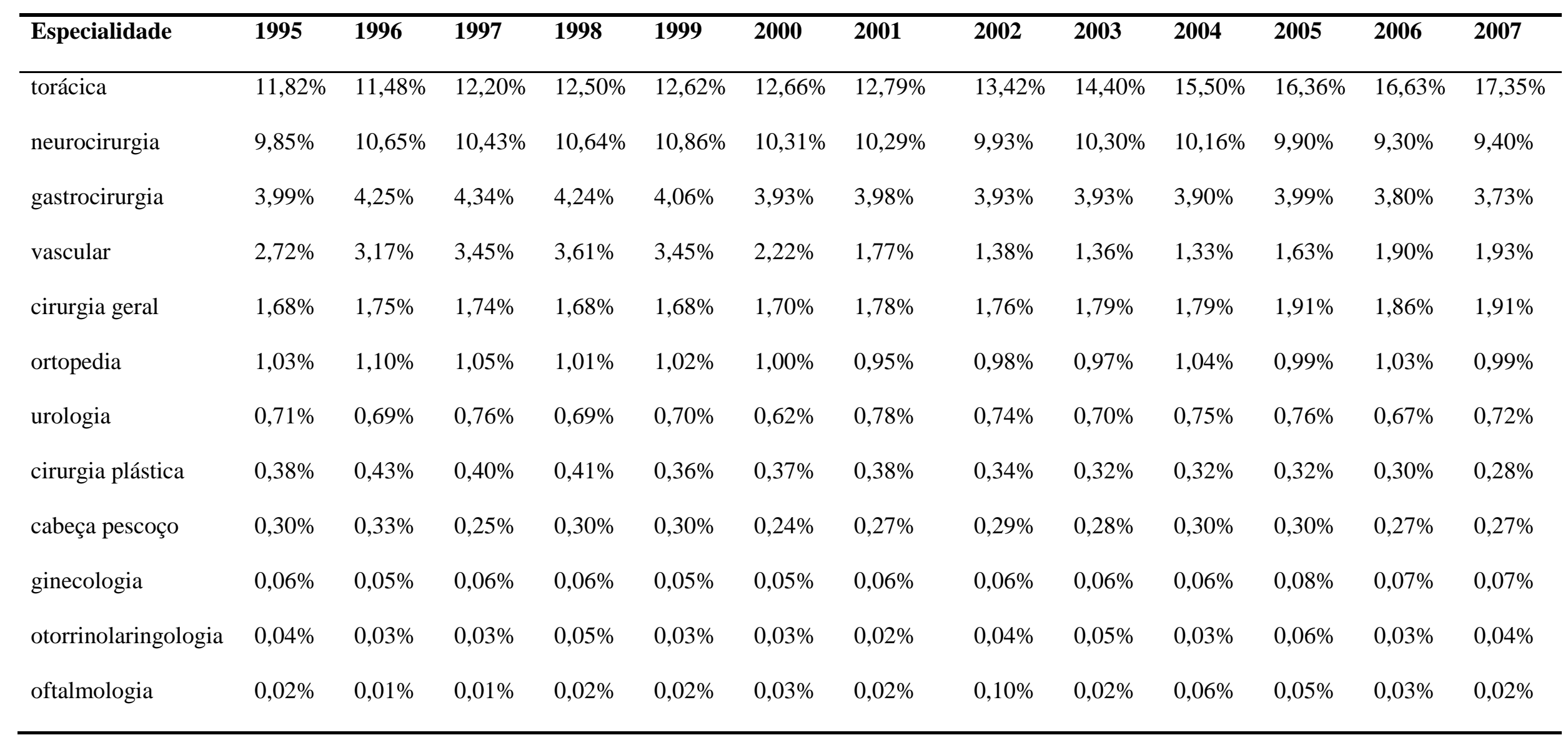


Tabela 16. Valores de gastos médios em reais por internação de cada especialidade cirúrgica corrigidos para inflação do período de 1995 a 2007

\begin{tabular}{|c|c|c|c|c|c|c|c|c|c|c|c|c|}
\hline Ano & $\begin{array}{l}\text { cabeça } \\
\text { pescoço }\end{array}$ & $\begin{array}{c}\text { cirurgia } \\
\text { geral }\end{array}$ & $\begin{array}{l}\text { cirurgia } \\
\text { plástica }\end{array}$ & gastrocirurgia & ginecologia & neurocirurgia & oftalmologia & ortopedia & otorrino & torácica & urologia & vascular \\
\hline 1995 & 280,60 & 311,15 & 236,33 & 509,27 & 174,19 & 972,46 & 313,45 & 431,18 & 141,61 & 750,02 & 380,87 & 428,09 \\
\hline 1996 & 205,02 & 226,71 & 170,58 & 365,46 & 122,39 & 691,50 & 223,88 & 313,55 & 126,92 & 538,25 & 274,21 & 311,10 \\
\hline 1997 & 177,35 & 182,37 & 145,02 & 325,22 & 103,25 & 611,96 & 191,25 & 268,44 & 130,29 & 480,23 & 237,67 & 311,31 \\
\hline 1998 & 196,75 & 198,48 & 159,04 & 355,72 & 114,37 & 686,50 & 208,86 & 292,57 & 136,00 & 538,98 & 261,10 & 363,65 \\
\hline 1999 & 217,18 & 232,32 & 174,58 & 401,81 & 128,50 & 1002,62 & 220,26 & 323,41 & 148,91 & 678,79 & 309,28 & 387,82 \\
\hline 2000 & 210,79 & 221,31 & 161,98 & 366,32 & 131,02 & 887,24 & 182,49 & 311,90 & 124,91 & 592,35 & 307,87 & 314,74 \\
\hline 2001 & 231,58 & 234,25 & 175,90 & 379,62 & 129,75 & 968,78 & 186,94 & 320,42 & 129,68 & 621,59 & 421,55 & 322,25 \\
\hline 2002 & 260,47 & 239,40 & 191,21 & 416,16 & 132,62 & 1034,70 & 205,32 & 327,47 & 140,53 & 652,52 & 402,34 & 326,31 \\
\hline 2003 & 296,73 & 249,28 & 203,48 & 433,02 & 135,07 & 1075,20 & 222,77 & 360,30 & 180,74 & 683,28 & 367,65 & 339,65 \\
\hline 2004 & 316,70 & 256,40 & 215,50 & 445,37 & 143,23 & 1118,20 & 234,46 & 386,68 & 190,46 & 747,57 & 375,22 & 354,04 \\
\hline 2005 & 314,73 & 257,02 & 213,68 & 443,08 & 140,21 & 1167,37 & 228,43 & 385,82 & 194,92 & 790,82 & 372,09 & 378,83 \\
\hline 2006 & 304,65 & 246,39 & 204,06 & 420,87 & 137,04 & 1148,47 & 212,51 & 378,78 & 166,87 & 787,66 & 335,49 & 411,63 \\
\hline 2007 & 302,70 & 260,19 & 208,57 & 425,62 & 139,00 & 1309,88 & 207,64 & 383,81 & 189,56 & 889,31 & 345,53 & 431,25 \\
\hline
\end{tabular}

Nota: 1995, ano-base, utilizado como referência para correção da inflação 
Tabela 17. Valores de gastos médios em reais de transfusão sanguínea por procedimento de cada especialidade cirúrgica corrigidos para inflação do período de 1995 a 2007

\begin{tabular}{|c|c|c|c|c|c|c|c|c|c|c|c|c|}
\hline Ano & $\begin{array}{l}\text { cabeça } \\
\text { pescoço }\end{array}$ & $\begin{array}{c}\text { cirurgia } \\
\text { geral }\end{array}$ & $\begin{array}{l}\text { cirurgia } \\
\text { plástica }\end{array}$ & gastrocirurgia & ginecologia & neurocirurgia & oftalmologia & ortopedia & otorrino & torácica & urologia & vascular \\
\hline 1995 & 1,29 & 4,66 & 1,29 & 11,82 & 1,07 & 9,30 & 0,02 & 3,42 & 0,23 & 17,55 & 3,36 & 6,55 \\
\hline 1996 & 0,90 & 3,16 & 0,99 & 8,11 & 0,69 & 6,70 & 0,02 & 2,38 & 0,13 & 11,63 & 2,29 & 5,27 \\
\hline 1997 & 0,78 & 2,85 & 0,85 & 7,54 & 0,69 & 6,22 & 0,02 & 2,11 & 0,11 & 11,60 & 1,99 & 5,70 \\
\hline 1998 & 0,88 & 3,02 & 1,00 & 8,51 & 0,76 & 6,79 & 0,02 & 2,41 & 0,12 & 13,18 & 2,26 & 6,68 \\
\hline 1999 & 0,85 & 3,17 & 1,00 & 8,52 & 0,78 & 7,50 & 0,04 & 2,46 & 0,14 & 13,73 & 2,32 & 6,35 \\
\hline 2000 & 0,87 & 3,15 & 1,04 & 8,16 & 0,81 & 6,38 & 0,02 & 2,34 & 0,14 & 13,16 & 2,20 & 4,18 \\
\hline 2001 & 0,98 & 3,20 & 1,00 & 8,07 & 0,86 & 7,01 & 0,04 & 2,42 & 0,17 & 14,02 & 2,76 & 3,94 \\
\hline 2002 & 0,88 & 2,94 & 0,88 & 7,33 & 0,78 & 6,77 & 0,04 & 2,39 & 0,13 & 12,86 & 2,67 & 2,90 \\
\hline 2003 & 0,85 & 2,81 & 0,68 & 6,43 & 0,75 & 6,30 & 0,04 & 2,20 & 0,13 & 12,28 & 2,23 & 2,45 \\
\hline 2004 & 0,89 & 2,87 & 0,76 & 6,73 & 0,84 & 6,79 & 0,05 & 2,50 & 0,11 & 13,59 & 2,53 & 2,60 \\
\hline 2005 & 0,91 & 3,08 & 0,82 & 6,84 & 0,96 & 7,15 & 0,06 & 2,66 & 0,23 & 15,31 & 2,71 & 3,28 \\
\hline 2006 & 0,77 & 2,82 & 0,70 & 6,00 & 0,86 & 6,64 & 0,03 & 2,44 & 0,15 & 14,49 & 2,38 & 3,58 \\
\hline 2007 & 0,74 & 2,77 & 0,67 & 5,54 & 0,84 & 6,45 & 0,05 & 2,39 & 0,16 & 14,53 & 2,32 & 3,35 \\
\hline
\end{tabular}

Nota: 1995, ano-base, utilizado como referência para correção da inflação 


\section{Apêndice B}

Gráfico 3 - Resultado gráfico da análise de tendências do número de internações em diversas especialidades

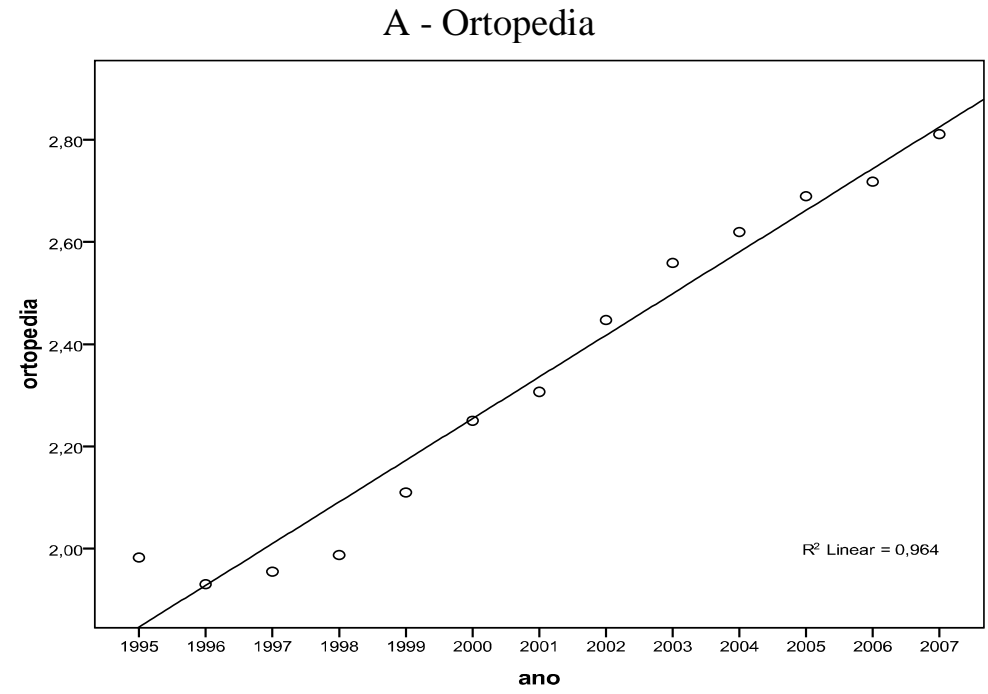

B - Gastrocirurgia

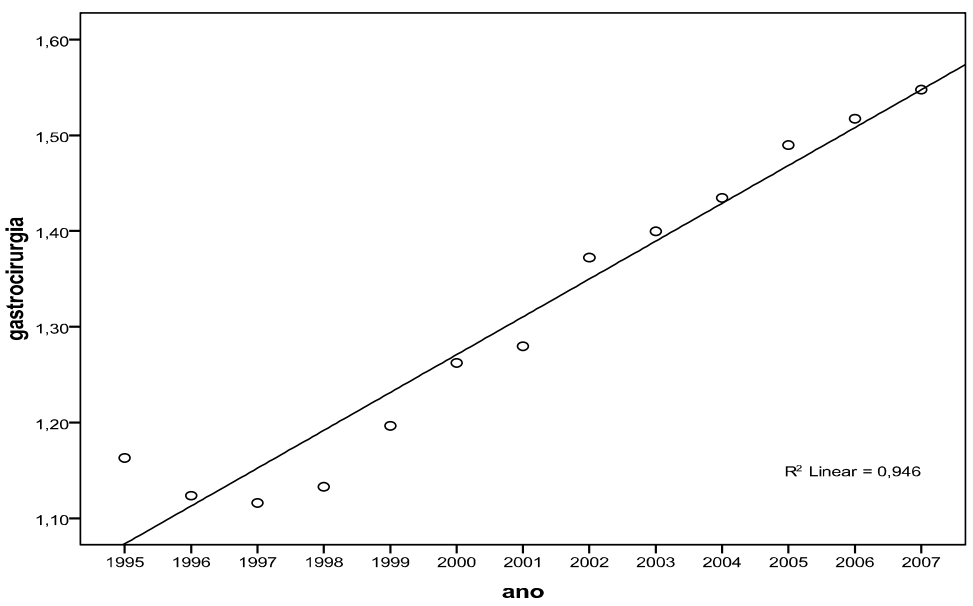

C- Cirurgia torácica

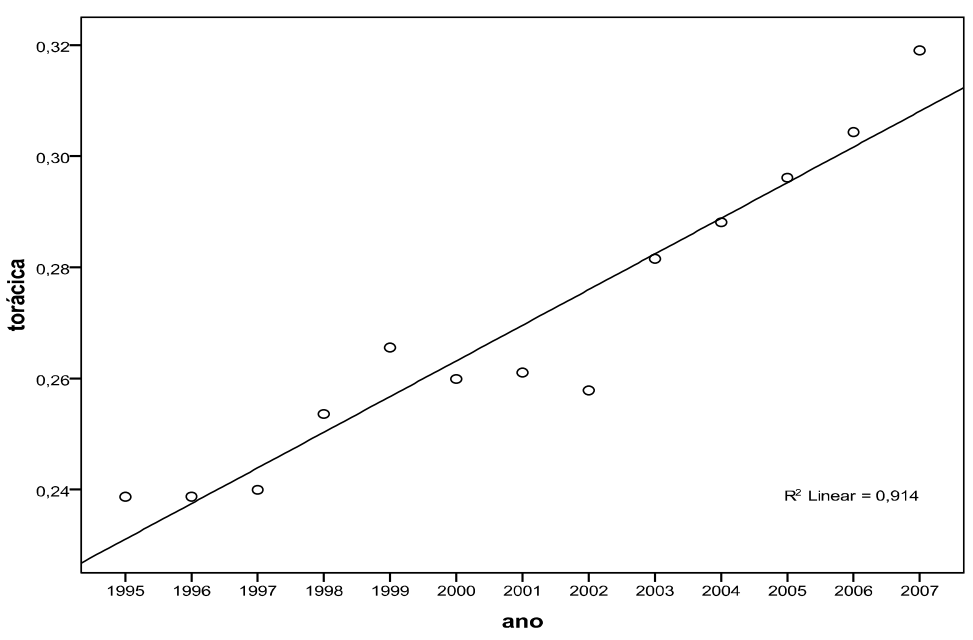


D- Otorrinolaringologia
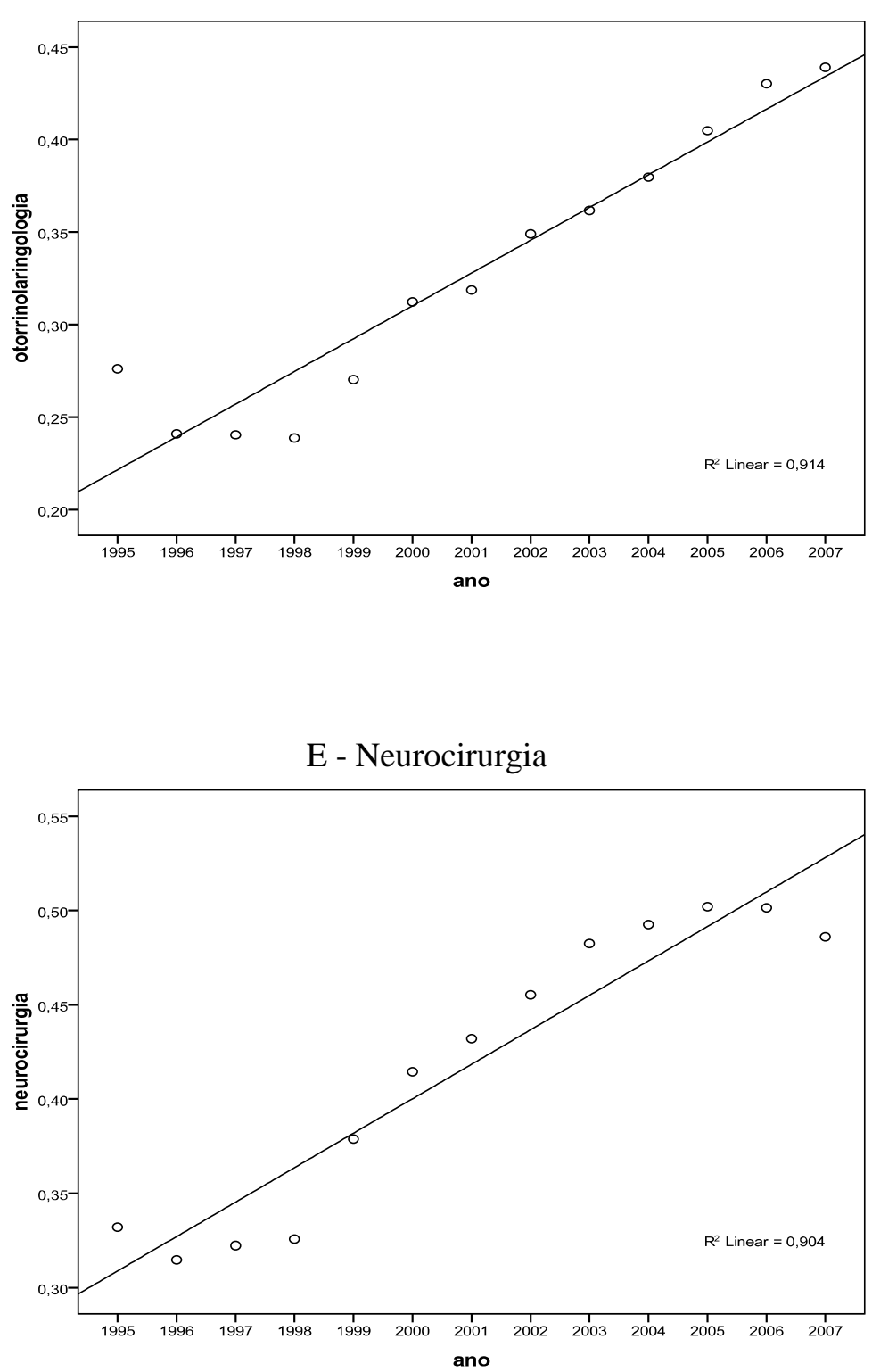
Gráfico 4 - Resultado gráfico da análise de tendências do tempo médio de internação em diversas especialidades
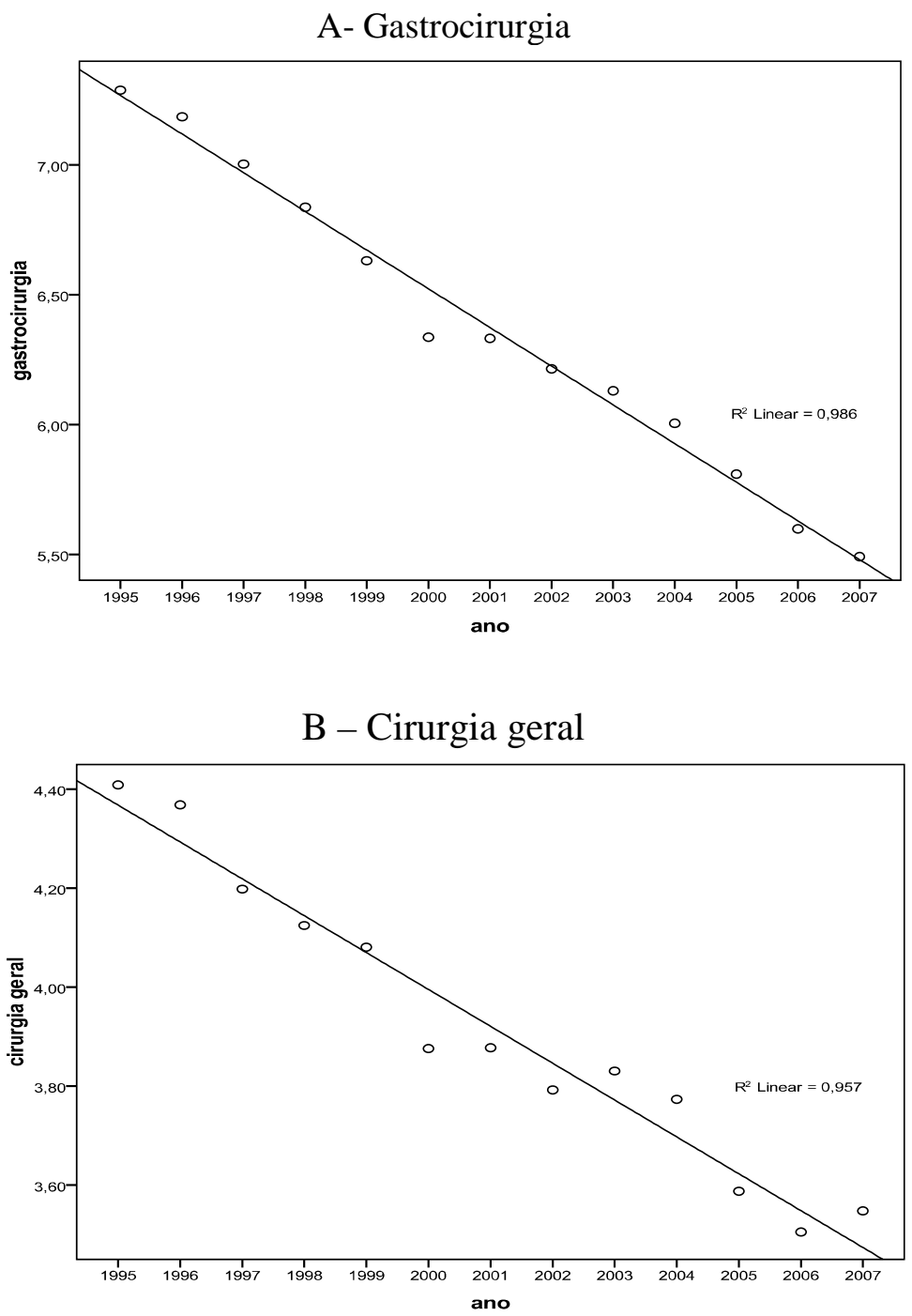

C- Cirurgia plástica

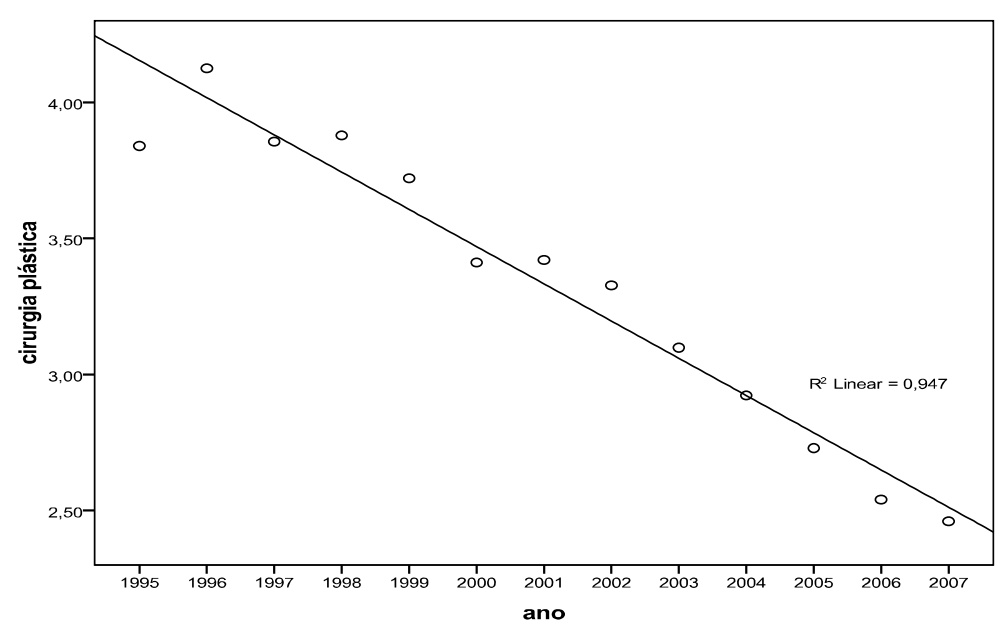



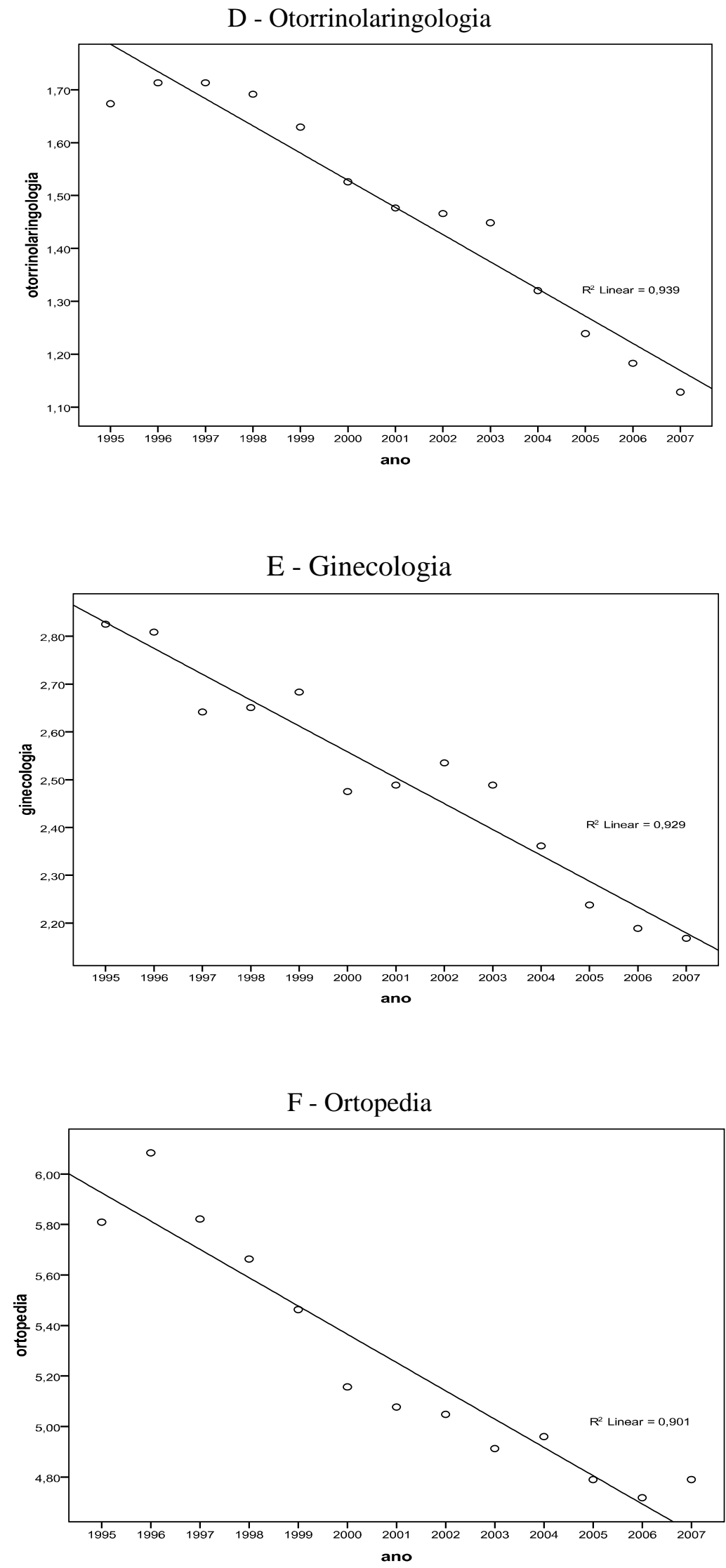
Gráfico 5 - Resultado gráfico da análise de tendências da mortalidade cirúrgica em diversas especialidades

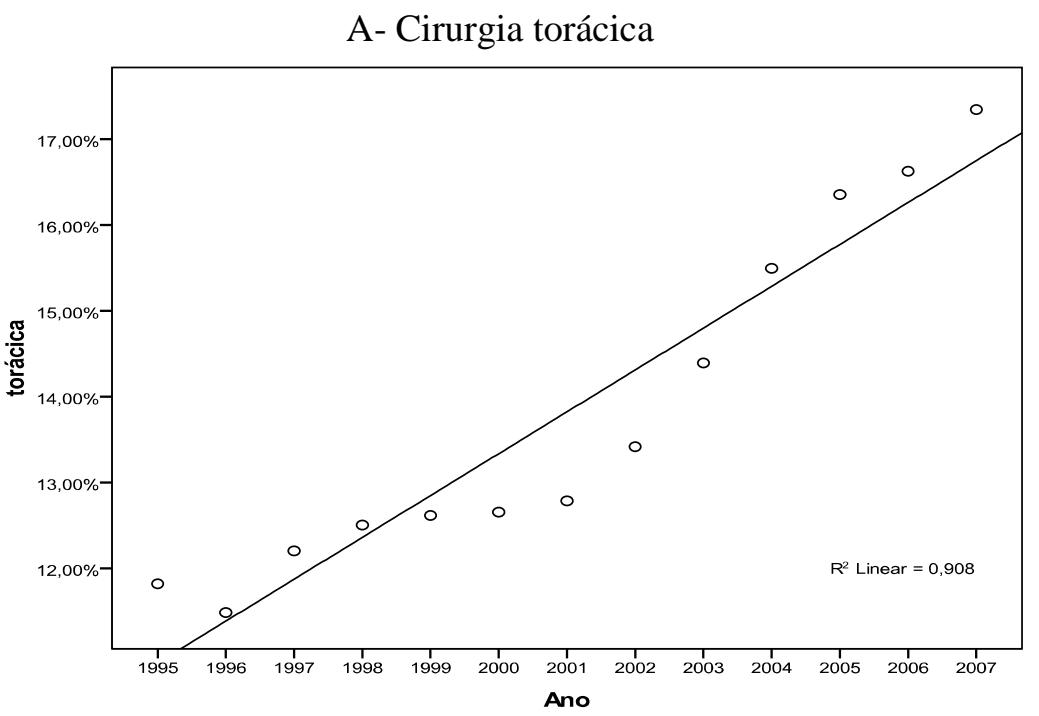

B- Cirurgia plástica

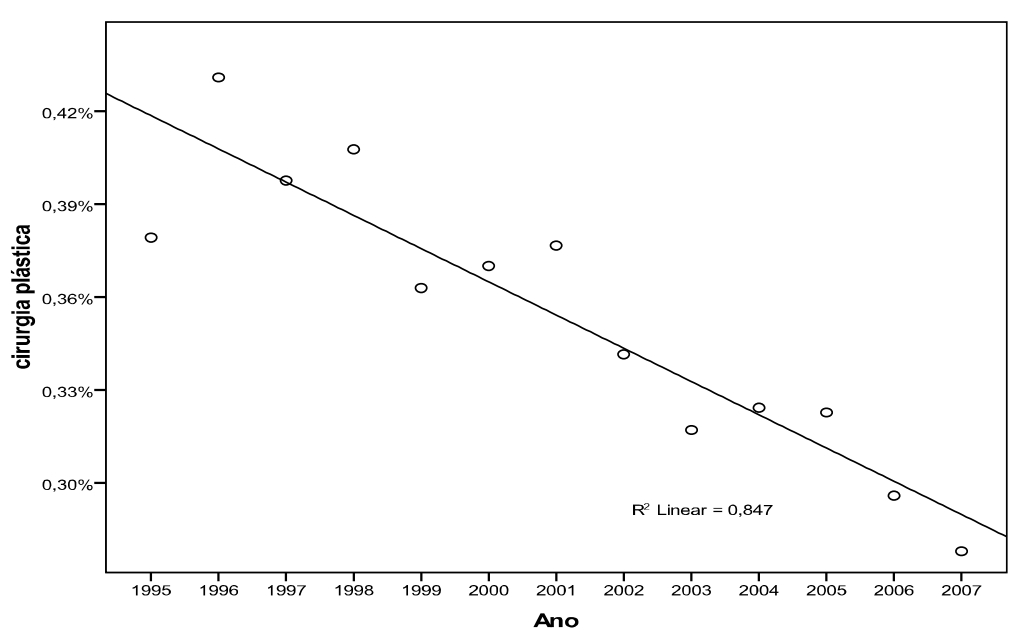

